\title{
WestVirginiaUniversity
}

THE RESEARCH REPOSITORY @ WVU

Graduate Theses, Dissertations, and Problem Reports

2013

\section{Impact of Geo-mechanical Properties on the Fracture Treatment of Utica Shale}

Tarig M. Osman

West Virginia University

Follow this and additional works at: https://researchrepository.wvu.edu/etd

\section{Recommended Citation}

Osman, Tarig M., "Impact of Geo-mechanical Properties on the Fracture Treatment of Utica Shale" (2013). Graduate Theses, Dissertations, and Problem Reports. 3408.

https://researchrepository.wvu.edu/etd/3408

This Thesis is protected by copyright and/or related rights. It has been brought to you by the The Research Repository @ WVU with permission from the rights-holder(s). You are free to use this Thesis in any way that is permitted by the copyright and related rights legislation that applies to your use. For other uses you must obtain permission from the rights-holder(s) directly, unless additional rights are indicated by a Creative Commons license in the record and/ or on the work itself. This Thesis has been accepted for inclusion in WVU Graduate Theses, Dissertations, and Problem Reports collection by an authorized administrator of The Research Repository @ WVU. For more information, please contact researchrepository@mail.wvu.edu. 
Impact of Geo-mechanical Properties on the Fracture Treatment of Utica Shale

Tarig M. Osman

Thesis submitted to the

College of Engineering and Mineral Resources

at West Virginia University

in partial fulfillment of the requirements for the degree of

\section{Master of Science}

In

Petroleum and Natural Gas Engineering

Ilkin Bilgesu, Ph.D., Committee Chairperson

Samuel Ameri, M.S.

Daniel E. Della-Giustina, Ph. D.

Department of Petroleum and Natural Gas Engineering

Morgantown, West Virginia

2013

Keywords: Utica shale, Geo-mechanical properties, Hydraulic fracturing, Fracture network, Formation stress, Stimulated reservoir volume. 


\section{Abstract \\ Impact of Geo-mechanical Properties on the Fracture Treatment of Utica Shale Tarig M. Osman}

Unconventional gas reservoirs become one of the most important energy sources in United States and all over the world. The Appalachian basin has very organic rich shale formations; it contains Marcellus and Utica shale formations with billions of cubic feet of natural gas as reserve. The development in hydraulic fracturing technology with horizontal drilling for thousands of lateral feet increase the recoverable gas from the shale formations and challenges the researchers to understand the fracturing mechanism and to study the relation between operation parameters and formation properties with the fracturing treatment outcome.

The main objective of this thesis was to study the impact of formation geo-mechanical properties such as horizontal stress level, Young's modulus and Poison's ratio on the fracturing treatment outcome and also on the complex fracture growth. More precisely, the impact of these properties on the growth of discrete fracture network (DFN). A single horizontal well model was built using commercial software to simulate the fracturing treatment. This model built based on Utica shale properties obtained from different sources.

In this thesis, we investigated the impact of horizontal stress level, Young's modulus, Poison's ratio and the leak-off coefficient. The results showed that the horizontal stress level plays a significant role in controlling the fracture orientation and growth, also affects the stimulated reservoir volume (SRV). The Young's modulus and the Leak-off coefficient also impact the fracture and the discrete fracture network. It has been determined that the formations with high Young's modulus generated high SRV. The Poison's ratio had negligible impact on the fracturing treatment outcome. 


\section{Dedication}

Dedicated to my dear God, without Him guiding me in every step, nothing would be possible for me.

This is also dedicated to my father, whose presence would make this achievement even more special.

Finally, I would like to dedicate this to my beloved mother Fatima Elfatih Mahadi, whose constant sacrifices to give me better life and led me to this point. 


\section{Acknowledgement}

I would like to express my deepest thanks and appreciations to my research advisor Dr. Ilkin Bilgesu for his continuous support, assistance and encouragement throughout this research. His contributions are numerous and valuable.

I would also like to thank all members of my research committee for their guidance and helpful suggestions. I strongly appreciate the support and advice from Professor. Sam Ameri, chair of Petroleum and Natural Gas Engineering Department. He has been father and friend throughout my study. Many thanks also to Dr. Della-Giustina for his participation in my research committee and great support.

Furthermore, my grateful thanks are due to my academic advisor Dr. Kashy Aminian for his support and advice and special thanks to all family of Petroleum and Natural Gas Engineering Department especially to Ms. Beverly Matheny for her friendly ambience and continuous help.

My Sincere appreciation also goes to my family and friends for their unconditional love, support, advice and prayers. I cannot express enough love and appreciation for my beloved mother for her support. Everything I have achieved is because of you. 


\section{Table of Contents}

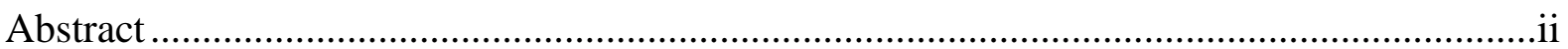

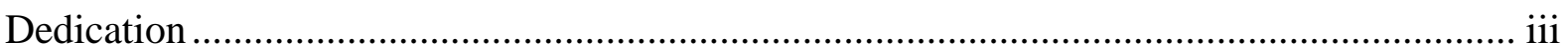

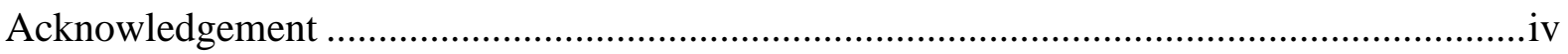

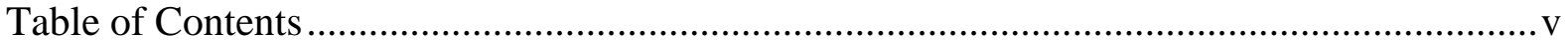

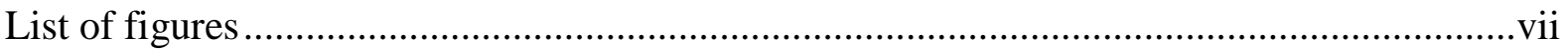

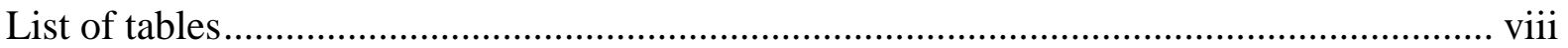

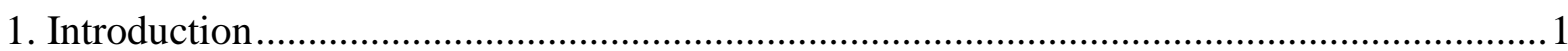

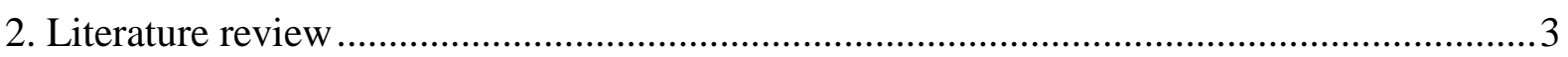

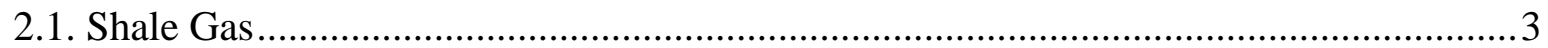

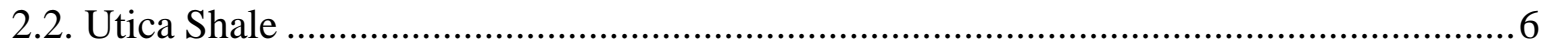

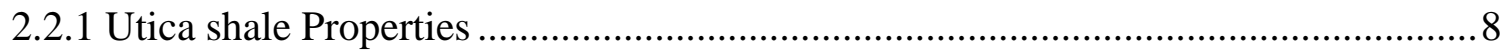

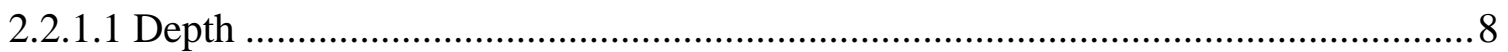

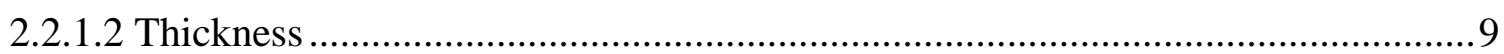

2.2.1.3 Composition and Thermal Maturity ................................................................ 9

2.2.1.4 Reservoir and Geo-Mechanical Properties ....................................................... 10

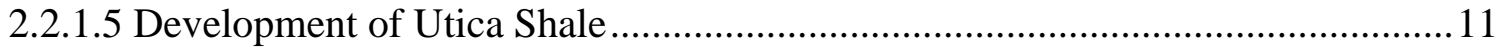

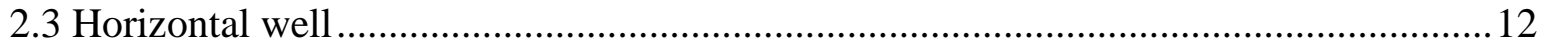

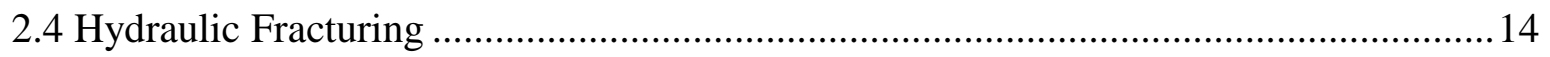

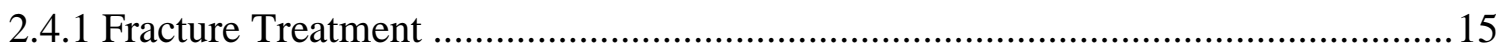

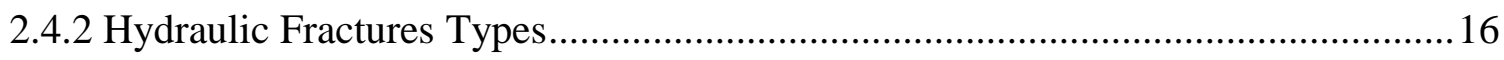

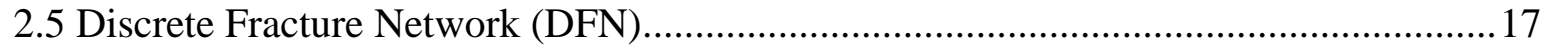

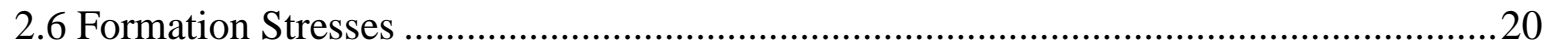

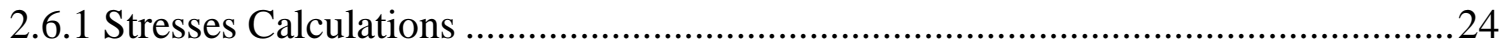

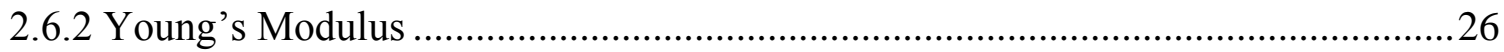

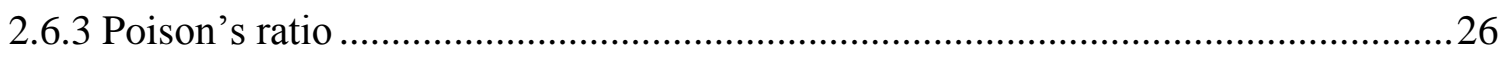

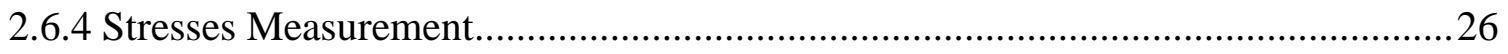

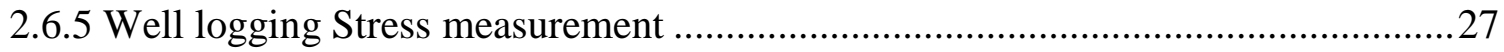

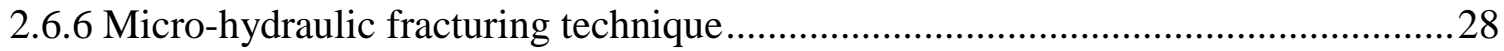

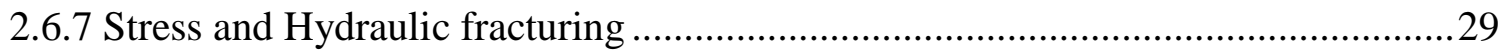

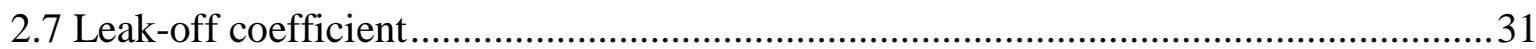

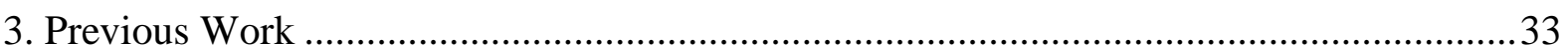

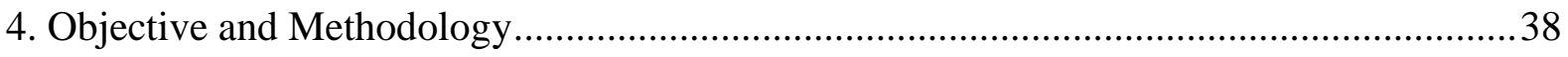




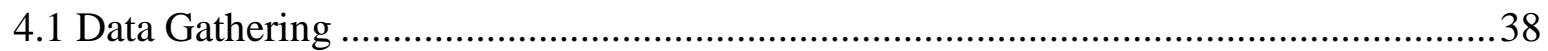

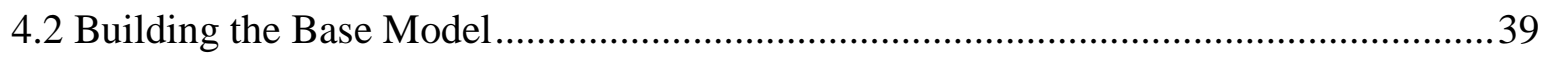

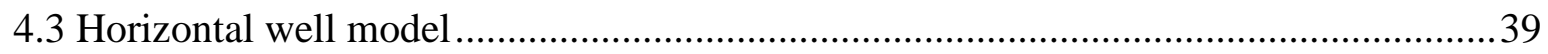

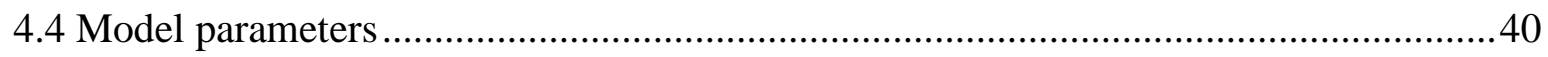

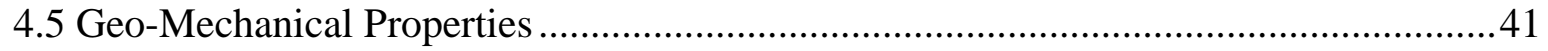

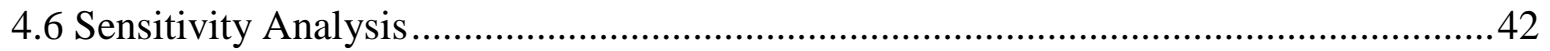

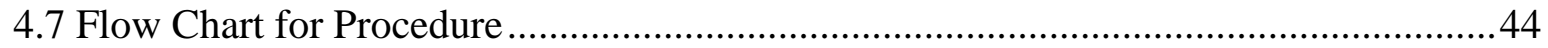

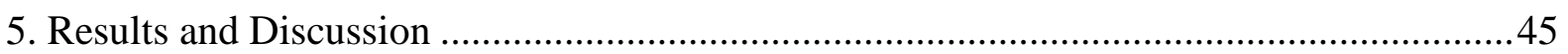

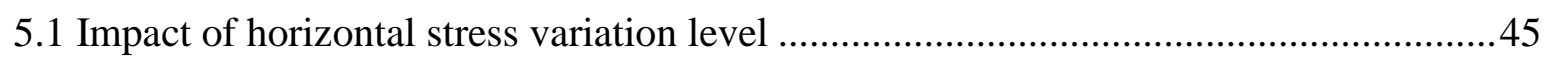

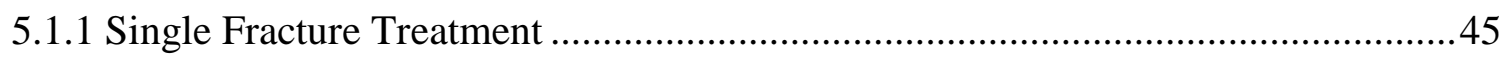

5.1.2 Three Clusters Fracturing Treatment ................................................................. 49

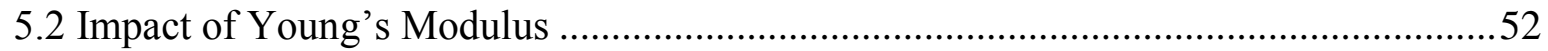

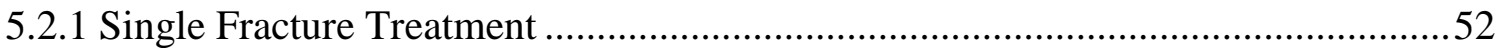

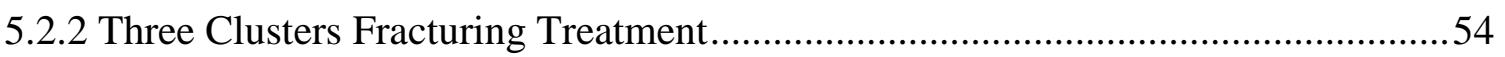

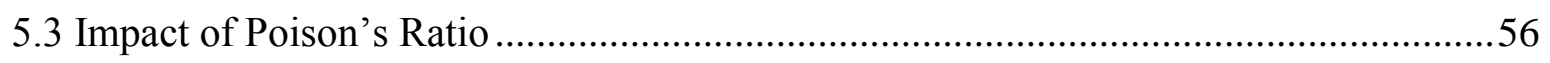

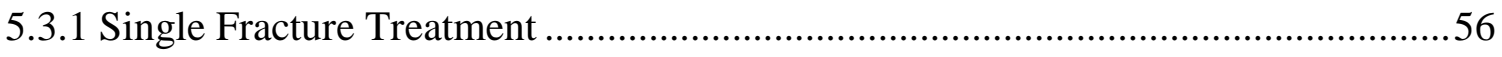

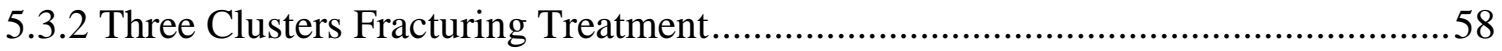

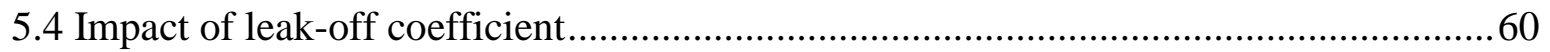

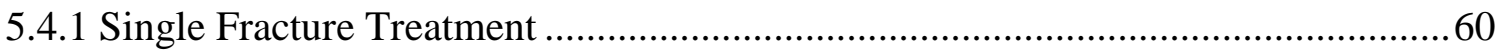

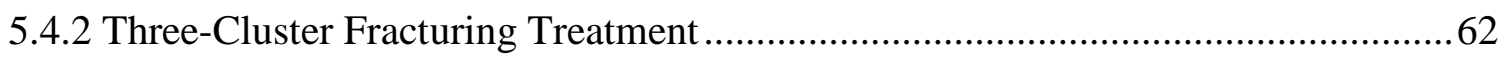

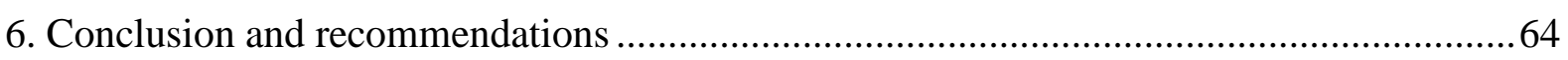

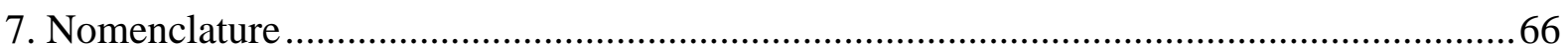

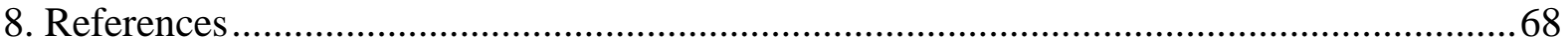

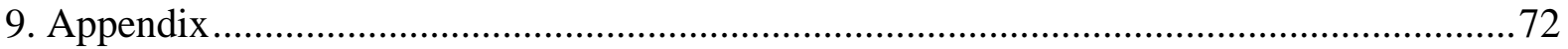

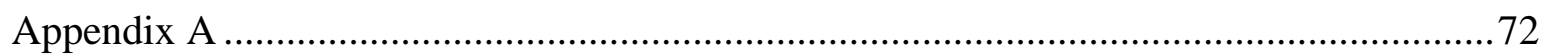




\section{List of figures}

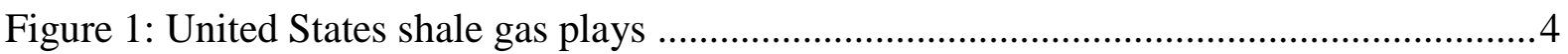

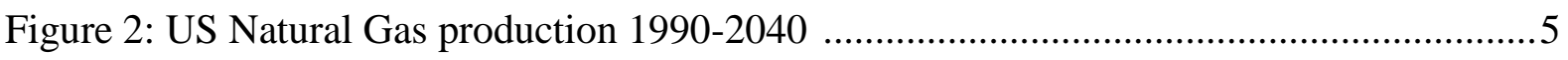

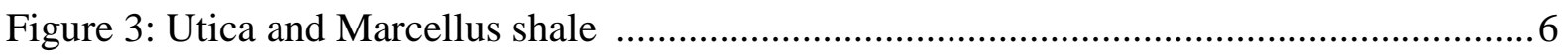

Figure 4: Stratigraphical sequence for rock units surrounding Utica and Marcellus shale, .....7

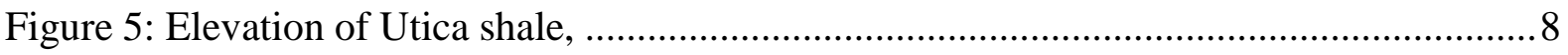

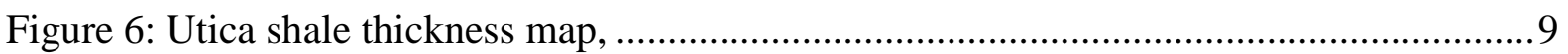

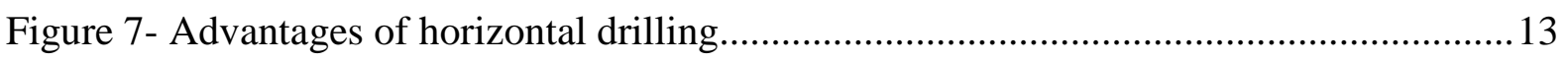

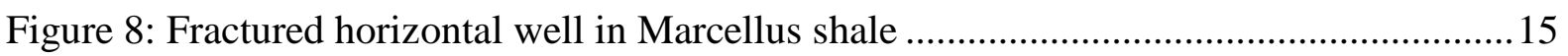

Figure 9: Hydraulic fracturing fluid composition by weight ................................................. 16

Figure 10: Transverse fracture (A) and Longitudinal fracture (B) in horizontal well ............ 17

Figure 11: Fracture growth and complexity scenarios.................................................... 19

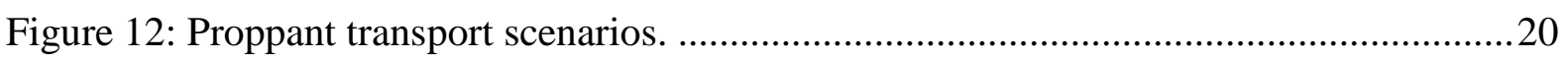

Figure 13-Sub-surface stresses acting on plane (vertical and two horizontal stresses) ..........22

Figure 14-Stress orientation according to the three faults regimes........................................2 23

Figure 15: Down-hole pressure profile during micro-fracturing test.......................................28

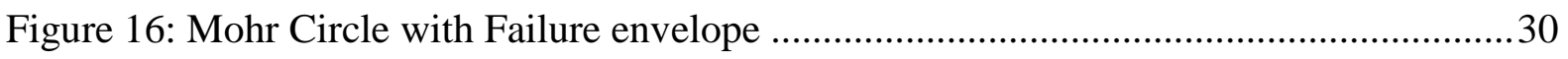

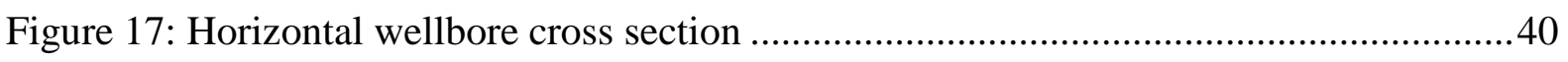

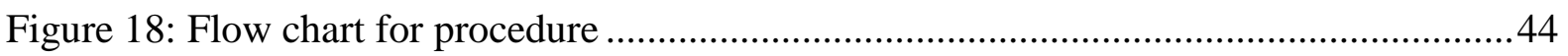

Figure 19: Fracture height and DFN height for horizontal stress levels ................................46

Figure 20: Fracture and DFN width for horizontal stress levels ........................................ 47

Figure 21: Single fracture half-length growth for horizontal stress levels ............................48

Figure 22: Stimulated reservoir volume for a single cluster with different horizontal stress levels .49

Figure 23: Comparison of SRVs with different levels of horizontal stress values ..................51

Figure 24: Fracture half length growth for single fracture with three different Young's

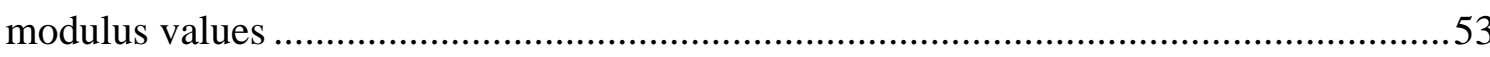

Figure 25: Stimulated reservoir volume for three different values of Young's modulus.........54

Figure 26: Comparison of Stimulated reservoir volume with three different values of Young's modulus

Figure 27: Fracture half length growth for single fracture with three different values of

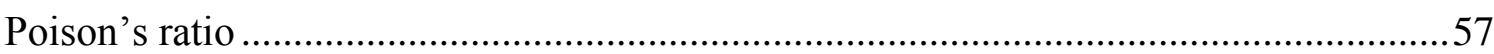

Figure 28: Stimulated reservoir volume for three different values of Poison's ratio ..............57

Figure 29: Comparison of Stimulated reservoir volume with three different values of Poison's ratio

Figure 30: Fracture half-length growth for single fracture with three different values of leakoff coefficient

Figure 31: Stimulated reservoir volume with three different values of leak-off coefficient ...61

Figure 32: Comparison of Stimulated reservoir volume using different values for leak-off coefficient 


\section{List of tables}

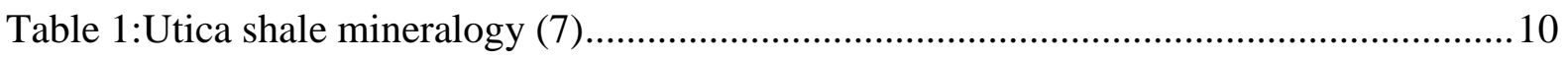

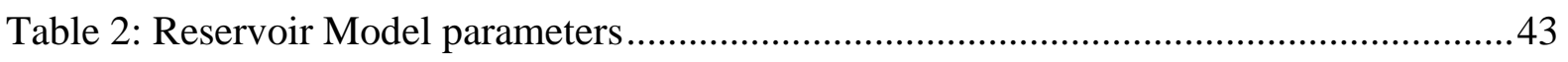

Table 3:Single fracture treatment for different horizontal stress levels................................45

Table 4: Results for three-cluster treatment with different horizontal stress levels ................50

Table 5: Single fracture treatment for different Young's modulus ........................................52

Table 6: Three clusters treatment using three different values of Young's modulus ...............54

Table 7: Single fracture treatment using different values for Poison's ratio ..........................56

Table 8: Three-cluster treatment with three different values of Poison's ratio ........................58

Table 9: Single fracture treatment for three different leak-off coefficients .............................60

Table 10: Three clusters treatment with three different values of leak-off coefficient ...........62 


\section{Introduction}

The enormous energy demand creates the challenge of looking for more economical, environmentally friendly sources for energy. Natural gas is one of the most important energy sources all over the world and especially in the United States, where approximately $24 \%$ of energy supplies in U.S come from natural gas. Aside from coal, conventional natural gas deposits have been the most practical and easiest to recover, but now the exploration and production for unconventional gas reservoirs has become the new challenge in oil and gas industry. Shale gas exploration and development is now all over the world; North America, Europe, China and the Middle East. Recently around 48 shale plays in 38 countries had been discovered and produced.

The combination of horizontal drilling and hydraulic fracturing technology increases the production from unconventional gas reservoir by creating high conductive flow bath from the matrix to fracture and then to the wellbore. It is very important to investigate the fracture treatment outcomes such as fracture geometry and conductivity properties. Many techniques are applied such as fracturing and reservoir simulation, pressure transient analysis and microseismic.

The discrete fracture network (DFN) is a new concept in order to understand the interaction between the hydraulic fracture and formation natural fractures and the growth for secondary fractures. Many research and studies conducted to understand the complexity in fracture growth and how the hydraulic fractures interact with natural fractures, fissures and other geological heterogeneities. Moreover, the impact of fracturing treatment parameters and 
formation properties in fracture complex growth were investigated. Furthermore, a numerical model to simulate the discrete fracture network growth was developed.

In this study we focused on understanding the impact of formation geo-mechanical properties on fracture growth and the discrete fracture network (DFN). A simulation model was constructed in order to simulate the fracturing operation and a variety of geo-mechanical properties were tested such as Young's modulus, Poison's ratio and horizontal stress level. The model was build using MShale software which provides a numerical solution for the discrete fracture network (DFN) equations and allow the user to change the properties to study their impact. 


\section{Literature review}

\subsection{Shale Gas}

Shale gas is defined as the gas that has been trapped within shale formations; Shale formations are fined-grained sedimentary rocks that can be rich source of oil and gas ${ }^{(1)}$. Shale gas is one of the unconventional sources for natural gas; others include tight sandstone, coal-bed methane and methane hydrates. Shale formations have very low permeability and they do not allow significant hydrocarbons to flow to the wellbore. In this case, shale gas formations were not economical source for natural gas, but in the last decades, the improvement in hydraulic fracturing and horizontal drilling has increased the economic production from shale formations ${ }^{(2)}$.

Shale gas plays have been discovered in many places around the world, as per Energy Information Administration (EIA) 48 shale basins in 38 countries has been proved. China is estimated to have the largest shale gas reserves with approximately 1,275 TCF estimated recoverable reserves. United States, Canada, Australia Algeria and many other countries discovered much shale plays which up till now; many countries have not explored the shale plays.

Shale gas has become one of the most important energy resources in United States in the last century. Recently, in 2000, shale gas provided about $1 \%$ of U.S. natural gas production, but by 2010 , it jumped to about $20 \%$ of the natural gas production. The EIA predicts that $46 \%$ of natural gas production will be from shale gas by 2035 . Historically, the first shale gas extracted was in 1821, in Fredonia, NY, in shallow low-pressure fractured formation. With the introduction and development of horizontal drilling in the 1930s, and the introduction of hydraulic fracturing technology in the 1940s, shale gas had been playing a key role as energy source in the United States ${ }^{(1)}$. 
Many shale plays have been discovered around the United States, but most shale gas lay in the lower 48 states. There are many active shale gas formations, such as, Barnett Shale, the Haynesville/Bossier Shale, the Fayetteville Shale, the New Albany Shale, the Marcellus Shale, and the Utica shale. The Figure-1 below shows the distribution of shale gas formation in the lower 48 states.

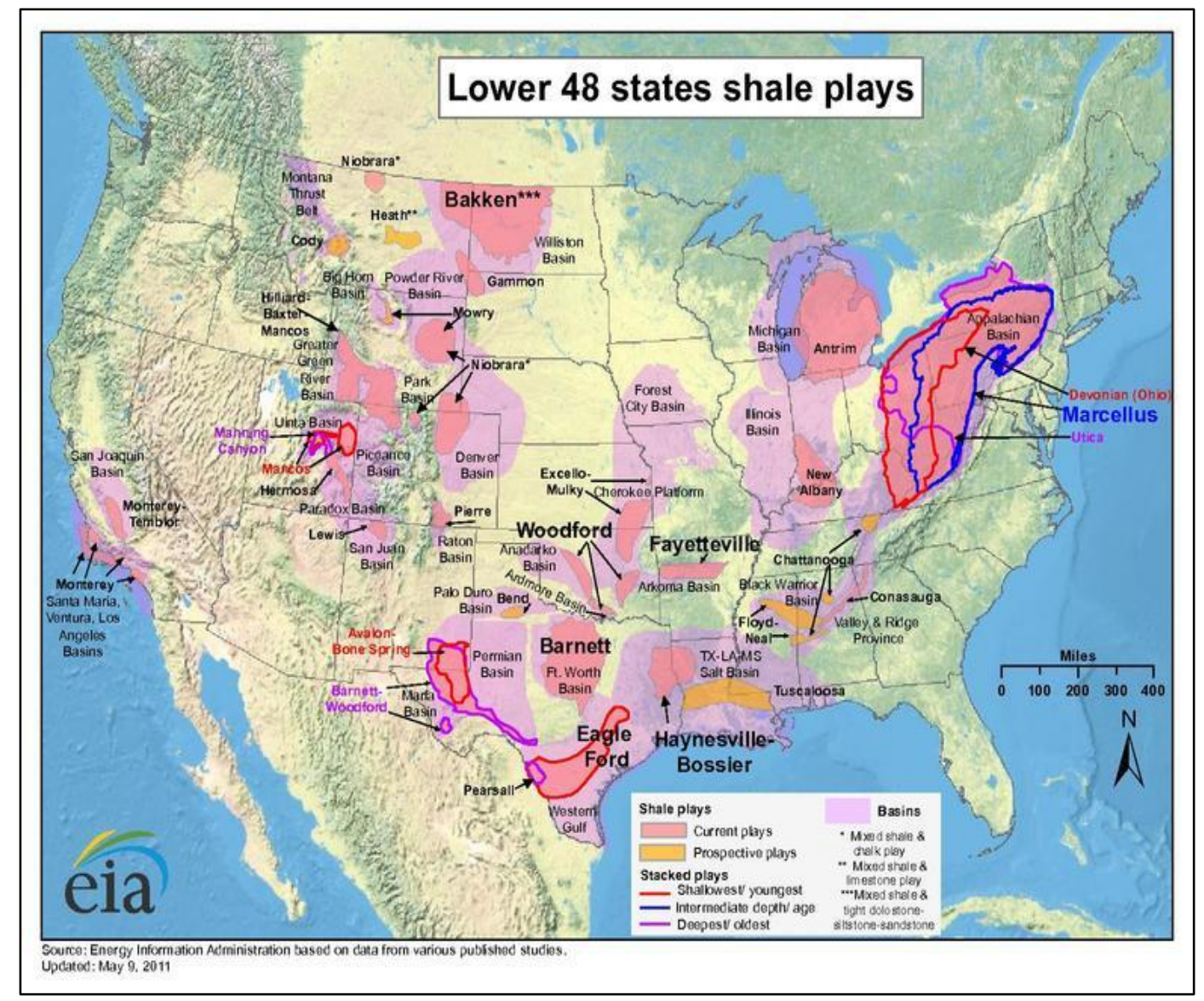

Figure 1: United States shale gas plays ${ }^{(1)}$

The production from shale gas recently increased very rapidly along with the development of horizontal drilling and fracturing technologies. In 2008 shale formations produced about $2.02 \mathrm{TCF}$ of gas, then the production from shale gas jumped by about $54 \%$ and reached 3.11 TCF. In 2010 the production from shale gas was estimated to be around $10 \%$ of total gas production. In 2011 the EIA increased the estimation of the recoverable gas from shale gas to 827 TCF from 353 TCF based on the collected data from drilling in new 
shale plays such as Marcellus shale, then again EIA lowered its estimation to 482 TCF in 2012. The EIA predicts that the percentage of shale gas production will increase from about $20 \%$ of total gas production in U.S. to about $50 \%$ of the total gas production. The Figure-2 below shows the gas production history and predictions through 2040 in United States from different sources with percentages based on the EIA study ${ }^{(3)}$.

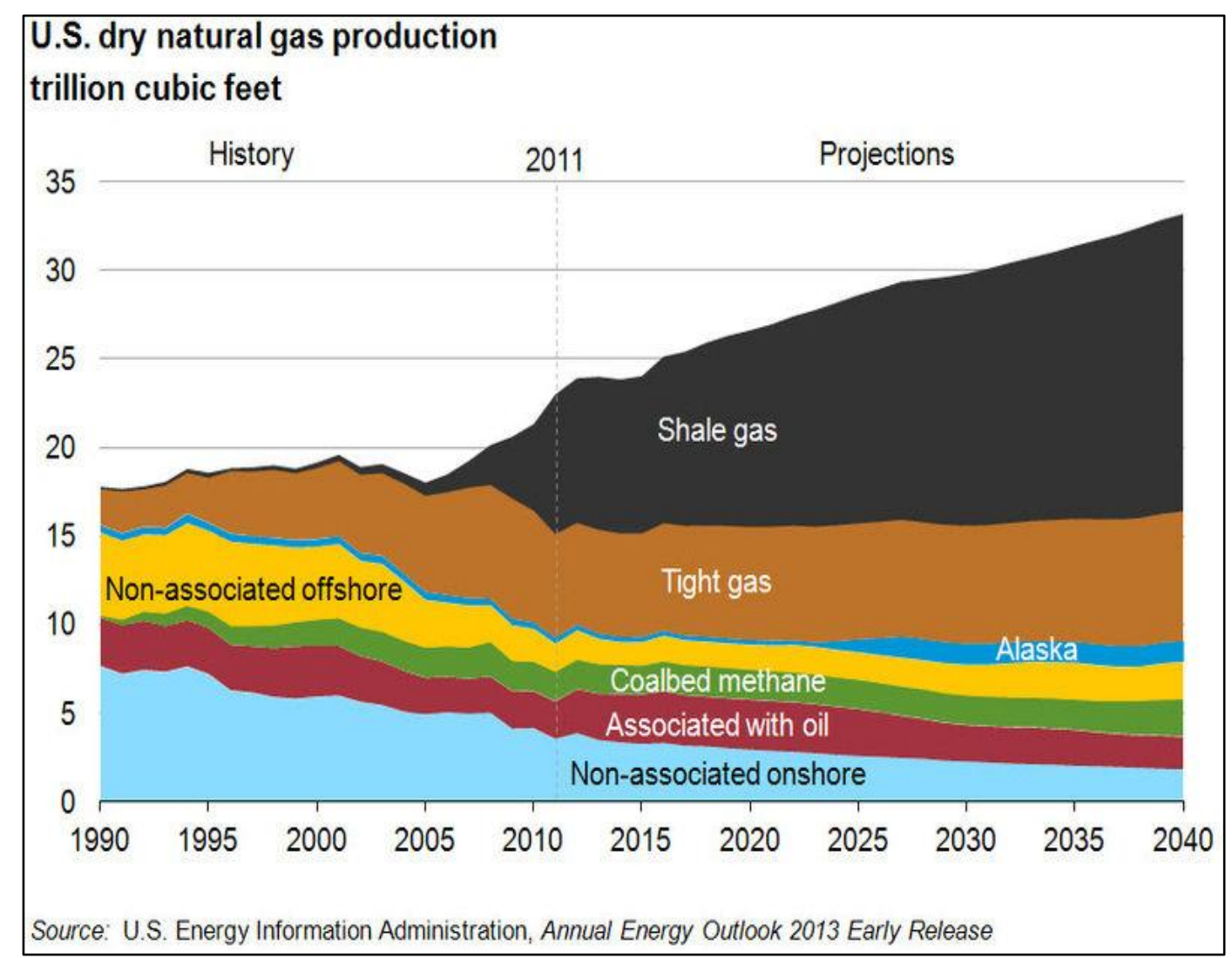

Figure 2: US Natural Gas production 1990-2040 ${ }^{(3)}$ 


\subsection{Utica Shale}

Utica shale is upper Ordovician-aged black shale; it is one of the most widely spread and oldest black shale in Appalachian basin. The Utica shale is a massive, fossiliferous, organic-rich, thermal-mature, black to grey-black shale ${ }^{(4)}$. This shale was deposited about 440 to 460 million years ago and it covers approximately around 28,500 square miles. The Utica shale is located few thousand feet below the Marcellus and it extends through Kentucky, Maryland, New York, Ohio, Pennsylvania, Tennessee, West Virginia and Virginia. Also Utica shale covers parts of Lake Ontario, Lake Erie and part of Ontario, Canada ${ }^{(5)}$. The Figure- 3 below shows the area covered by Utica and Marcellus shale.

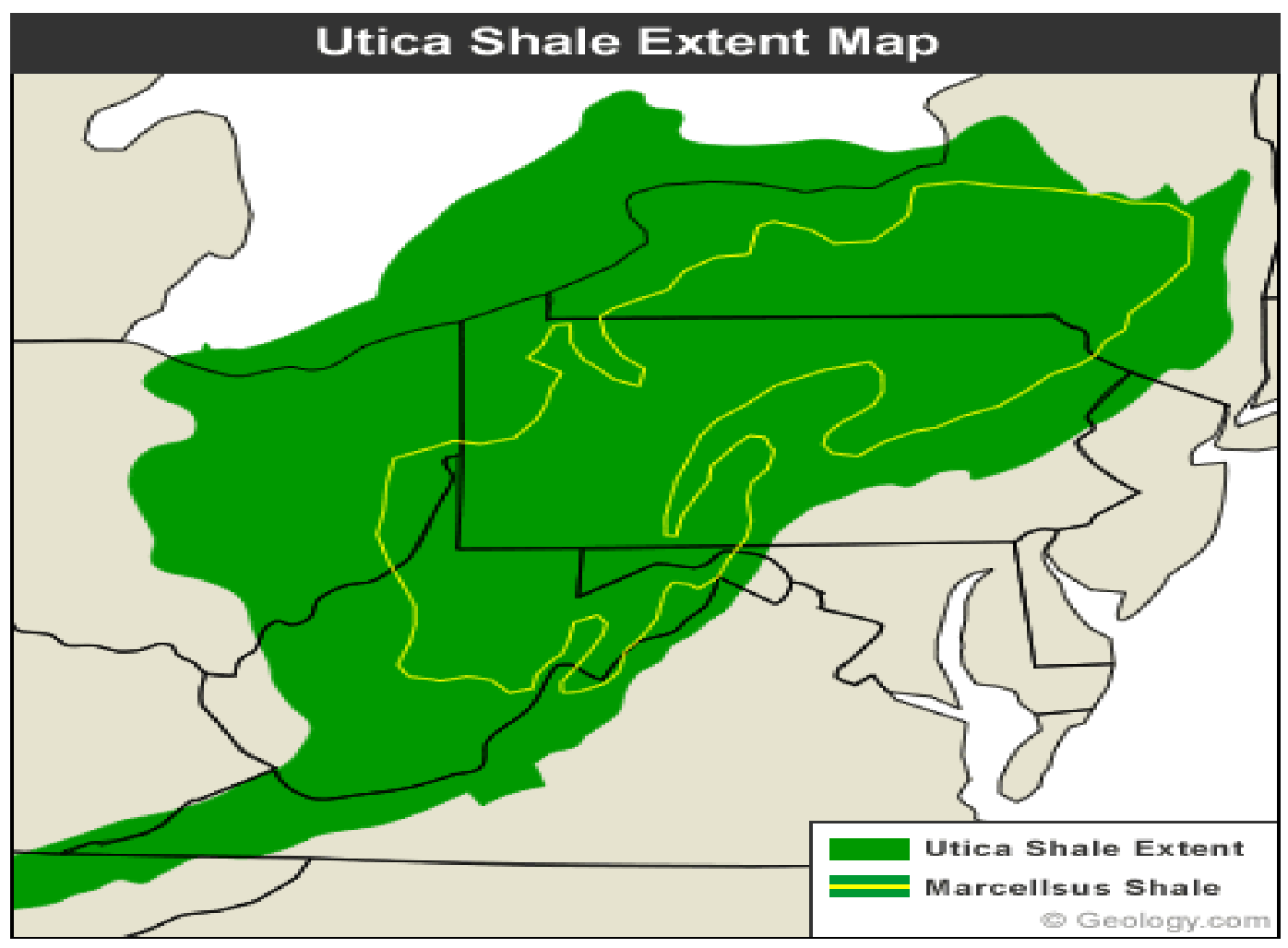

Figure 3: Utica and Marcellus shale ${ }^{(6)}$ 
The Utica shale overlies the Trenton/Black River limestone and it is few thousand feet below the Marcellus shale, Onondage formation and Hamilton Devonian formations and it is derived from the erosion of the Taconic Mountains at the end of Ordovician ${ }^{(7)}$. The Figure- 4 below shows generalized stratigraphic sequence of the formation units surrounding Utica and Marcellus shale.

\begin{tabular}{|c|c|c|}
\hline \multirow{4}{*}{318 MYA } & & Pottsville Group \\
\hline & \multirow{3}{*}{ 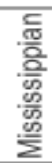 } & Mauch Chunk Group \\
\hline & & Greenbriar Limestone \\
\hline & & Pocono Group \\
\hline \multirow{8}{*}{359 MYA } & \multirow{8}{*}{ 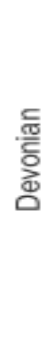 } & Ohio Shale \\
\hline & & Genesee / Sonyea / West Falls / Java Fms \\
\hline & & Tully Limestone \\
\hline & & Hamilton Group \\
\hline & & Marcellus Formation \\
\hline & & $\begin{array}{l}\text { Onondaga Formation } \\
\text { Bois Blanc Formation / Huntersville Chert }\end{array}$ \\
\hline & & Ridgeley Sandstone \\
\hline & & Helderberg Group \\
\hline \multirow{4}{*}{416 MYA } & \multirow{5}{*}{ 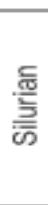 } & Bass Islands Dolomite / Keyser Formation \\
\hline & & Salina Group \\
\hline & & Lockport Dolomite and McKenzie Formation \\
\hline & & Clinton Group \\
\hline \multirow{7}{*}{443 MYA } & & Medina Group / Tuscarora Formation \\
\hline & \multirow{6}{*}{ 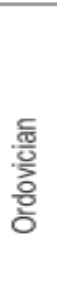 } & Queenston Shale / Oswego Formation \\
\hline & & Reedsville Shale \\
\hline & & Utica Formation \\
\hline & & Trenton / Black River Limestones \\
\hline & & Loysburg Formation \\
\hline & & Beekmantown Group \\
\hline \multirow{2}{*}{$488 \mathrm{MYA}$} & \multirow{2}{*}{ 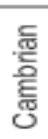 } & Rose Run Sandstone \\
\hline & & Copper Ridge Dolomite \\
\hline
\end{tabular}

Figure 4: Stratigraphical sequence for rock units surrounding Utica and Marcellus shale, ${ }^{(6)}$ According to the State of Ohio Geological Survey, the recoverable Utica shale potential is estimated to be around 3.8 to 15.7 trillion cubic feet of natural gas and between 1.3 to 5.5 billion barrels of oil ${ }^{(8)}$. 


\subsubsection{Utica shale Properties}

\subsubsection{Depth}

The Utica shale varies in depth throughout its extension areas; this depth changes from about 2,000 feet below the sea level at the west part (Eastern Ohio) and to the North West under the Great Lakes and into Canada and the depth can reach 14,000 feet below the sea level in some parts of Pennsylvania ${ }^{(6)}$. The Figure-5 below shows the elevation of Utica shale.

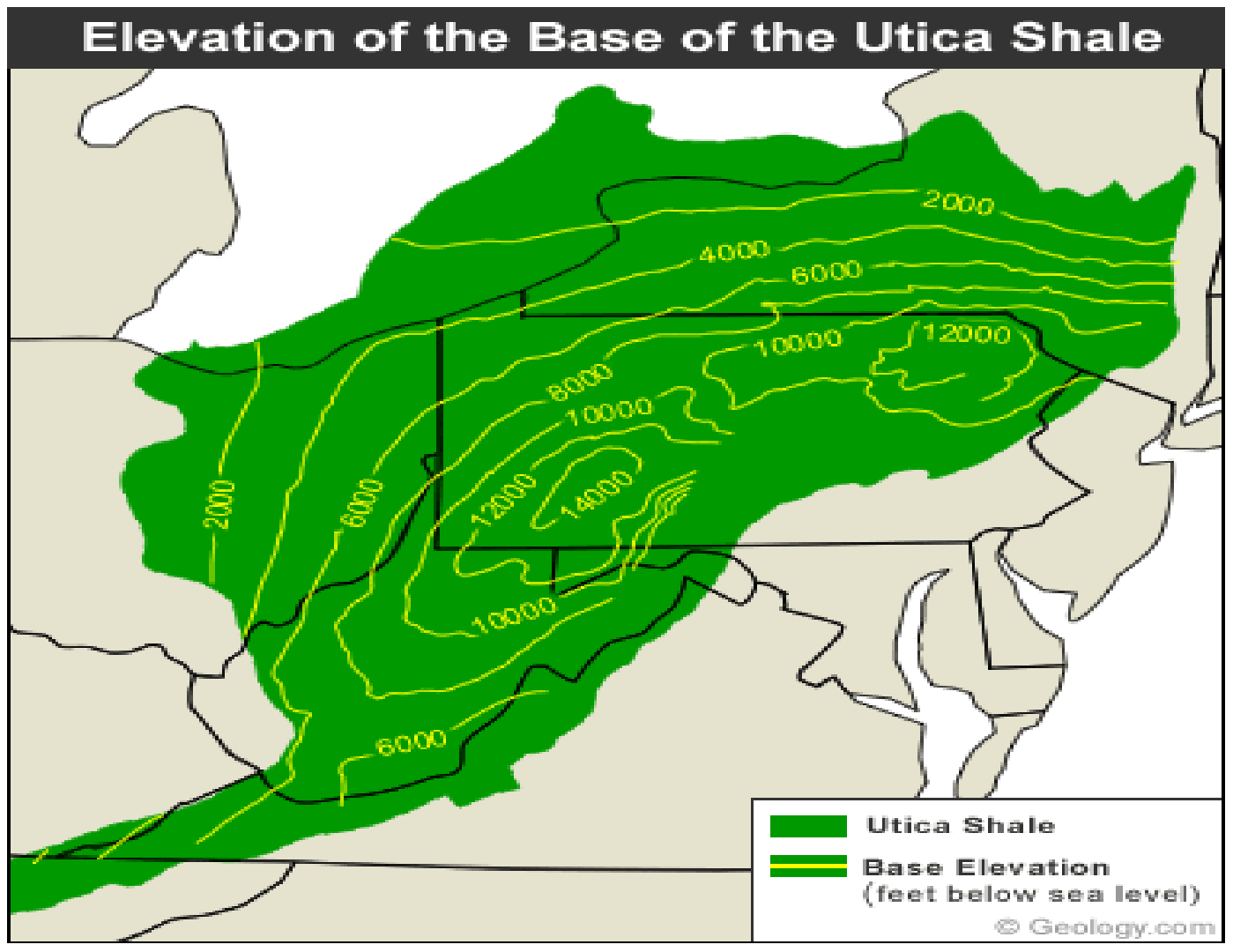

Figure 5: Elevation of Utica shale, ${ }^{(6)}$

In general, Utica shale is deeper than Marcellus shale. In central Pennsylvania; Utica can be up to 7,000 feet below the Marcellus but that depth differences decreases to the west and could be less than 3,000 feet in eastern part of Ohio. 


\subsubsection{Thickness}

The Utica shale thickness varies from 100 feet up to over than 500 feet and it is thicker in the eastern part and thinner toward the west like most of the source rocks in Appalachian basin. Marcellus shale also follows the same trend ${ }^{(6)}$. Figure- 6 below shows the thickness distribution for Utica shale.

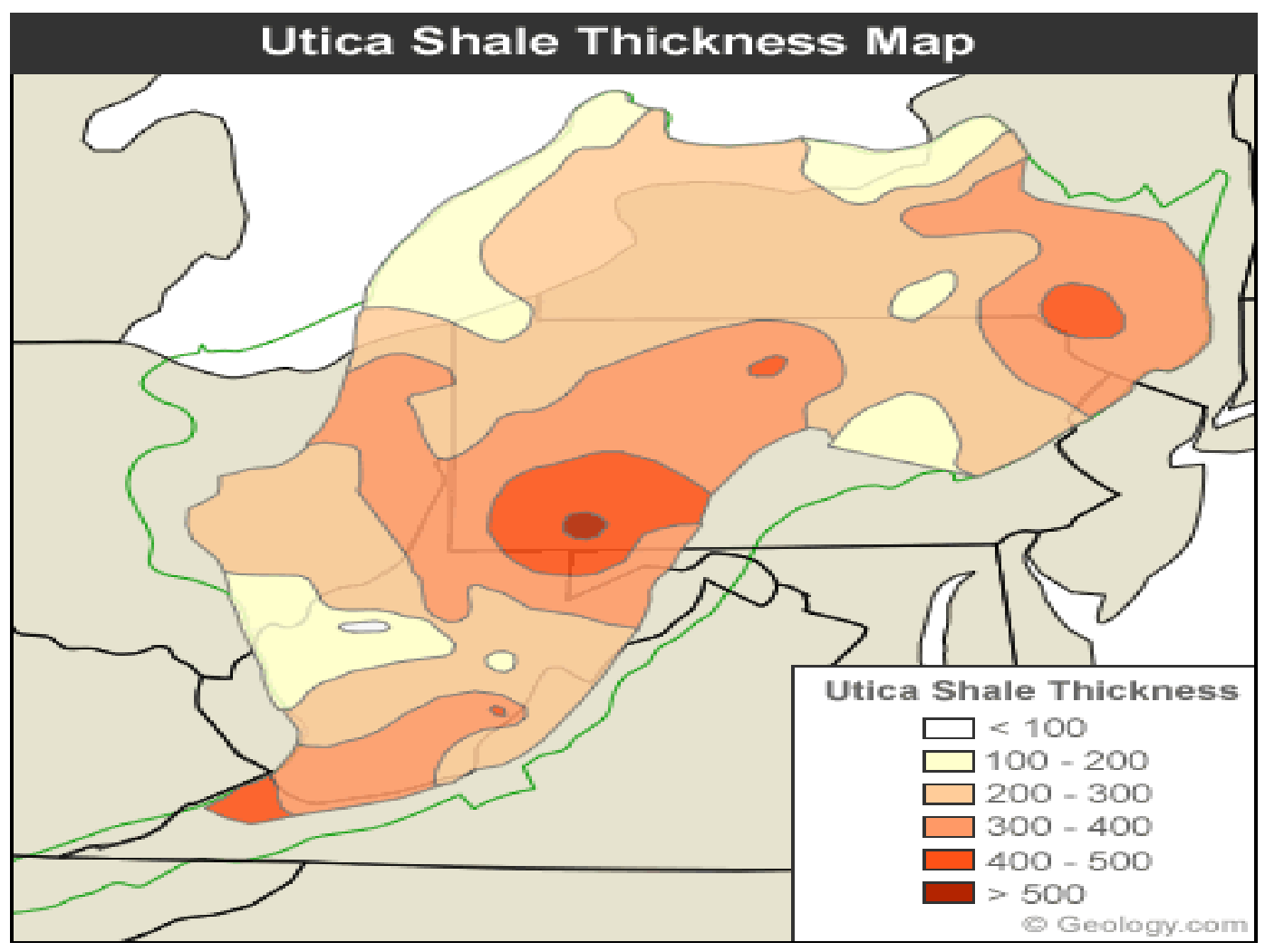

Figure 6: Utica shale thickness map, ${ }^{(6)}$

\subsubsection{Composition and Thermal Maturity}

Utica shale comprises more than 25 percent of Detrital quartz and Feldspar, also contains considerable percentage of Calcite and Dolomite. The Utica shale is considered as high clays shale formation and that should be taken into consideration in the selection of drilling and fracturing fluids ${ }^{(7)}$. 
The Total Organic Carbon (TOC) in Utica shale estimated to be between $1.5 \%$ and $3 \%$ in eastern New York and varies from $2 \%$ up to $15 \%$ in Northern New York, Ontario and Quebec. Some core samples measure around 2.06\% TOC in Utica shale ${ }^{(4)}$. Table-1 below describes the mineralogy of Utica shale.

Table 1:Utica shale mineralogy (7)

\begin{tabular}{|c|c|}
\hline Mineral/Clay & Percent \\
\hline Quartz/Feldspar & 25 \\
\hline Calcite & 26 \\
\hline Fe Dolomite & 8 \\
\hline Plagioclase & 8 \\
\hline Pyrite & 4 \\
\hline Smectite & 8 \\
\hline Illite & 13 \\
\hline Chlorite & 6 \\
\hline Other/Organic & 2 \\
\hline Total & 100 \\
\hline
\end{tabular}

\subsubsection{Reservoir and Geo-Mechanical Properties}

The information about porosity and permeability for Utica shale is sparse. However some core analysis of samples from Utica shale shows the tight nature of this formation. The porosity of Utica shale varies between $3.7 \%$ to $6 \%$ and the permeability ranges from $0.00008 \mathrm{md}$ up to $0.003583 \mathrm{md}$. These results revealed that Utica shale is tighter when compared with other black shale such as Devonian shale in the Appalachian basin. The 
reservoir pressure in Utica shale varies from less than 1,000 psi up to 2,500 psi. The reservoir pressure depends on the depth; in general, pressure gradient of $0.5 \mathrm{psi} / \mathrm{ft}$ can be assumed.

Young's modulus for shale formations estimated to be between $2 \mathrm{Mpa}$ and $6 \mathrm{Mpa}$ and for Utica shale is estimated around 2.2E+6 psi. While Poison's ratio was estimated to be around $0.2^{(7)}$.

\subsubsection{Development of Utica Shale}

During 2011 and 2012, Eastern Ohio region was a very active region in terms of Utica shale development; the gas companies spent millions of dollars to acquire areas in eastern Ohio. The shallow depth of Utica attracts these companies as there are significant amount of natural gas liquids and oil for production ${ }^{(9)}$. 


\subsection{Horizontal well}

In the last two decades, horizontal drilling has become one of the most important tools in oil and gas industry for exploration and development for both conventional and unconventional reservoirs. Horizontal wells have been very effective in terms of increasing wells productivity, adding more reserves and improving cost-effectiveness in field operations. The improvement in the horizontal drilling technology increases the efficiency and the economic feasibility for horizontal wells. Horizontal wells technology requires better completion design to optimize the production rates for long-term economic production and ultimate producible reserves ${ }^{(10)}$.

Horizontal wells system has many advantages for the oil and gas exploration and production. The major advantage of horizontal well technology is to increase the contact area with the reservoir ${ }^{(11)}$. Using the new technologies presented in drilling operations, the horizontal lateral can reach around 6,000 feet long.

The horizontal wells are usually faster, economical and more effective than vertical wells. The horizontal wells also can provide:

1) Better access to reservoirs at sites with surface restrictions, e.g. buildings, residential areas, etc...

2) Intersecting natural fractures, as shown in Figure-7 below.

3) Reduction water and/or gas coning. (Figure-7).

4) Minimizing the environmental impact by reducing the foot print for well drilling and also requiring fewer wellheads.

5) Better exploitation for thin oil or gas zone (Figure-7).

6) Reduction in the field operation and maintenance expense with less number of wells.

7) Improvement of drilling cost since several horizontal wells can be drilled using the same surface site that reduces the rig mobilization cost and time. 
8) Enhancement of heavy oil recovery (Figure-7).

9) Improvement the production from reservoirs with vertical bedding planes "multiple layers" as shown in Figre-7 below.

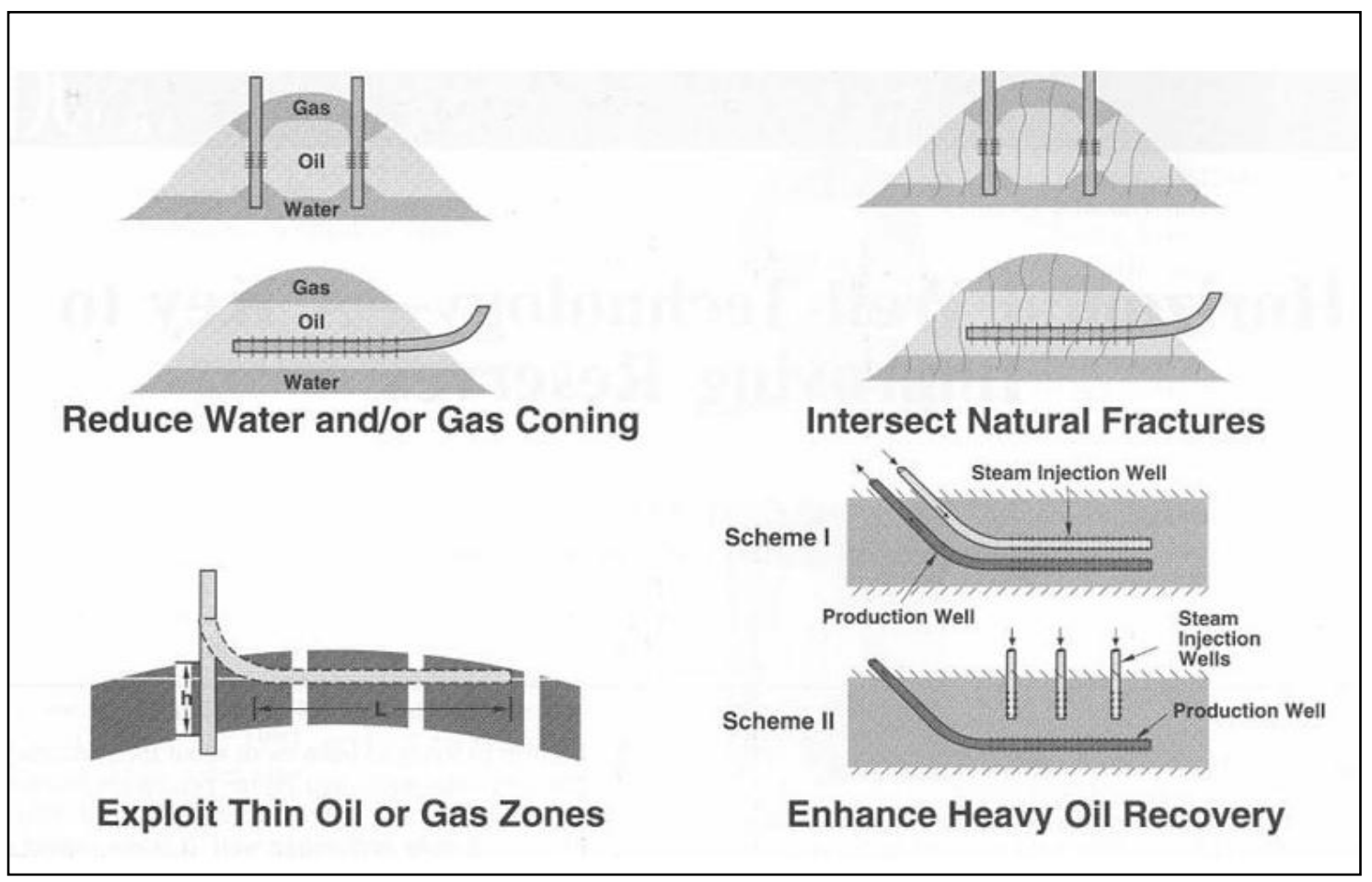

Figure 7- Advantages of horizontal drilling ${ }^{(12)}$

According to Joshi, the major disadvantage for the horizontal well is the ineffectiveness in very thick reservoirs $(500 \mathrm{ft}$ to $600 \mathrm{ft}$ ) and also in formations with low vertical permeability ${ }^{(13),(14)}$. The low vertical permeability results in increased resistance in vertical flow in the horizontal well and decreases the oil or gas production rate.

The horizontal wells method has other major disadvantages ${ }^{(15)}$ :

1) Only one zone at a time can be produced. If the reservoir has different zones with variety in depth, the horizontal well will not be able to drain one zone.

2) High drilling cost when compared with a vertical well cost. Horizontal well costs are approximately 1.5 to 2.5 times more than a vertical well if it is drilled from the 
surface. A re-entry horizontal well costs about 0.4 to 1.3 times more than the vertical well.

Horizontal well technologies with the multistage hydraulic fracturing techniques now have been used for many years to improve the gas recovery from shale gas formations in Appalachian basin such as Marcellus shale and Utica shale.

\subsection{Hydraulic Fracturing}

Hydraulic fracturing, commonly known as fracking, is one of the most important technologies in oil and gas industry. Hydraulic fracturing plays significant role in gas production from shale formations, first and foremost, in well stimulation ${ }^{(16)}$. The hydraulic fracturing can be defined as creating a highly conductive flow path extended far beyond the damage zone around the wellbore and that increases the exchange between the wellbore and the reservoir ${ }^{(17)}$. Fracturing is also used to measure formation stresses, as a method to improve the water flooding and more recently, as a method to store drilling wastes.

Historically, fracturing had been used for more than 100 years, but the first commercial use was in 1949. It took around 40 years for engineers and geologists to optimize the process and after that the payoff of the technology becomes more than expectation. By 1988 hydraulic fracturing was applied more than million times ${ }^{(18)}$. As of 2012, 2.5 million fracturing jobs have been performed worldwide, more than one million of them in the United States. More recently, the combination of hydraulic fracturing technology and horizontal drilling becomes the key method in order to develop the low permeability formations. The Figure-9 below shows an example for hydraulically fractured horizontal well in Marcellus shale ${ }^{(19)}$. 


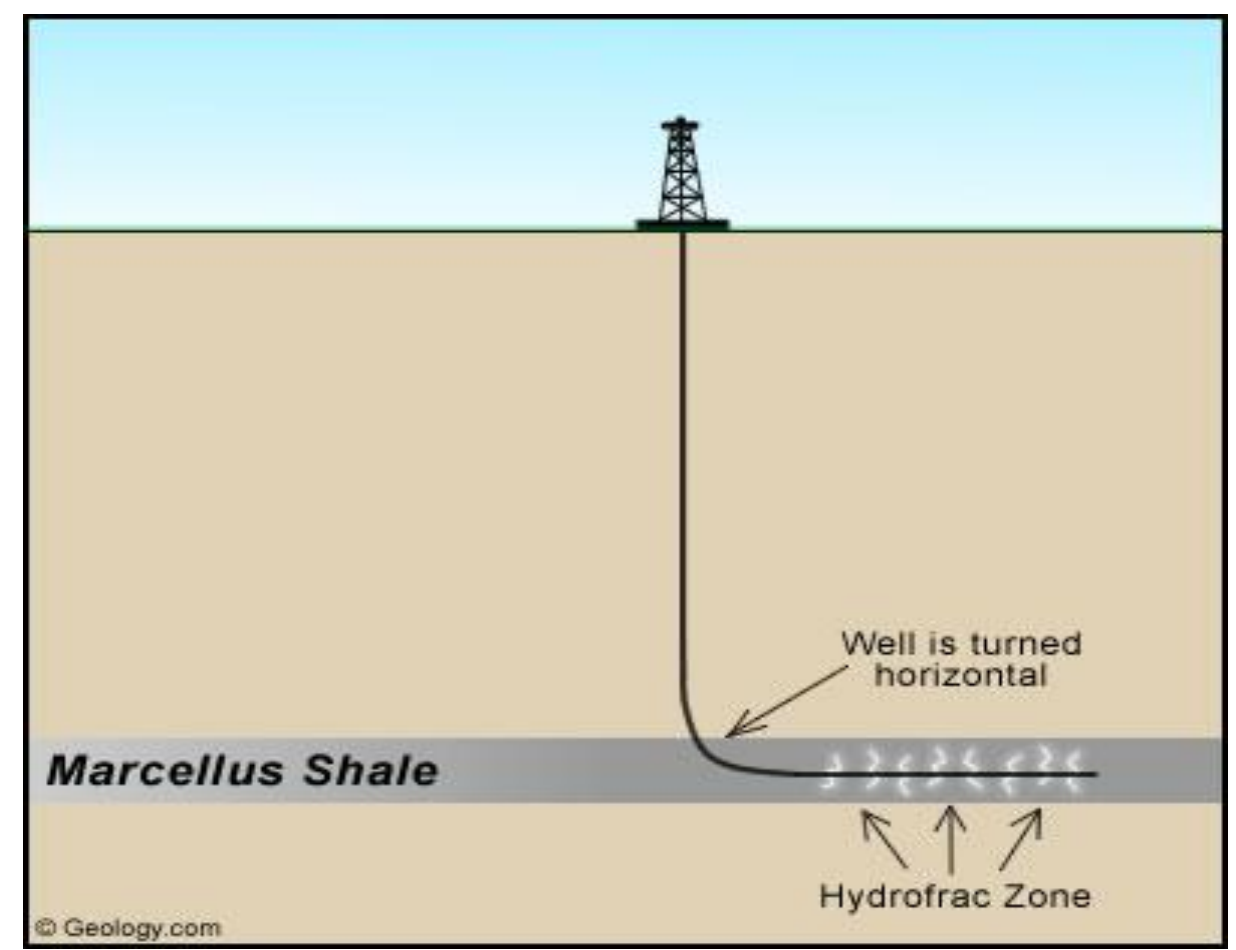

Figure 8: Fractured horizontal well in Marcellus shale ${ }^{(6)}$

\subsubsection{Fracture Treatment}

A hydraulic fracture is generally formed by pumping the fracturing fluid into the wellbore at high pressures. At these high pressures, the formation cracks due to high stress and the fracture initiated. In order for the formation to be hydraulically fractured, the stress pressure generated from the injection fluid must exceed the maximum formation stress. Then, the fracture propped by sand to allow the hydrocarbon to flow and keep the fracture from closing. The fracturing fluid contains about $90 \%$ water and $9.5 \%$ proppant (sand) with chemical additives counting about $0.5 \%$. The water soluble gelling agent added to the fracturing fluid to increase the viscosity to allow the fluid to carry the proppant deep into the formation. The Figure-10 below shows the main components of the hydraulic fracturing fluid (20). 


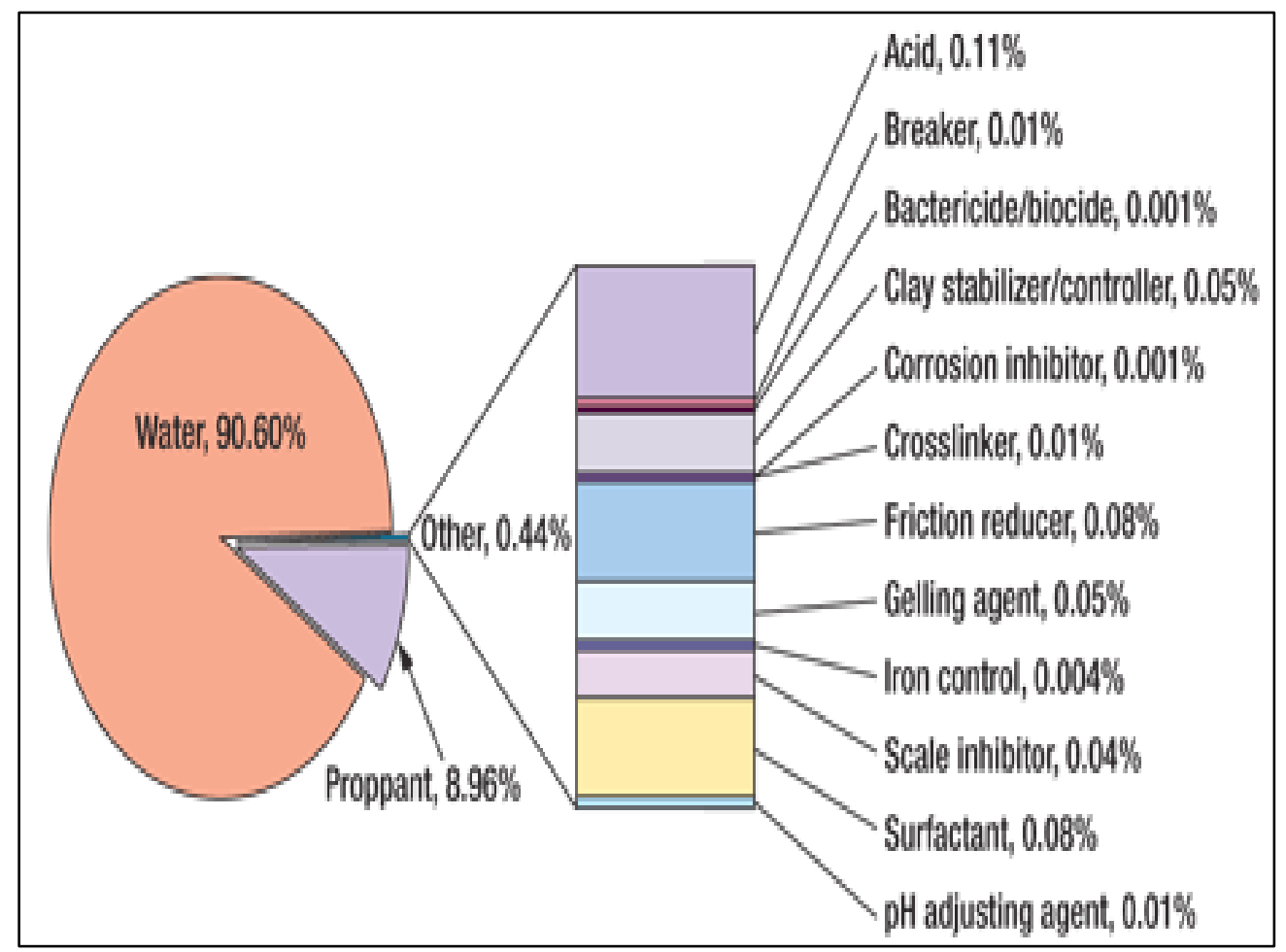

Figure 9: Hydraulic fracturing fluid composition by weight ${ }^{(20)}$

\subsubsection{Hydraulic Fractures Types}

Based on the wellbore orientation and the direction of the minimum horizontal stress; two types of hydraulic fractures can be created, longitudinal or transverse fracture.

If the horizontal well drilled perpendicular to the minimum horizontal stress, the generated fracture will be longitudinal. If the horizontal well drilled parallel to the minimum horizontal stress, the fracture created will be perpendicular to the wellbore (transverse fracture). The Figure-11 below shows the two types of hydraulic fractures ${ }^{(21)}$. 


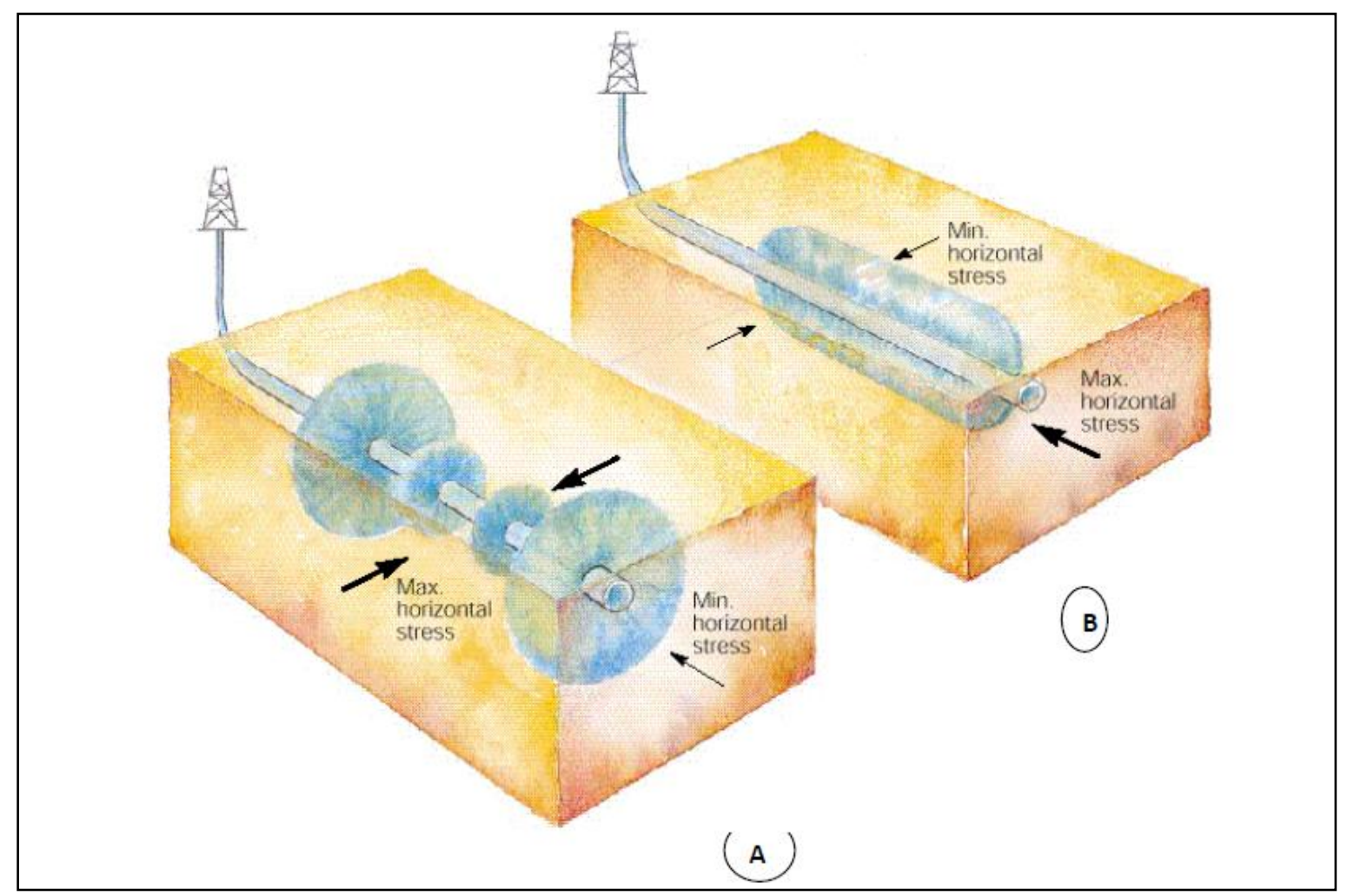

Figure 10: Transverse fracture (A) and Longitudinal fracture $(B)$ in horizontal well ${ }^{(21)}$

\subsection{Discrete Fracture Network (DFN)}

Understanding the growth of hydraulic fracture is very important in order to evaluate the well performance and to optimize the fracturing treatment to achieve high well productivity. The information about the hydraulic fracture extension into the formation, width, height and other properties, gives in depth knowledge about the fracturing process outcomes.

The success in fracturing operations and using the multi-stages and multi-clusters per stage, fracture treatments increases the productivity by increasing the reservoir area affected by the stimulation, this area is known as the stimulated reservoir volume (SRV). This increase in the stimulated reservoir volume also increases the estimated ultimate recovery (EUR) from the low permeability formations ${ }^{(22)}$. 
The conventional fracturing treatments generally result in bi-wing fracture geometry. In many formations, complex fracture growth occurs due to the interaction of the hydraulic fracture with formation's natural fractures, fissures, cleats and other geological heterogeneities. This complex fracture growth has been documented in mine-back experiments and also from direct observation in variety of formations such as tight sandstone and coalbed methane reservoirs. Moreover, the use of micro-seismic techniques shows the complexity in fractures growth and the large fracture extensions in naturally fractured formations.

In 2008, Wapiniski et al. and Cipolla et al. investigated the complex fracture growth scenarios. Their study shows four main scenarios for the fracture complexity ${ }^{(23)}$ :

1. Planar-coupled growth.

2. Planar- decoupled growth.

3. Complex growth (communicating and non-communicating).

4. Network growth.

The Figure-12 shows the four scenarios for complex fracture growth. 


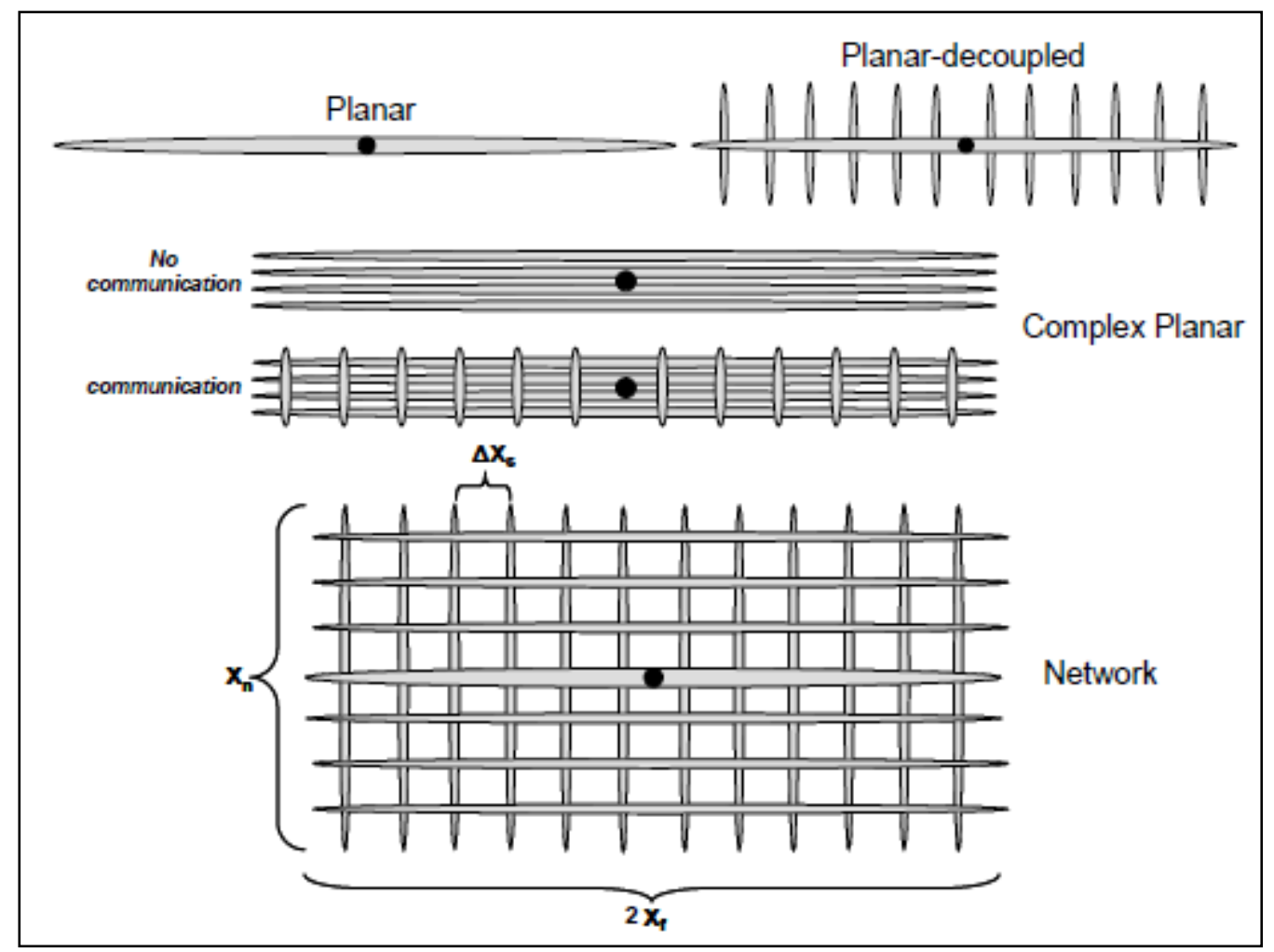

Figure 11: Fracture growth and complexity scenarios. ${ }^{(23)}$

The proppant also follows different scenarios for placement in complex fractures. According to Cipolla et al. the proppant distribution had three main distribution scenarios:

1. "The proppant is evenly distributed throughout the complex fracture system."

2. "The proppant is concentrated in a dominant planar fracture with un-propped complex fracture system accepting fluid only."

3. "The proppant settle and forms pillars that are evenly distributed within the complex fracture system."

The Figure-13 below shows the three different scenarios for proppant transportation. 


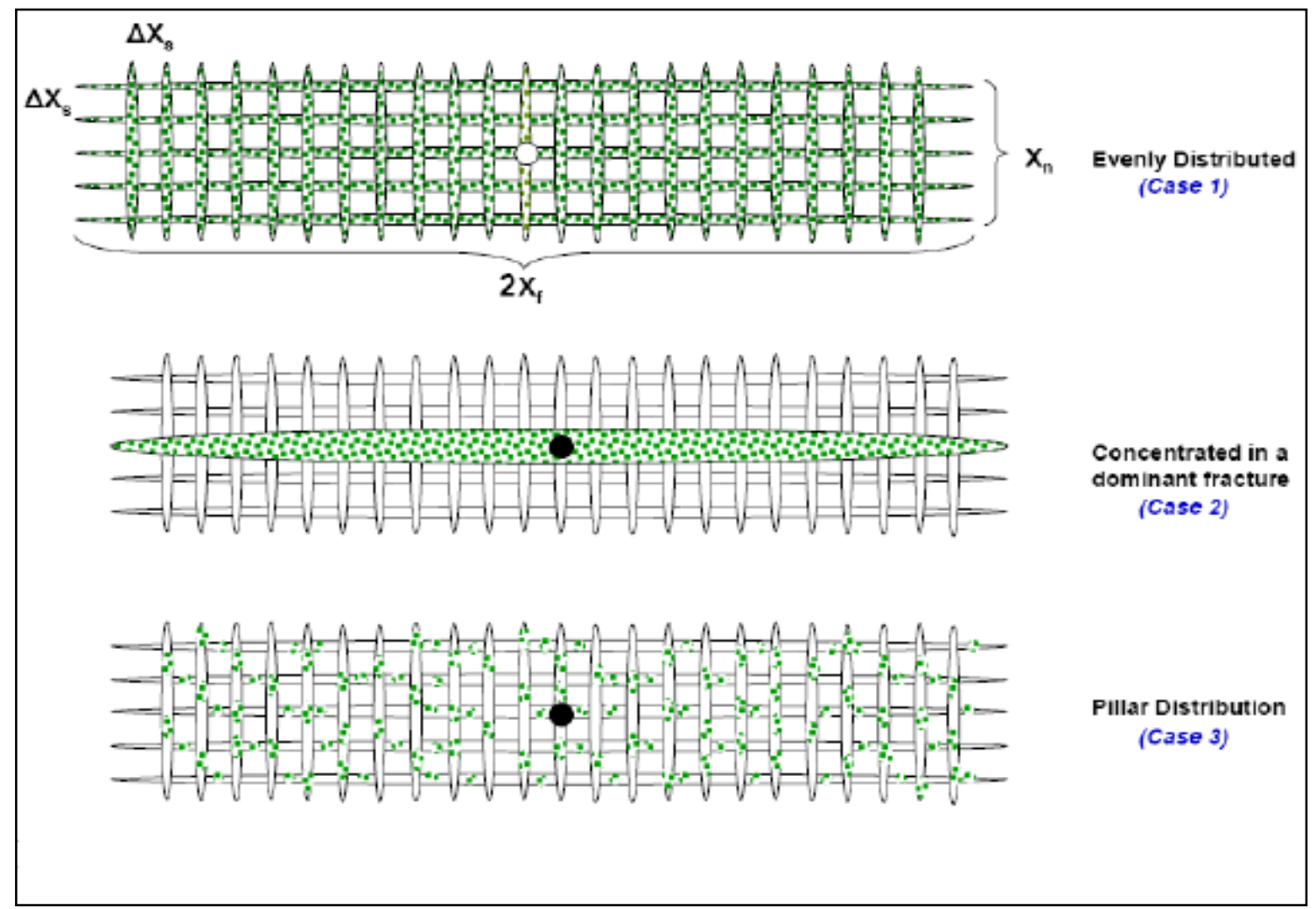

Figure 12: Proppant transport scenarios. ${ }^{(23)}$

The concept of the discrete fracture network (DFN) is based on the interaction between the main fracture and the natural fractures; it may be composed of secondary fractures in the three main axes (X-Y-Z). The primary fracture extends in $\mathrm{X}-\mathrm{Z}$ direction and it is perpendicular to the minimum horizontal stress. The other secondary fractures in $\mathrm{X}-\mathrm{Y}$ and Y-Z directions are perpendicular to $\sigma_{1}$ and $\sigma_{2}$ respectively. The simulation for the discrete fracture network (DFN) growth is based on numerical solution for the equations satisfying continuity, mass conservation, constitutive relationship and momentum equations ${ }^{(24)}$. Appendix A shows the basic equations for the discrete fracture network (DFN) simulation.

\subsection{Formation Stresses}

Hydraulically fractured formations are often at very high depths and overlain by other high thick earth formations. The weight of overburden formations make the targeted 
formation subjected to high stresses. These stresses are highly affected by two main factors, the geological deposition and the historical tectonic movement besides other factors such as lithology, temperature and pore-pressure ${ }^{(25)}$.

The stress can be defined as "the force applied to a body that can result in deformation or strain and usually described in terms of magnitude per unit area or intensity" [Schlumberger] ${ }^{(26)}$. If we consider a random plane of area $\Delta \mathrm{A}$ and also consider a resultant force $\Delta \mathrm{F}$ acts on the selected plane so we can define the stress at any point as:

$$
\sigma=\lim _{\Delta A \rightarrow 0} \frac{\Delta F}{\Delta A}
$$

For a complete description of the state of stress, it is necessary to specify the magnitude of the acting force and also the direction of force.

The state of stress in the earth is very complex and critical geological parameters are required for hydraulic fracturing design as well as the drilling. Generally, we can define the stress in terms of magnitude of maximum and minimum and also define the orientation where the stress acts on using the three principal axes [the vertical axes and two perpendicular horizontal axes], so we have the vertical stress $\sigma_{\text {vertical }}$ and the maximum and minimum horizontal stress $\left(\sigma_{\mathrm{H}, \max }, \sigma_{\mathrm{h}, \min }\right)$. The Figure-14 below shows the three principal stresses acting on a plane ${ }^{(25)}$. 


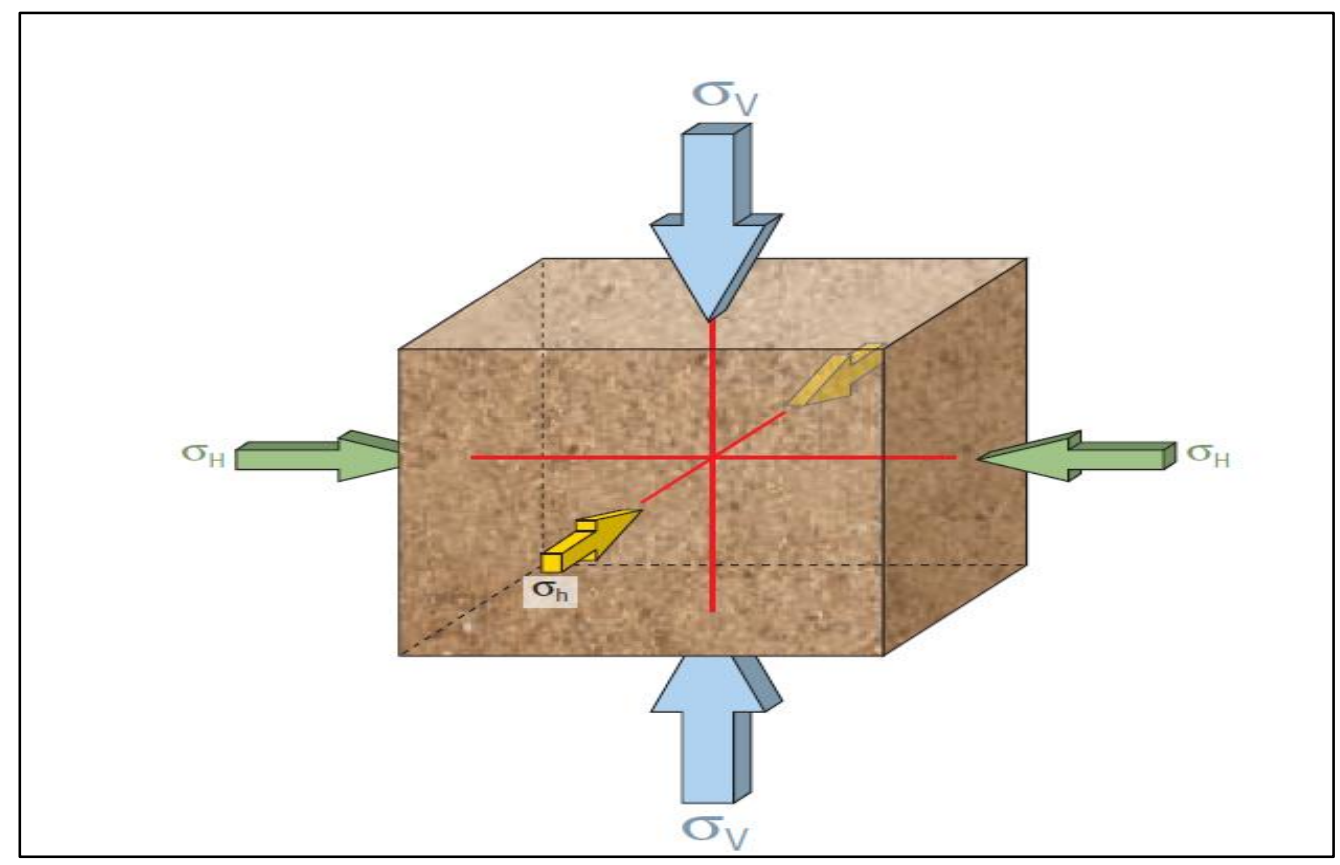

Figure 13-Sub-surface stresses acting on plane (vertical and two horizontal stresses) ${ }^{(27)}$

These three principle stresses also can be defined in order of greatest, intermediate and least principal stress as $\sigma_{1}, \sigma_{2}$ and $\sigma_{3}$ respectively ${ }^{(28)}$. This order is subjected to change with the historical tectonic movement. The changes in these stresses have three regimes associated with the three classical fault regimes (Normal, thrust and strike-slip fault regimes). The Figure-15 below shows the three fault regimes and how the three principal stresses order changes based on the fault regime ${ }^{(29)}$. 


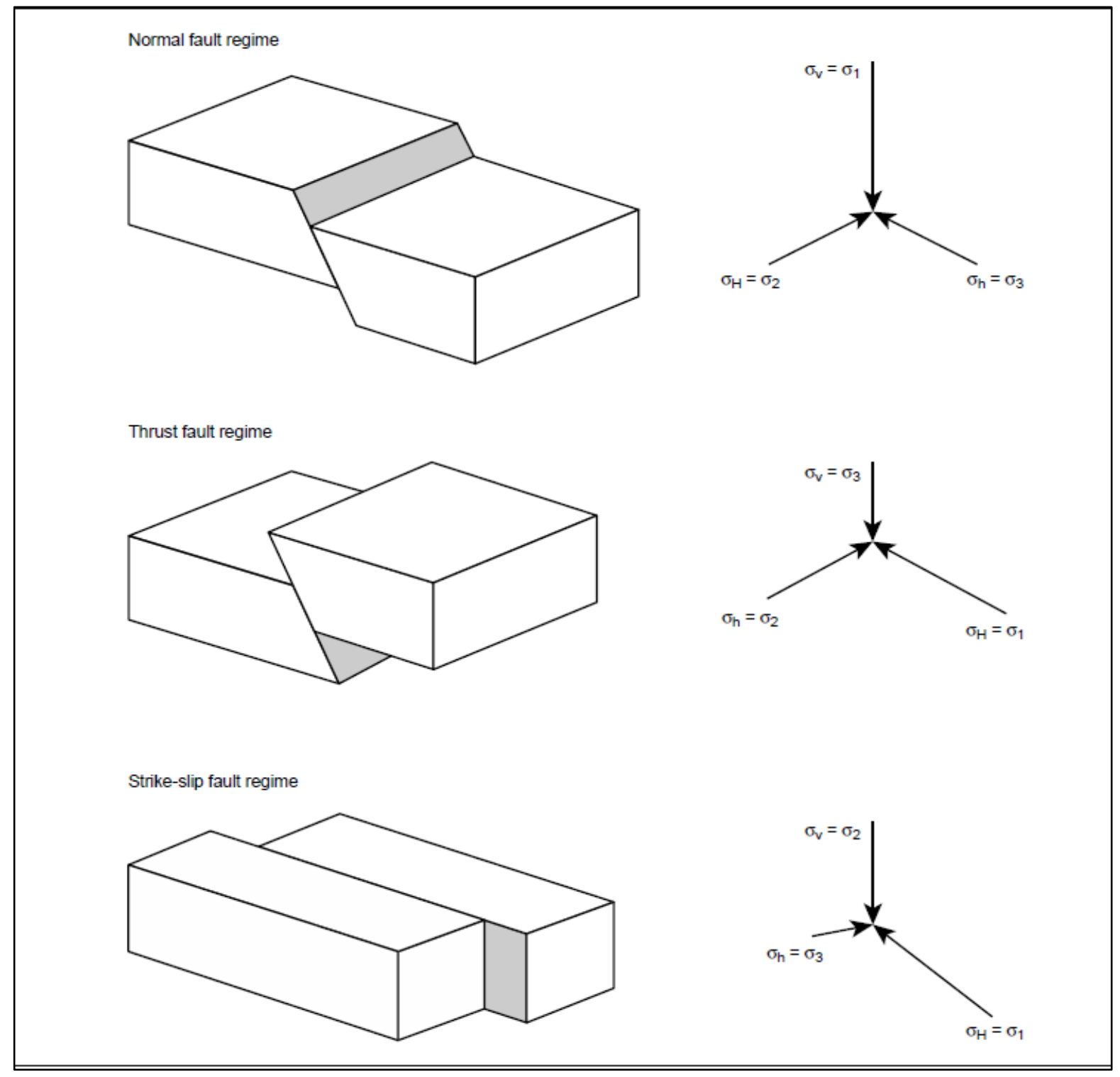

Figure 14-Stress orientation according to the three faults regimes ${ }^{(29)}$ 


\subsubsection{Stresses Calculations}

Stress magnitude and orientation determination is a very complicated process; it requires knowing different geological and geo-mechanical parameters using set of techniques such as well logging, mini-fracture test and core analysis. It also requires understanding the tectonic history of the region and fault regime that occurred as a result.

The absolute vertical stress simply can be considered equal to the weight of the overburden formations and can be calculated using the equation below:

$$
\sigma_{v}=g \int_{0}^{H} \rho \cdot d H
$$

Where $\mathrm{g}$ is gravity force, $\mathrm{H}$ the depth of targeted formations and $\rho$ is the density of targeted formation and can be determined using the density sonic logs. For the sandstone formations, the rock density estimated to be in the range of 2500 to $2700 \mathrm{~kg} / \mathrm{m}^{3}$ and in average of $2650 \mathrm{~kg} / \mathrm{m}^{3}$. Based on this average value the typical value for the sandstone formation overburden stress gradient was estimated to be approximately $1.1 \mathrm{psi} / \mathrm{ft}$., which is a well known constant in oil and gas industry for estimating the formation stress.

This calculated stress gradient represents the absolute vertical stress without considering the effect of the porous medium and pore-inhibiting fluid, so the effective vertical stress can be calculated based on the estimation of the pore pressure using the following equation:

$$
\sigma_{v}^{\prime}=\sigma_{v}-\alpha P_{p}
$$


Where Pp is the pore pressure and $\alpha$ is the Biot poro-elastic constant. This effective stress is subjected to change, as the reservoir pressure change is a result of production and injection. Normally the under pressured formations have greater effective stresses than the over pressured zones.

The horizontal stress is a more complicated parameter than the vertical stress; it requires knowing the formation geo-mechanical parameters such as the Poison's ratio and Young's modulus, $(\gamma)$ and $(E)$, respectively. The Poison's ratio represents the ratio between the lateral strains to the longitudinal strain and the Young's modulus represents the stress/strain relationship.

Based on these two relations, the minimum horizontal stress can be estimated using the absolute vertical stress by the following relationship.

$$
\left.\sigma_{h, \min }=\frac{v}{1-v} \sigma_{v}-\alpha P_{p}\right\rfloor \alpha P_{p}
$$

The tectonic phenomena also results in an additional horizontal stress component, thus the maximum horizontal stress can be defined as:

$$
\sigma_{H, \max }=\sigma_{h, \min }+\sigma_{t e c t}
$$

Where $\sigma_{\text {tect }}$ is the net tectonic stress component, ${ }^{(25)}$. 


\subsubsection{Young's Modulus}

The Young's modulus represents the longitudinal stress to strain longitudinal ratio and can be defined with the equation below.

$$
E=\frac{\sigma}{\varepsilon}=\frac{F / A}{\Delta L / L}
$$

Young's modulus presents in stress units (psi). And for shale formations it varies from 3Mpsi to $6 \mathrm{Mpsi}$. (Schlumberger) ${ }^{(30)}$.

\subsubsection{Poison's ratio}

Poison's ratio can be defined as "An elastic constant that is a measure of the compressibility of material perpendicular to applied stress". Also, it can be defined as the ratio of lateral to longitudinal strain and it can be described using the equation below.

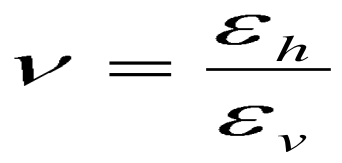

The Poison's ratio is related to modulus such as bulk modulus, elastic modulus and shear modulus and can be determined using the geo-mechanical logs. Poison's ratio for shale formations varies from 0.15 to 0.3 (Schlumberger) ${ }^{(31)}$.

\subsubsection{Stresses Measurement}

Oil and gas industry introduced different techniques to estimate the vertical and horizontal stresses. Stresses are very critical in hydraulic fracturing operation in order to identify the horizontal well direction and the fracture initiation orientation. Moreover, the difference in stress between the targeted layer and adjacent layers can also be a good 
indication for the fracture height growth and determination of the barrier formations. Also, we can estimate the fracture net pressure based on the minimum horizontal stress information. Many methods have been used within the industry to estimate the state of stress such as core sample analysis, well logging and the mini-fracturing test.

\subsubsection{Well logging Stress measurement}

Well logging is one of the key technologies used for formations property evaluation and identifies the producing zones. Also, well logging is used to estimate rocks' geo-mechanical properties. Formation bulk density is one of these properties and it can be determined using the radioactive logging tool (Gamma-ray) and the bulk density can be used to estimate the overburden stress (vertical stress). Moreover, sonic logs are used to estimate other geo-mechanical properties such as Poison's ratio and Young's modulus. The sonic waves propagate through the rocks and that causes rocks deformation, this deformation affects both compression and shear waves. The modern sonic logging tools have sufficient spacing between wave transmitting and receiving points for better determination for the velocities slowness. Poison's ratio and Young's modulus can be calculated from sonic logs using the following formulas ${ }^{(25)}$ :

$$
\begin{gathered}
\nu=\frac{0.5 q_{c} / u_{s}^{2}-1}{\alpha_{c} / u_{s}^{2}-1} \\
E=\rho u_{s}^{2}\left[\frac{3 u_{c}^{2}-4 u_{s}^{2}}{u_{c}^{2}-u_{s}^{2}}\right] \ldots
\end{gathered}
$$




\subsubsection{Micro-hydraulic fracturing technique}

For more accuracy in determination of the stresses, the micro-hydraulic fracturing testing is used to estimate the minimum horizontal stress. This test is usually conducted with small treatment volume and low flow rate after pumping for certain time the pumps are suddenly stopped and the pressure observed. The pressure drops abruptly to a stabilized pressure, this stabilized pressure is the instantaneous shut-in pressure (ISIP) and it can be defined as "the static pressure required holding the fracture open". ${ }^{(33)}$. The ISIP is considered to be equal to the minimum horizontal stress.

$$
P_{I S I P} \cong \sigma_{h, \min }
$$

The Figure-16 below shows the pressure change with time during the typical micro-hydraulic fracturing test and also shows the ISIP after pumps shut-in.

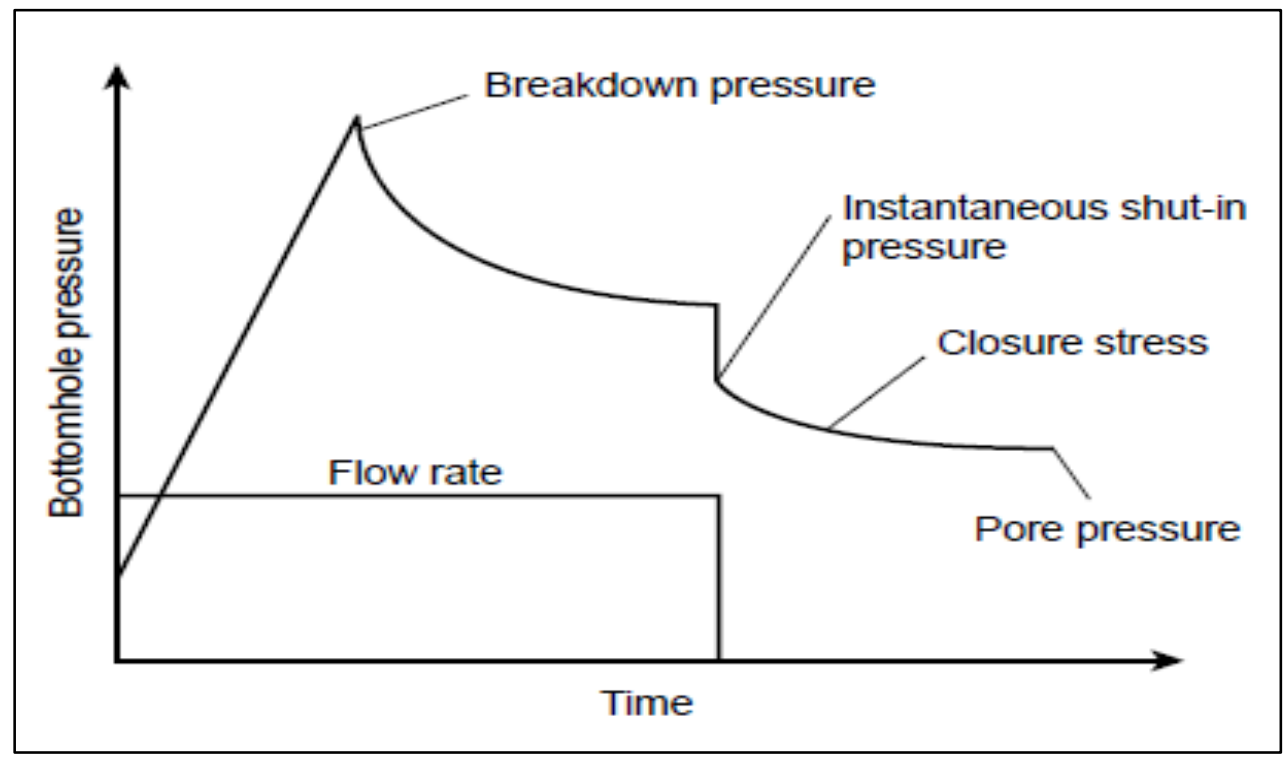

Figure 15: Down-hole pressure profile during micro-fracturing test ${ }^{(29)}$ 


\subsubsection{Stress and Hydraulic fracturing}

The rocks normally respond to changes in stress in different stages of deformation. This deformation can be elastic or permanent plastic deformation and then end with the rock failure. This failure in brittle rocks occurs catastrophically, and in more ductile materials the failure occurs gradually. The state of horizontal stresses is very important for the determination the failure mechanism ${ }^{(27)}$. To determine the relation between horizontal stresses and failure, first one needs to identify the relation between these stresses $\left(\sigma_{1}, \sigma_{3}\right)$ and normal stress $\left(\sigma_{\mathrm{n}}\right)$ and shear stress $\left(\zeta_{\mathrm{n}}\right)$ with arbitrary angle $\alpha$ in direction of least principle stress $\sigma 3$. The equations below show this relation ${ }^{(28)}$ :

$$
\begin{gathered}
\sigma_{n}=\frac{\sigma_{1}+\sigma_{3}}{2}+\frac{\sigma_{1}-\sigma_{3}}{2} \cos 2 \alpha \\
\tau=\frac{\sigma_{1}-\sigma_{3}}{2} \sin 2 \alpha \ldots \ldots \ldots
\end{gathered}
$$

This can be described by Mohr's circle of failure concept. According to Mohr's, the rock's failure occurs when the circle touches Mohr's envelope which depends on other geomechanical parameters such as cohesion and friction angle ${ }^{(27)}$. The Figure-17 below shows the Mohr's circle with failure envelope. 


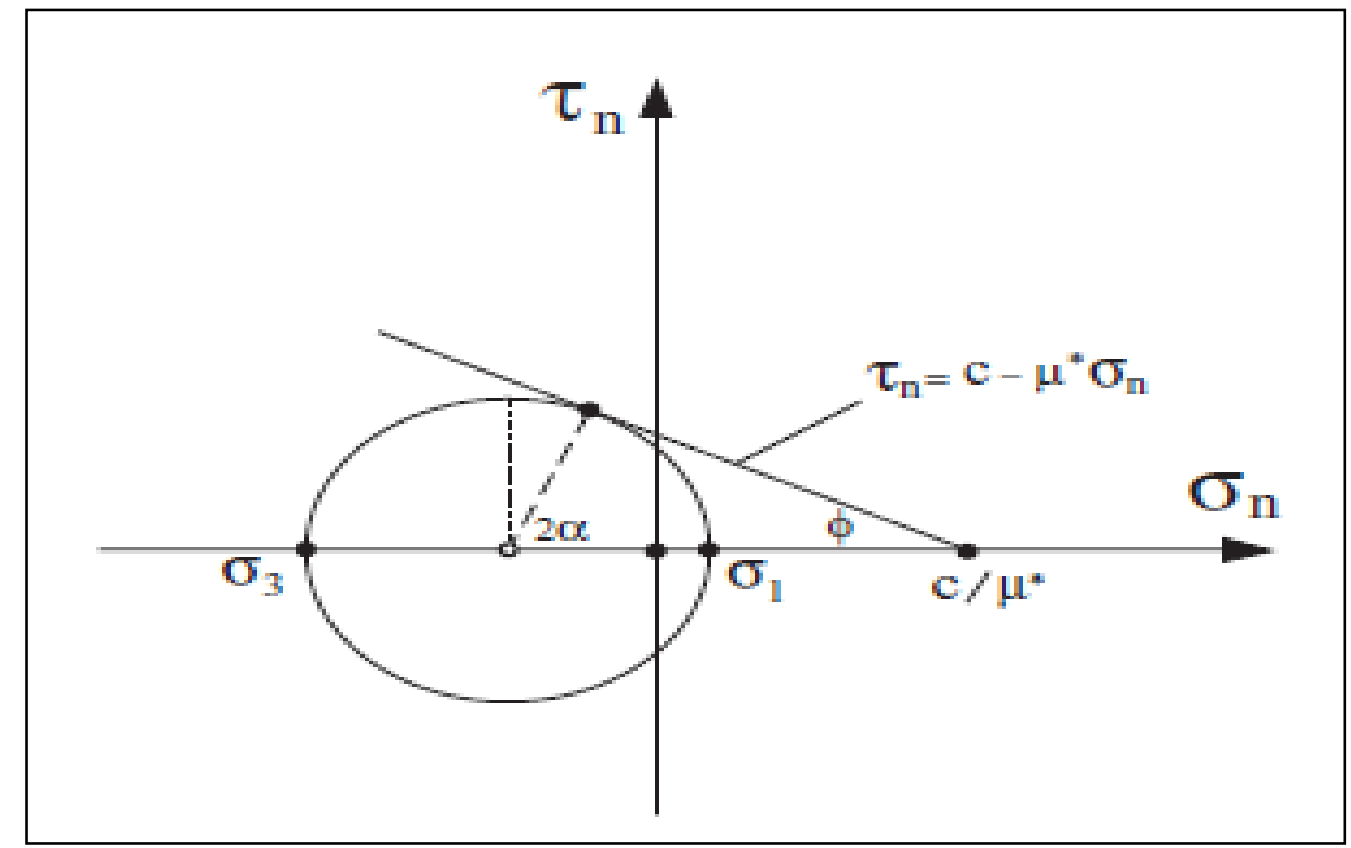

Figure 16: Mohr Circle with Failure envelope ${ }^{(32)}$

Also the value for horizontal stresses is critical in order to calculate the fracture break-down pressure using the following equation:

$$
P_{p d}=3 \sigma_{3}-\sigma_{1}+T-P_{p}
$$




\subsection{Leak-off coefficient}

The leak-off coefficient can be defined as the rate of fluid loss into the formations during drilling and hydraulic fracturing operations. The leak-off coefficient is a critical parameter in hydraulic fracturing design optimization in shale gas reservoirs, and change in the leak-off coefficient can lead to great differences in fracture geometry and proppant displacement. It is very difficult to determine an accurate value for the leak-off coefficient in shale gas formations ${ }^{(34)}$.

In hydraulic fracturing design, the total leak-off coefficient can be estimated by considering constant or harmonic and dynamic models. The harmonic and dynamic models assume that the total leak-off coefficient is affected by the fracture fluid pressure reduction based on three different phenomena. These include the effect of the fracturing fluid filtrate viscosity and relative permeability $(\mathrm{C} 1)$, the reservoir fluid viscosity and rock's compressibility effect (C11) and the effect of wall building or filter cake (C111) ${ }^{(34)}$.

The equations below show the harmonic and dynamic total leak-off coefficient model calculations and the three total leak-off coefficient components calculations ${ }^{(35)}$.

For harmonic model

$$
C=\frac{\boldsymbol{C}_{1} C_{11} C_{111}-}{\boldsymbol{C}_{1} C_{11}+C_{11} C_{111}+C_{1} C_{111}}
$$

For dynamic model

$$
C=\frac{2 C_{1} C_{11} C_{111}}{C_{1} C_{111}+\sqrt{C_{1} C_{11}{ }^{2}+C_{11}{ }^{2} C_{1}{ }^{2} C_{11}{ }^{2}}}
$$


For the fracturing fluid filtrate affect $\mathrm{C}_{1}$

$$
C_{1}=0.0469 \sqrt{\frac{k_{f} \Delta P \phi}{\mu_{f}}}
$$

For the reservoir fluid viscosity and rock's compressibility affect $\mathrm{C}_{11}$

$$
C_{11}=0.0347 \Delta P \sqrt{\frac{k_{r} C_{t} \phi}{\mu_{r}}}
$$

The wall building or filter cake affect can be calculated from laboratory using the following equation.

$$
C_{111}=\frac{0.0164 m}{A}
$$




\section{Previous Work}

Formation Stress is a critical geo-mechanical criterion in producing gas from shale formation. Much research has been conducted on the effect of stress in the fracturing treatment and fracture properties such as length, width and conductivity, and the fracture network distribution. Although the shale gas is becoming one of the key sources of energy, not much research have been done on that area. Utica shale is a new promising formation with liquid rich content, and until now it's not a well-known formation in terms of geomechanical properties and its effect on the hydraulic fracturing treatment and fracture properties.

Paktinat et.al ${ }^{(7)}$ conducted research in Utica shale formation. Their study gives a general survey about geology of Utica shale formation and reservoir properties such as thickness, porosity and permeability and also compares Utica shale with other Appalachian basin shale formations like Marcellus and Lewis. In addition, it provides more information about Utica mineralogy. This study discussed how the fracturing treatment and production can be improved. They suggested to optimize the fracturing fluid by studying the impact of clay's content on the formation stability and proved that using KCL is helpful to stabilize high clay content formations. Also the study gives general overview about the geomechanical properties such as Young's Modulus and poison's ratio ${ }^{(7)}$.

Research done by Schepers et.al ${ }^{(4)}$ focused on the reservoir modeling in shale gas formations by taking Utica shale as an example. This research describes a systematic process used in the evaluation of a new prospect area with limited data available. The research depends on reservoir simulation using a triple porosity and dual permeability system. A reservoir model was built based on average Utica shale properties to run the history matching 
and prediction for the development strategy. In the first stage, they history matched one vertical well located in the state of New York and then predicted the cumulative gas production and gas recovery for 30 years. Their study uses Monte Carlo based simulation with two assumptions, one is the homogenous reservoir with uniform properties distribution, and the other assumption is the geo-statistical reservoir characterization to get spatial distribution for some of the reservoir parameters such as matrix permeability and matrix porosity $^{(4)}$.

Lavoie et.al ${ }^{(36)}$ conducted research about the estimation of the gas potential in Utica shale; it focuses on the formation extension in Quebec, Canada. It gives general survey about the formation properties for Utica such as depth, pressure and geological background.

The State of Ohio Department of Natural Resources, Division of Geological Survey published an article about Utica shale in 2012. This article contains the key information about Utica shale and also provides maps, properties distribution, faults locations, level of maturation and wells with locations. Also this article shows the major investors in Utica shale and the number of acres they used. This study provides some estimation for Utica shale properties. It estimates the total organic content in Utica shale as $1.34 \%$ and the reserves in Utica shale as 15.7 TCF of gas and 5.5 billion barrels of oil which makes Utica shale as one of the rich shale formations in US. The reserves of oil can encourage the companies to invest in Utica shale ${ }^{(8)}$.

Since the hydraulic fracturing technology is required for gas production from low permeability formations, the researchers and engineers to started to study the relation between formation stresses and fracturing propagation and growth. Hubbert and Willis (28) conducted a study about the effect of formation stress on the fracturing propagation and the 
generated stresses around well-bore. The study was basically experimental study. This study was an analysis of the effect of the three principal stress on the fracture induced.

This study concludes that the state of stresses underground is not, in general, hydrostatic but it depends on the tectonic condition. And the least stress in the tectonically relaxed areas is normally will be horizontal. However, in the area of tectonic compression, the least stress will be vertical and considered equal to approximately the overburden pressure. Also, the study established that the fracture breakdown pressure is different from area to area depending on the pre-existing regional stresses and the borehole geometry including any pre-existing fissures and also affected by the quality of penetration fluid ${ }^{(28)}$.

Achourov et.al ${ }^{(37)}$ conducted research about the direct measurement of the minimum horizontal stress and its importance in optimization of hydraulic fracture placement for best management of the water flooding process to maximize the recovery. The source for this study was based on the data from Priobskoe field in western Siberia. In this study, a set of wire line formation evaluation tools were used such as WFT (Wire line Formation Tester) to perform micro-fracture tests to estimate the stress magnitude and orientation, also sonic and image logging were used to acquire the data needed to achieve the optimal well and fracture placement and best recovery and reservoir management ${ }^{(37)}$.

Mayerhofer et.al ${ }^{(38)}$ published a paper about integration of micro-seismic fracture mapping results with numerical fracture network production modeling in Barnett shale. In this research an approach presented to approximate the fracture network measured using the micro-seismic mapping technique with a numerical production simulator to model the fracture network in both vertical and horizontal wells. The study started with production history matching for a vertical well in Barnett shale and the micro-seismic mapping results were used to estimate the fracture network properties, and then they conducted a parametric 
study on a horizontal well to investigate the impact of the fracture network characteristic on gas production.

Many fracture network parameters were tested such as network size, network density (fracture spacing), network conductivity and the effect of high near well fracture conductivity, the research showed that large fracture network with higher SRV (stimulated reservoir volume) resulted in better well performance. Also the fracture spacing had a great impact on gas production. Furthermore, increasing of the near-well fracture conductivity also provide enhancement for production ${ }^{(38)}$.

Bazan and Meyer ${ }^{(24)}$ published a paper about the Discrete Fracture Network (DFN) modeling in the Marcellus and other shale formations. Based on this study, many scenarios for the fracture growth may occur, the fracture might grow as a single simple fracture or complex fracture with/without fissure opening and also can grow as a fracture network. According to these different fracture growth scenarios, many proppant distribution scenarios also can be expected, the proppant may be evenly distributed in the fracture network or concentrated in the dominant fracture. Also it can be distributed only in pillars.

This study gives the DFN governing and initiation equations and also the numerical method to simulate the fracturing propagation and growth process. A micro-seismic data from Marcellus shale well was used to compare the numerical simulation results and the real fracture network distribution and the results found to be very close to each other. Also, a comparison between the DFN and the bi-wing fracture had been performed and it showed that the DFN fracture length is shorter than the bi-wing fracture length but the stimulated reservoir area in DFN fracture model was greater ${ }^{(24)}$.

Bilgesu and Yusuf ${ }^{(39)}$ conducted research to study the impact of stress and formation properties on the outcome of fracture in horizontal shale well. This study performed with 
Marcellus shale data to basically study the effects of variations in horizontal stress levels on the fracture geometry and properties and also understand their impact on the production from horizontal shale wells. The geo-mechanical properties used in this study such as vertical stress, young's modulus and poison's ratio was based on the average geo-mechanical properties in Marcellus shale and other Appalachian basin shale formations.

In their research, fracturing and reservoir simulation software were used and different horizontal stress levels were examined with different pumping scenarios to get the generated fracture properties and compare the results to the effect of the horizontal stress variation on the generated fracture geometry and properties. Then, reservoir simulation software was used to obtain the production from horizontal wells in Marcellus shale with the generated fracture geometry and properties from the previous step and the production output was compared for different horizontal stress cases.

The fracture volume, length and average fracture height were compared for different stress level values and treatment volume. Also, secondary fracture volume and length were compared to study the effect on the Discrete Fracture Network (DFN) and they noticed that there is an increase in the fracture half-length and fracture volume with the increase of the horizontal stress level; however, there is a decrease in the secondary fracture half-length but there is an increase in stimulated reservoir area. This was clearly indicated on the production output because the production increased with the increase in the horizontal stress level ${ }^{(39)}$. 


\section{Objective and Methodology}

The main goal of this research is to understand the impact of variations in geomechanical formation properties on the fracturing outcome in horizontal wells in Utica shale. Specifically, to study the impact of the variations in Young's modulus, Poison's ratio, and Horizontal stress level on the fracture geometry in terms of length, width, and height and also the impact on the discrete fracture network (DFN). Moreover, the impact of leak-off coefficient on the fracturing treatment outcome and the discrete fracture network (DFN) will be examined using different values of the properties based on available data from Utica shale.

The first step is to gather data about Utica shale properties and the fracturing treatment parameters for this formation, then to build a base fracturing model. The next step is to select different treatment parameters and geo-mechanical properties to understand their impact on the fracture and fracture network.

\subsection{Data Gathering}

The data gathering is a very important step for building hydraulic fracturing and reservoir models in order to present a realistic model for the formation under investigation. Therefore, it is necessary to do extensive research to obtain the most accurate data for better modeling. Utica shale formation is a new area under development, so it is very difficult to find accurate information and not many data sources are available.

Different data sources were used in this study, such as papers published by Society of Petroleum Engineers (SPE), American Association of Petroleum Geologist (AAPG), major books in hydraulic fracturing technology, documents from State of West Virginia and the State of Ohio Geological services' and talking to industry experts.

Because of the lack of data in Utica shale formation, it is very difficult to obtain accurate data for rock and reservoir properties. The rocks' geo-mechanical properties can be 
estimated based on previous research conducted in Utica shale and the treatment parameters can also be estimated based on the related developed formations in Appalachian basin such as Marcellus shale. Since the main goal of this study was to investigate the fracture treatment and its relationship with geo-mechanical properties, it was not necessary to build a model to predict production data or to history match any production data.

\subsection{Building the Base Model}

After the data was gathered, the information was used to build the formation model for simulating the fracturing treatment. The model was built based on design mode option and linear conventional reservoir coupling of MShale software and designed for proppant treatment without acid. The constant fluid loss model was used without taking the effect of heat transfer into consideration.

\subsection{Horizontal well model}

Based on data collected about Utica shale's depth and thickness, a horizontal well configuration had been built to reach the horizontal lateral length of $2000 \mathrm{ft}$ at a depth of $7125 \mathrm{ft}$. and $90^{\circ}$ as the final horizontal angle. The pay zone thickness was around $110 \mathrm{ft}$. Figure-18 below shows the horizontal well configuration used in this study. 


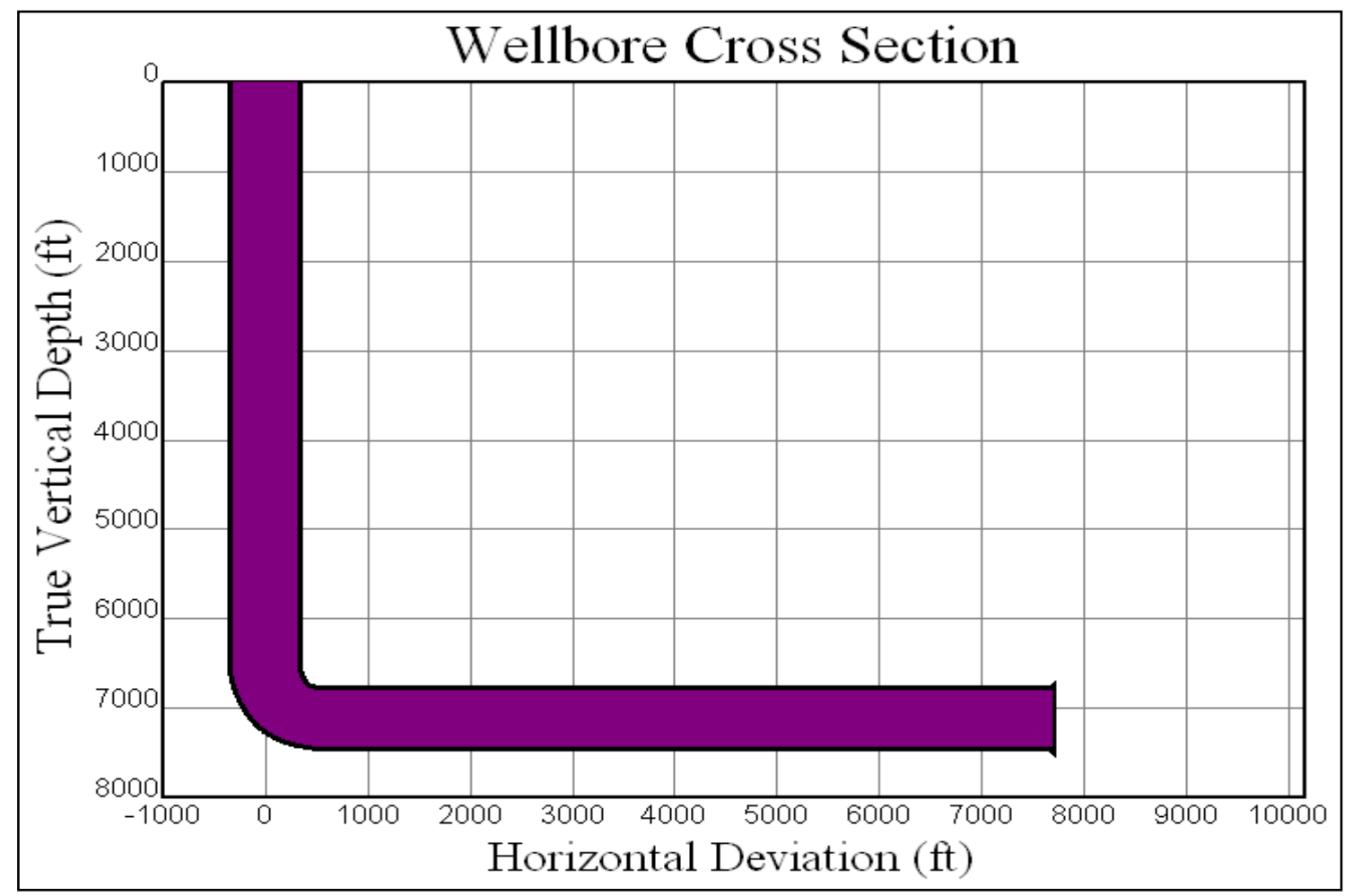

Figure 17: Horizontal wellbore cross section

\subsection{Model parameters}

The fracturing model was built based on three dimensional design concept to estimate the fracture geometry because the $3 \mathrm{D}$ design concept is the most close to reality than PKN and GDK design mode. The model did not take the flow back into consideration and also the wall roughness. The proppant design mode for this model was selected based on conventional transport methodology and empirical setting option.

For the treatment design, the fluid injection selected to be through the casing and used the perforated interval as the injection target points. The targeted zone permeability was around 1E-6 md. The differences between the vertical and minimum horizontal stress was fixed to be around 2000 psi and the difference between minimum and maximum horizontal stresses was subjected to change as a parameter studied in this research. We used a range of 100 to 400 psi for horizontal stress difference. 
The treatment fluid was slick water with a specific gravity of 1.01 and fluid temperature of about $80^{\circ} \mathrm{F}$. The proppant size was selected based on treatments conducted in Utica shale formation by the industry. The normal size used for Utica treatment is $30 / 50$ mesh. The injection volume for the treatment was varied to study its impact on the output for single and multi-cluster fracturing. The injection rate for the treatment was one of the parameters examined in this study. Different injection rates were used to study the impact on the stimulated reservoir volume.

\subsection{Geo-Mechanical Properties}

The geo-mechanical properties for the model were selected based on parameters published in different sources. The information about Utica shale properties are not available, most of the parameters estimated were based on other shale formations in the Appalachian region such as Marcellus shale. The Young's modulus for shale formations was varied between $2 \mathrm{MPa}$ and $6 \mathrm{MPa}$, and in this study we examined different values for Young's modulus. Poison's ratio values of $0.15,0.2$ and 0.25 were used to investigate their impact on treatment outcome.

The most important parameter in this study was the horizontal stress level. As discussed earlier, the horizontal stress level is the critical parameters to be determined, so three levels of horizontal stress level were tested (100, 200 and 400 psi). Also, the leak-off coefficient is very important for treatment. The data about Utica shale leak-off coefficient value was not available, so we used the default value available for shale formation in the simulation software (0.00056) and we examined other values to determine the impact on the outcome of discrete fracture network (DFN). 


\subsection{Sensitivity Analysis}

Once the fracturing base model has been created, a sensitivity analysis was performed to understand the impact of different operational parameters and formation properties on the outcome of fracturing treatment and the distribution of the discrete fracture network (DFN). The treatment schedule has great impact on the fracture design. Normally in shale gas formations, multistage fracturing is used to increase the stimulated area, so a single fracture treatment model and multistage fracture model were used to investigate their impact.

Different treatment volumes and pumping rates were used to study their impact on the outcome. The proppant size has impact on the properties of the designed fracture such as fracture conductivity, dimensionless fracture conductivity and the propped length and width. Increase in treatment volume normally increases the length of the generated fracture, and we used different volumes and rates to understand their contribution to the fracture design for Utica shale.

Formation properties have a great impact on the fracturing results. The leak-off coefficient affects the amount of fluids escaping into formations without contributing to the treatment. The variations in geo-mechanical properties also have a great impact on the generated fracture. Young's modulus normally varies between different formations and also within specific formation. The Poison's ratio has a narrow range, and the study was limited within this narrow range. Horizontal stress level also examined for different values to understand the impact on the fracture network properties and growth.

The Table-2 below shows all the parameter used to build the model and the values of parameters studied. 
Table 2: Reservoir Model parameters

\begin{tabular}{|c|c|}
\hline \multicolumn{2}{|l|}{ Model Parameters } \\
\hline Depth, ft & 7000 \\
\hline Permeability, md & 0.000001 \\
\hline Porosity, fraction & 0.1 \\
\hline Thickness, ft & 110 \\
\hline Casing outer diameter, in & 5 \\
\hline Casing inner diameter, in & 4.276 \\
\hline Injection through & casing \\
\hline Fluid loss model & constant \\
\hline Fracture geometry design mode & 3-Dimensional \\
\hline \multicolumn{2}{|l|}{ Treatment parameters } \\
\hline Injection fluid & Slick water \\
\hline Proppant size & $30 / 50$ mesh \\
\hline Injected volume, bbl & $1000,2000,4000$ \\
\hline Injection rate, bpm & $40,60,80$ \\
\hline \multicolumn{2}{|l|}{ Formation properties } \\
\hline Vertical stress gradient, psi/ft & 0.9 \\
\hline Young's modulus, psi & $2 \mathrm{e}+6,3 \mathrm{E}+6,4 \mathrm{E}+6$ \\
\hline Poison's ratio & $0.15,0.2,0.25$ \\
\hline Leak-off coif, ft/min $\wedge^{\wedge / 2}$ & $0.00056,0.00084,0.00112$ \\
\hline Horizontal stress level, psi & $100,200,400$ \\
\hline
\end{tabular}




\subsection{Flow Chart for Procedure}

The Figure-19 below briefly shows the procedure used in this study.

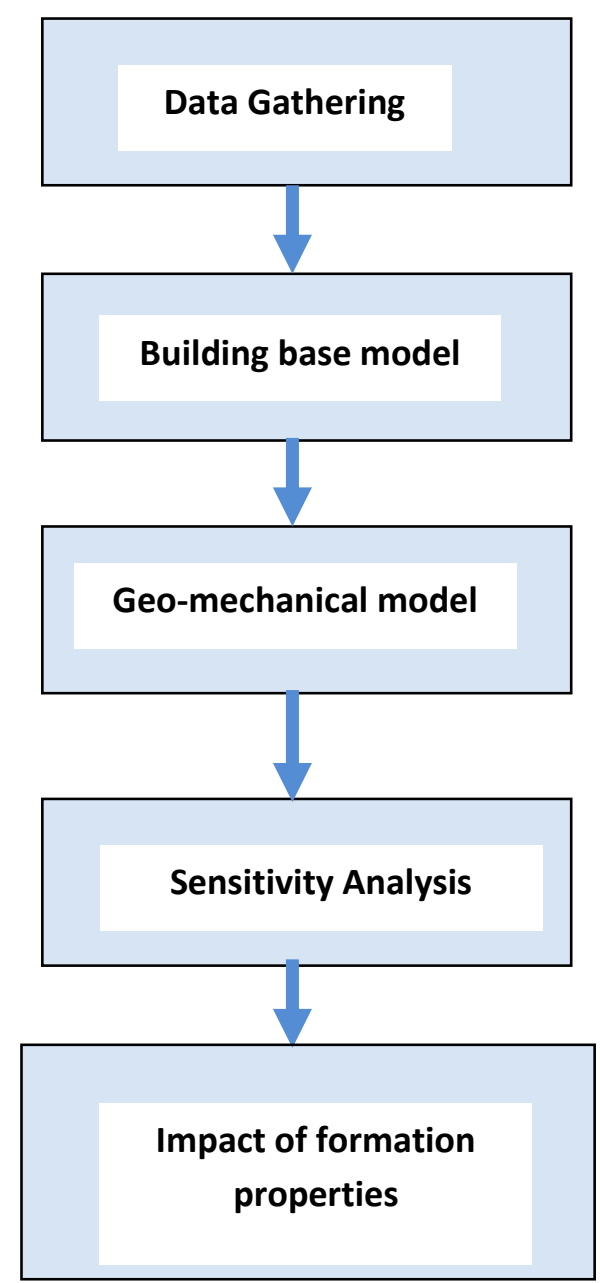

Figure 18: Flow chart for procedure 


\section{Results and Discussion}

The objective of this study was to investigate the impact of variation in the geomechanical properties of Utica shale on the outcome of fracturing treatment such as bi-wing fracture half length, width and height, and also the impact on the distribution of discrete fracture network (DFN). Several runs were conducted using Mshale software and the results were compared for different geo-mechanical properties values. The horizontal stress level, Young's Modulus, Poison's ratio and leak-off coefficient were subjected to change to study their impact for a single cluster and 3 clusters fracturing treatments.

\subsection{Impact of horizontal stress variation level}

\subsubsection{Single Fracture Treatment}

Runs were conducted for a single fracture treatment with three horizontal stress levels of 100, 200, 400 psi with $1000 \mathrm{bbl}$ of fluid pumped at rate of $60 \mathrm{bpm}$. The Table-3 below summarizes the main fracture and discrete fracture network (DFN) properties from three runs.

Table 3:Single fracture treatment for different horizontal stress levels

\begin{tabular}{|l|c|c|c|}
\hline \multirow{2}{*}{\multicolumn{1}{|c|}{ Parameter, Unit }} & \multicolumn{3}{c|}{ Horizontal stress Level, Psi (1000 bbl) } \\
\cline { 2 - 4 } & $\mathbf{1 0 0}$ & $\mathbf{2 0 0}$ & $\mathbf{4 0 0}$ \\
\hline Fracture half length, ft & 218 & 378 & 784 \\
\hline Fracture Avg. width, in & 0.069 & 0.076 & 0.092 \\
\hline Fracture height, ft & 96.05 & 96.63 & 97.38 \\
\hline Fracture volume, gal & 1801.6 & 3468 & 8748 \\
\hline DFN length, ft & 3606.7 & 3465 & 2727.2 \\
\hline DFN width, in & 0.15772 & 0.15892 & 0.1968 \\
\hline DFN height, ft & 84.74 & 87.05 & 92.67 \\
\hline Stimulated reservoir volume (SRV), gal & $3.55 \mathrm{E}+07$ & $2.92 \mathrm{E}+07$ & $2.54 \mathrm{E}+7$ \\
\hline
\end{tabular}


The Figures 20 and 21 below compare the average fracture width and average height for bi-wing fracture and the discrete fracture network (DFN) for the different horizontal stress levels. The average fracture height increased as the horizontal stress level increased. But this increase wasn't significant because the fracture height is mainly controlled by the stress contrast above and below the targeted zone. The fracture width also increased for the primary fracture and the discrete fracture network (DFN) as the horizontal stress level increased. This increase was in the range of 10 to $20 \%$ as the horizontal stress level increased by $100 \%$.

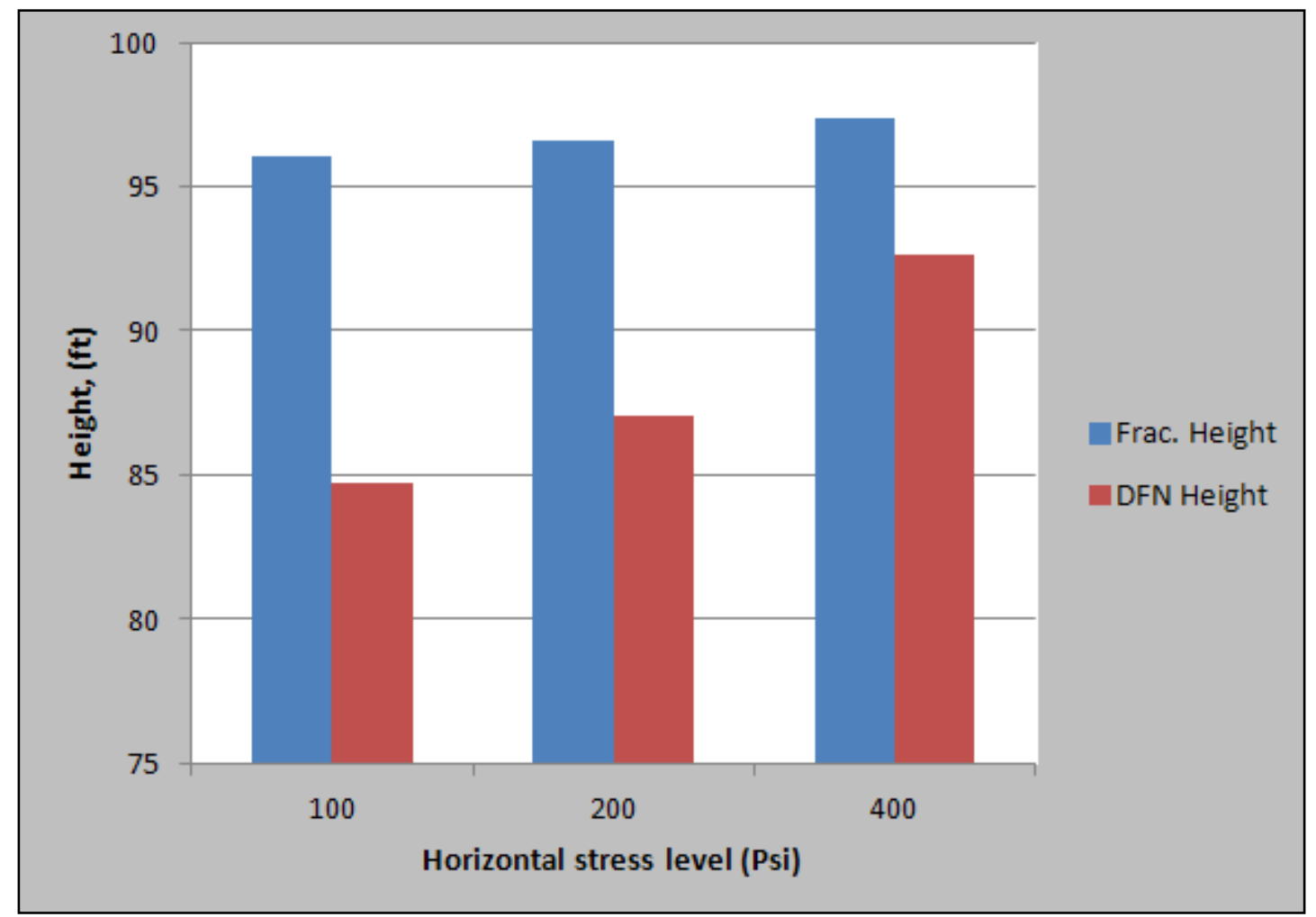

Figure 19: Fracture height and DFN height for horizontal stress levels 


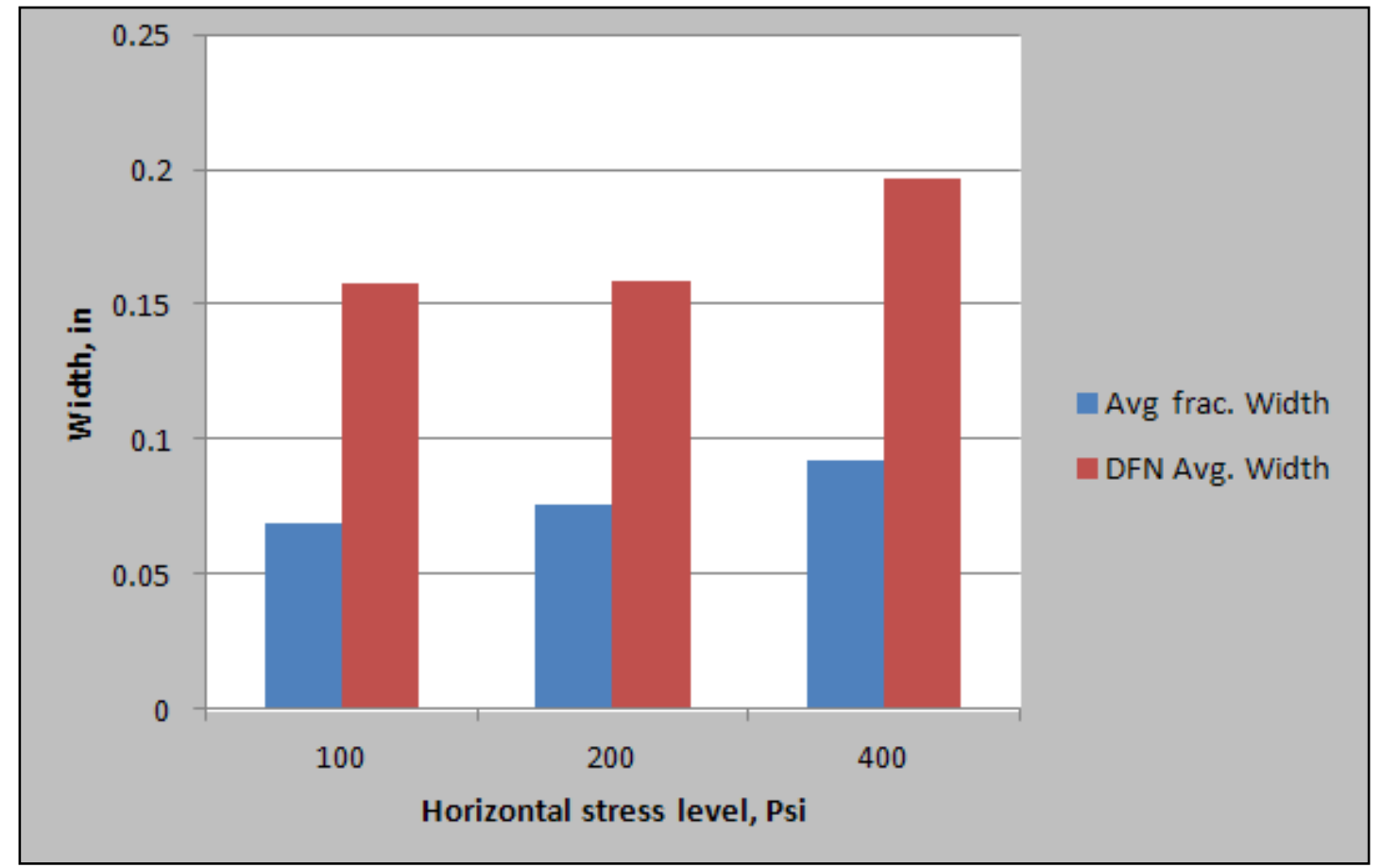

Figure 20: Fracture and DFN width for horizontal stress levels

Figure-22 below shows the primary fracture length for different horizontal stress levels. The primary fracture length increased with the increase of the horizontal stress difference. The primary fracture half-length was $218 \mathrm{ft}$. for stress difference of 100 Psi and it increased to $378 \mathrm{ft}$. for stress difference of $200 \mathrm{Psi}$, and then increased to $784 \mathrm{ft}$. for stress difference of 400 Psi. The primary fracture length followed this trend because the fracture normally initiated perpendicular to the least horizontal stress, and the increase in the horizontal stress difference either means increase of maximum horizontal stress or decrease in the minimum horizontal stress. This difference increases the ability to create extended fractures perpendicular to the least stress and the fracture length increases while the secondary fractures in the other directions becoming shorter. 


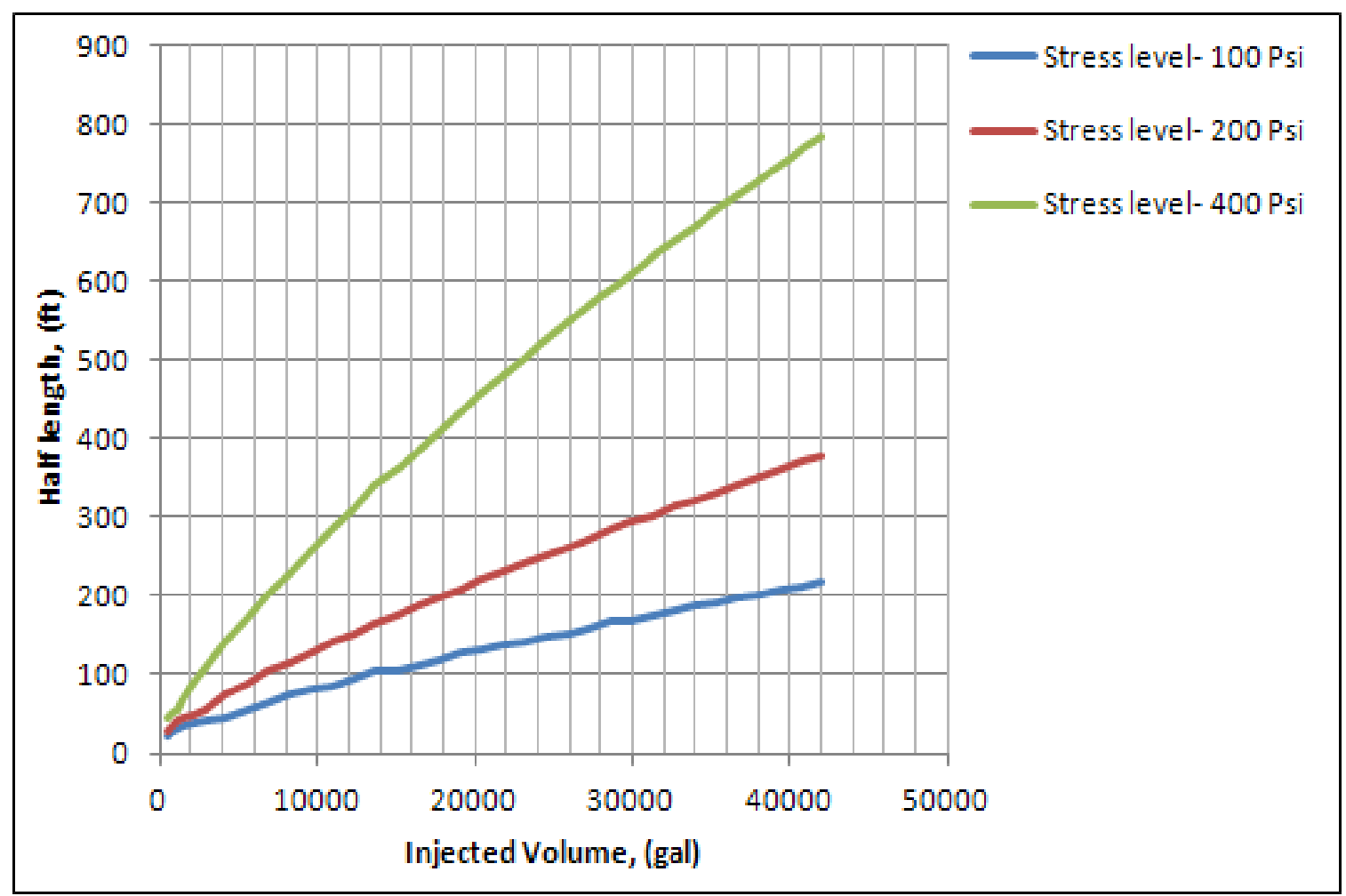

Figure 21: Single fracture half-length growth for horizontal stress levels

The Figure-23 below shows the stimulated reservoir volume (SRV) for different horizontal stress levels. The stimulated reservoir volume (SRV) decreased as the horizontal stress level increased. The stimulated reservoir volume (SRV) was $3.55 \mathrm{E}+7$ (gal) for horizontal stress level of 100 Psi and it decreased by $17 \%$ with the increase of the horizontal stress level to 200 Psi. This behavior for the stimulated reservoir volume was attributed to the increase in the bi-wing fracture growth more than the discrete fracture network growth and resulted in a reduced degree of complexity in fracture growth. It shows that the fracture treatment in areas with low horizontal stress differential results in higher stimulated reservoir volumes as reported in literature ${ }^{(7)}$. 


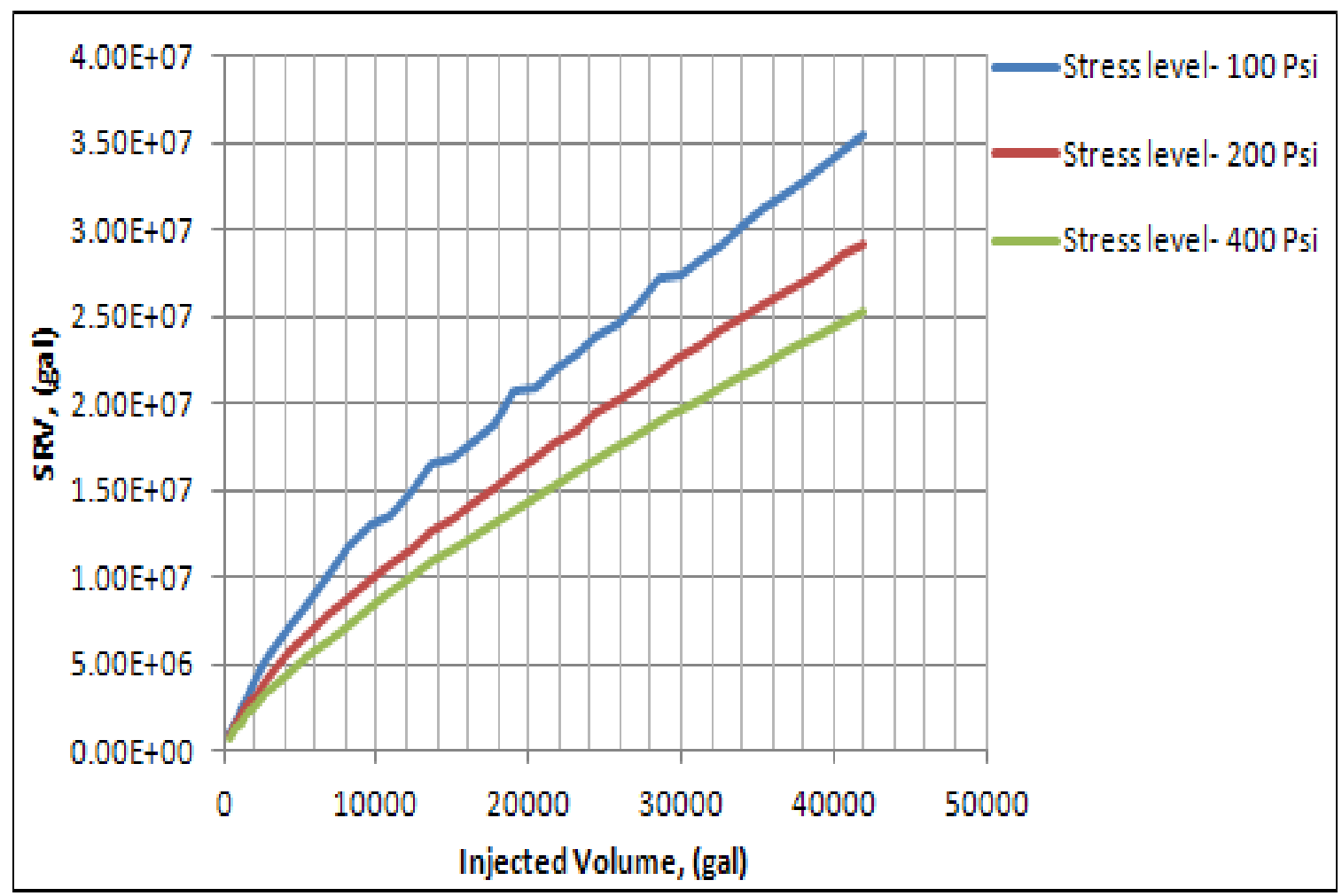

Figure 22: Stimulated reservoir volume for a single cluster with different horizontal stress levels

\subsubsection{Three Clusters Fracturing Treatment}

For the three-cluster fracturing treatment, $4000 \mathrm{bbl}$ of fluid was used because 1000 bbl is too small for three-cluster treatment with $60 \mathrm{bpm}$ pumping rate. Three horizontal stresses differences were used to study their impact. Table-4 below summarizes the simulation results for the three-cluster treatment. The results with three-cluster runs yielded identical values for the bi-wing fracture properties such as fracture length, width, height and volume and also the discrete fracture network (DFN) for each cluster. Table-4 below lists the results for one cluster except the stimulated reservoir volume (SRV) which represents the total SRV for the whole treatment (three-clusters). 
Table 4: Results for three-cluster treatment with different horizontal stress levels

\begin{tabular}{|l|c|c|c|}
\hline \multirow{2}{*}{ Parameter, Unit } & \multicolumn{3}{c|}{$\begin{array}{l}\text { Horizontal stress level, Psi (4000 bbl): } \\
\text { Three-Clusters }\end{array}$} \\
\cline { 2 - 4 } & $\mathbf{1 0 0}$ & $\mathbf{2 0 0}$ & $\mathbf{4 0 0}$ \\
\hline Fracture half length, ft & 253.27 & 503.24 & 1730 \\
\hline Fracture Avg. width, in & 0.066 & 0.071 & 0.105 \\
\hline Fracture heigth, ft & 96.161 & 96.672 & 97.898 \\
\hline Fracture volume,gal & 2013.5 & 4331.4 & 22095 \\
\hline DFN length,ft & 3745.7 & 3744.8 & 3459.1 \\
\hline DFN width, in & 0.1469 & 0.1383 & 0.105 \\
\hline DFN height, ft & 84.176 & 85.152 & 97.898 \\
\hline Stimulated reservoir volume (SRV), gal & $1.04 \mathrm{E}+08$ & $7.88 \mathrm{E}+07$ & $1.18 \mathrm{E}+06$ \\
\hline
\end{tabular}

The results for three-cluster treatment showed that the bi-wing fracture length increased as the horizontal stress differences increased. The length increased from $253.27 \mathrm{ft}$. for 100 Psi stress difference to $503.24 \mathrm{ft}$. for 200 Psi then to $1730 \mathrm{ft}$. for 400 Psi stress difference. The fracture width and volume also increased in significant amounts as the stress level increased. The discrete fracture network (DFN) properties decreased as the stress difference increased. At the high stress difference (400 Psi), the DFN properties were similar to the bi-wing fracture properties. The discrete fracture network is more likely to form at low levels of stress difference. At the high stress level, the fracturing treatment resulted with biwing fracture characteristic.

The results showed that the SRV decreased as the horizontal stress difference increased. The stimulated reservoir volume (SRV) increased around $24 \%$ as the horizontal stress difference increased from 100 Psi to 200 Psi. The SRV decreased sharply from $7.88 \mathrm{E}+7$ gal to $1.18 \mathrm{E}+6$ gal when the horizontal stress level increased from 200 Psi to 400 Psi. 
Generally, the multi-cluster treatment created shorter bi-wing fracture length when compared with the single fracture treatment; but, in the multi-cluster treatment the fluid distribution into the formations were more uniform and that resulted in a larger stimulated reservoir area. The difference between the SRV for the multi-cluster treatment and the single cluster treatment diminished as the horizontal stress level increased. The SRV for the single cluster treatment was much larger for the high horizontal stress difference as a result of the bi-wing fracture growth.

The Figure-24 below compares SRV values for the single fracture treatment with threecluster treatment for three different horizontal stress levels.

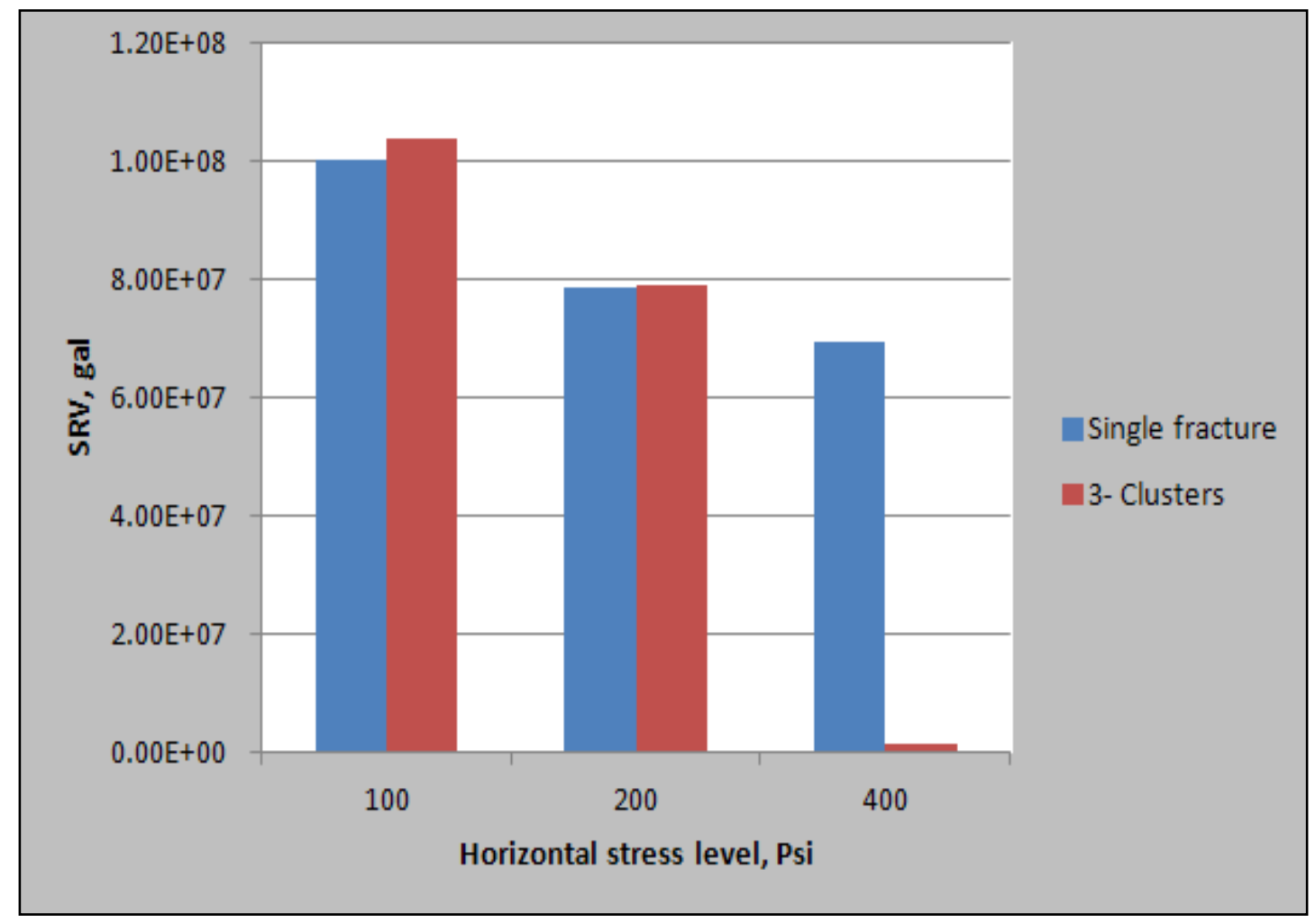

Figure 23: Comparison of SRVs with different levels of horizontal stress values 


\subsection{Impact of Young's Modulus}

\subsubsection{Single Fracture Treatment}

Table-5 below shows the main fracture and discrete fracture network (DFN)

properties from runs for single fracture treatment using $1000 \mathrm{bbl}$ of fluid and for three different Young's modulus values, namely, 2, 4 and 6 Mpsi.

Table 5: Single fracture treatment for different Young's modulus

\begin{tabular}{|l|c|c|c|}
\hline \multirow{2}{*}{ Parameter, Unit } & \multicolumn{3}{c|}{ Young's Modulus, Psi (1000 bbl) } \\
\cline { 2 - 4 } & $\mathbf{2 . 0 0 E + 0 6}$ & $\mathbf{4 . 0 0 E + 0 6}$ & $\mathbf{6 . 0 0 E + 0 6}$ \\
\hline Fracture half length, ft & 218 & 208.67 & 192.3 \\
\hline Fracture Avg. width, in & 0.069 & 0.042 & 0.031 \\
\hline Fracture heigth, ft & 96.05 & 96.09 & 96.07 \\
\hline Fracture volume,gal & 1801.6 & 1035.9 & 709.75 \\
\hline DFN length,ft & 3606.7 & 4844 & 5592.6 \\
\hline DFN width, in & 0.15772 & 0.098 & 0.073 \\
\hline DFN height, ft & 84.74 & 83.855 & 82.88 \\
\hline Stimulated reservoir volume (SRV), gal & $3.55 \mathrm{E}+07$ & $4.86 \mathrm{E}+07$ & $5.72 \mathrm{E}+07$ \\
\hline
\end{tabular}

Based on results presented on Table-5, the bi-wing fracture volume, length, width decreased as the Young's modulus increased. The bi-wing fracture length decreased from 218 $\mathrm{ft}$ to $208 \mathrm{ft}$ (around 4\%) as the Young's modulus increased by 100\% from 2 MPsi to 4 MPsi and then decreased to $192 \mathrm{ft}$ with 6 MPsi. The Young's modulus had a greater impact on biwing fracture width, it decreased by $40 \%$ as the Young's modulus increased from 2 MPsi to 4 MPsi. The Figure-25 below shows the bi-wing fracture length growth for three different values of Young's modulus. 


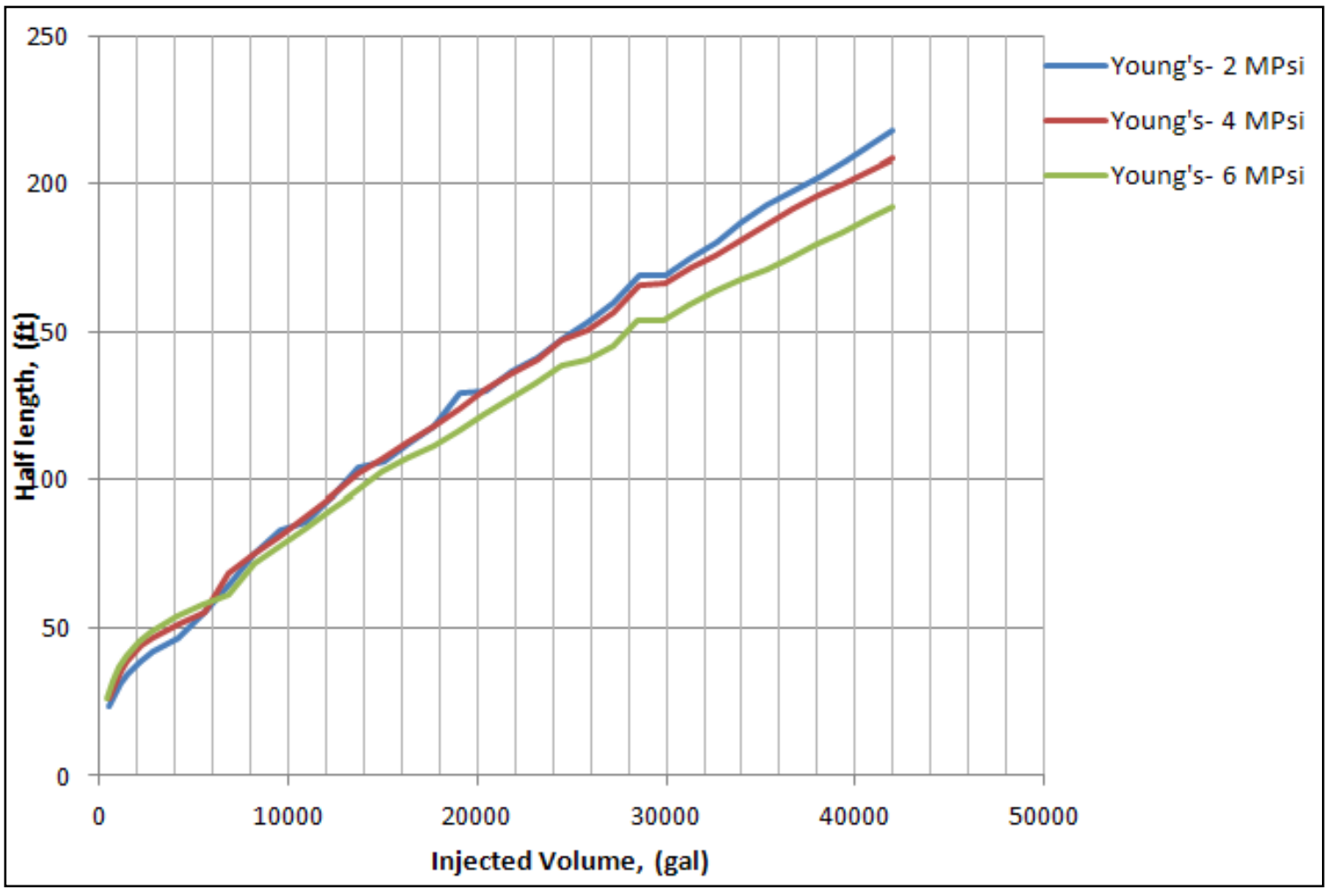

Figure 24: Fracture half length growth for single fracture with three different Young's modulus values

The Young's modulus generally describes how much a material will deform elastically under a load and relates to the hardness of the rock. It is more difficult to propagate long and wide fracture in rocks with high values Young modulus since it requires more energy to induce fracture. The higher value for Young's modulus makes it difficult for the fluid to generate facture width. For the discrete fracture network (DFN) properties, the average discrete fracture network width decreased as the young's modulus stress increased while the discrete fracture network length increased. The stimulated reservoir volume also increased as the injected fluid created secondary fractures instead of widening the primary fracture due to the higher Young's modulus value. Figure-26 below shows the stimulated reservoir volume (SRV) for three different values of Young's modulus. 


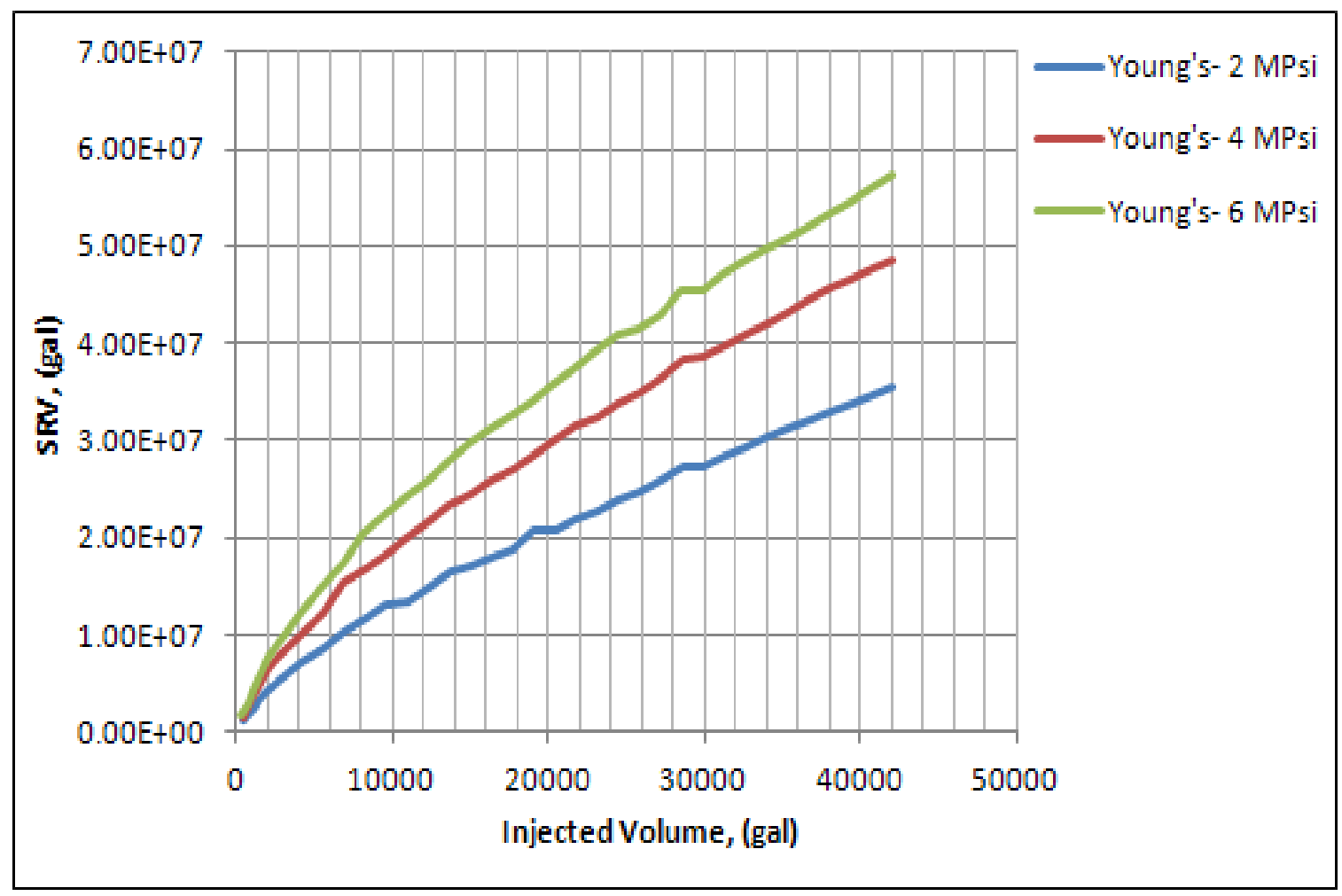

Figure 25: Stimulated reservoir volume for three different values of Young's modulus

\subsubsection{Three Clusters Fracturing Treatment}

The Table- 6 below summarizes the results for three Young's Modulus values (2, 4 and 6 MPsi).

Table 6: Three clusters treatment using three different values of Young's modulus

\begin{tabular}{|l|c|c|c|}
\hline \multirow{2}{*}{ Parameter, Unit } & \multicolumn{3}{|c|}{ Young's Modulus, Psi (4000 bbl)-3 Clusters } \\
\cline { 2 - 4 } & $\mathbf{2 . 0 0 E + 0 6}$ & $\mathbf{4 . 0 0 E + 0 6}$ & $\mathbf{6 . 0 0 E + 0 6}$ \\
\hline Fracture half length, ft & 253.27 & 249.85 & 225.59 \\
\hline Fracture Avg. width, in & 0.066 & 0.038 & 0.028 \\
\hline Fracture heigth, ft & 96.161 & 96.213 & 97.173 \\
\hline Fracture volume,gal & 2013.5 & 1151.2 & 748.35 \\
\hline DFN length,ft & 3745.7 & 4630.2 & 5056.7 \\
\hline DFN width, in & 0.1469 & 0.0881 & 0.0646 \\
\hline DFN height, ft & 84.176 & 83.041 & 83.818 \\
\hline Stimulated reservoir volume (SRV), gal & $1.04 \mathrm{E}+08$ & $1.33 \mathrm{E}+08$ & $1.51 \mathrm{E}+08$ \\
\hline
\end{tabular}

For the three-cluster fracturing treatment, the fracture characteristics followed the same trend as the single fracturing treatment. The bi-wing fracture length, width and volume 
decreased as the Young's modulus increased. The discrete fracture network length increased as the Young's modulus increased while the DFN width decreased. The DFN length increased from $3745.7 \mathrm{ft}$ to $4630.2 \mathrm{ft}$ as the Young's modulus value increased from 2 MPsi to 4 Mpsi, then increased to $5056.7 \mathrm{ft}$ with 6 MPsi.

The stimulated reservoir volume (SRV) also increased as the Young's modulus value increased. The SRV increased from 1.04E+8 gal at 2 MPsi Young's modulus to $1.51 \mathrm{E}+8$ gal with 6 MPsi Young's modulus. The Figure-27 below compares results for single fracture treatment with three-cluster treatment for three different values of Young's modulus.

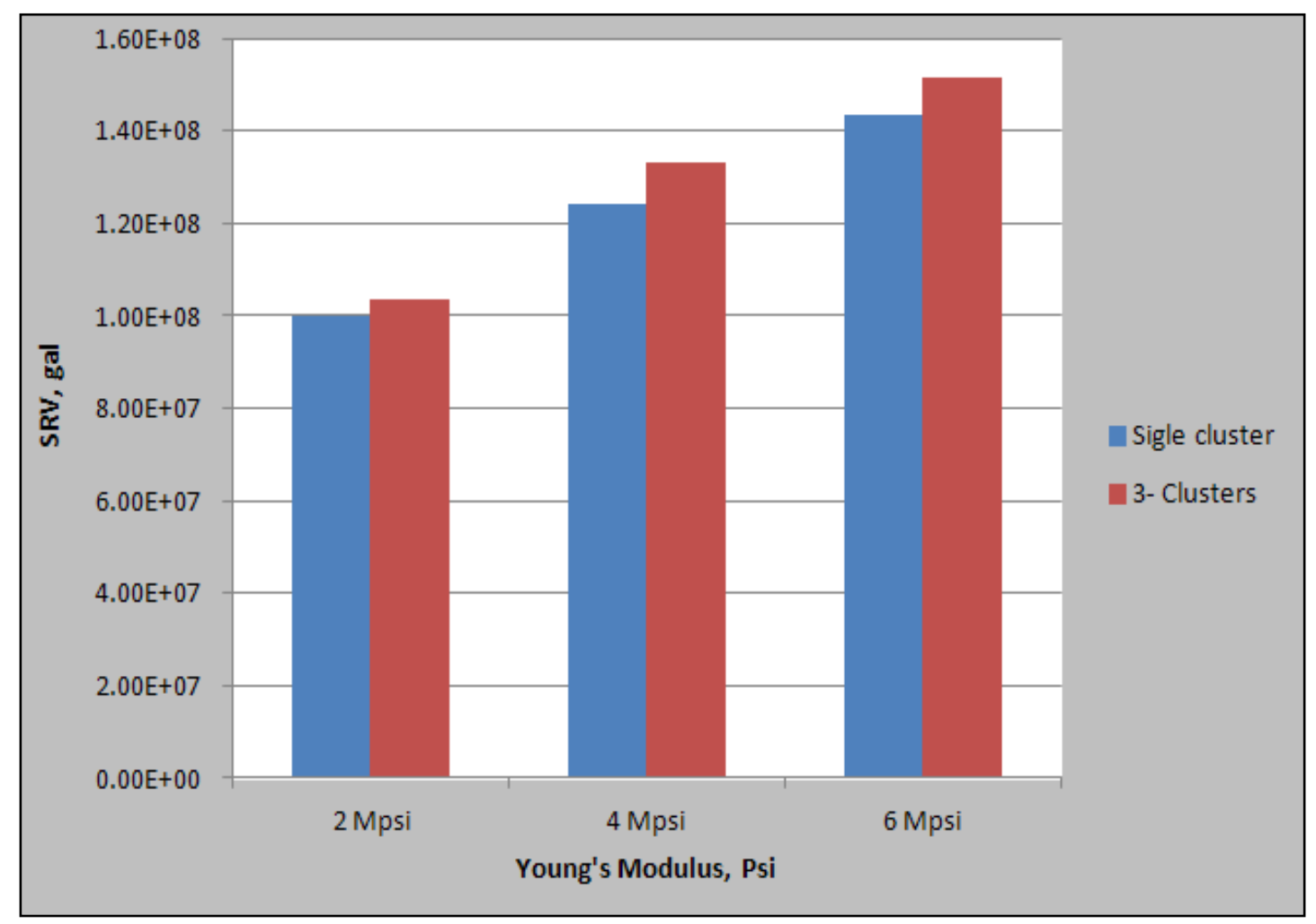

Figure 26: Comparison of Stimulated reservoir volume with three different values of Young's modulus 


\subsection{Impact of Poison's Ratio}

\subsubsection{Single Fracture Treatment}

Table-7 below shows the results for single fracture treatment with three different values of Poison's ratio, namely, $0.15,0.2$ and 0.3 . This range for Poison's ratio is the typical range for the Appalachian basin shale.

Table 7: Single fracture treatment using different values for Poison's ratio

\begin{tabular}{|l|c|c|c|}
\hline \multirow{2}{*}{ Parameter, Unit } & \multicolumn{3}{|c|}{ Poison's ratio (1000 bbl) } \\
\cline { 2 - 4 } & $\mathbf{0 . 1 5}$ & $\mathbf{0 . 2 0}$ & $\mathbf{0 . 3 0}$ \\
\hline Fracture half length, ft & 218 & 218.6 & 220.75 \\
\hline Fracture Avg. width, in & 0.069 & 0.068 & 0.065 \\
\hline Fracture heigth, ft & 96.05 & 96.06 & 96.08 \\
\hline Fracture volume,gal & 1801.6 & 1783 & 1720.2 \\
\hline DFN length,ft & 3606.7 & 3630 & 3717 \\
\hline DFN width, in & 0.15772 & 0.15596 & 0.14978 \\
\hline DFN height, ft & 84.74 & 84.81 & 85.04 \\
\hline Stimulated reservoir volume (SRV), gal & $3.55 \mathrm{E}+07$ & $3.58 \mathrm{E}+07$ & $3.72 \mathrm{E}+07$ \\
\hline
\end{tabular}

Based on results presented in Table-7, the Poison's ratio had insignificant impact on the fracturing treatment outcome. The bi-wing fracture length, width and volume increased by less than $1 \%$ as the Poison's ratio increased from 0.15 to 0.2 . Also the discrete fracture network properties such as the DFN length and stimulated reservoir volume (SRV) increased negligibly as the Poison's ratio increased. The Poison's ratio in shale formations in general ranges from 0.2 to 0.3 and for Utica shale it ranges from 0.15 to 0.25 . The Figure- 28 and Figure-29 below show the impact of Poison's ratio on the bi-wing fracture length and the stimulated reservoir volume (SRV), respectively. 


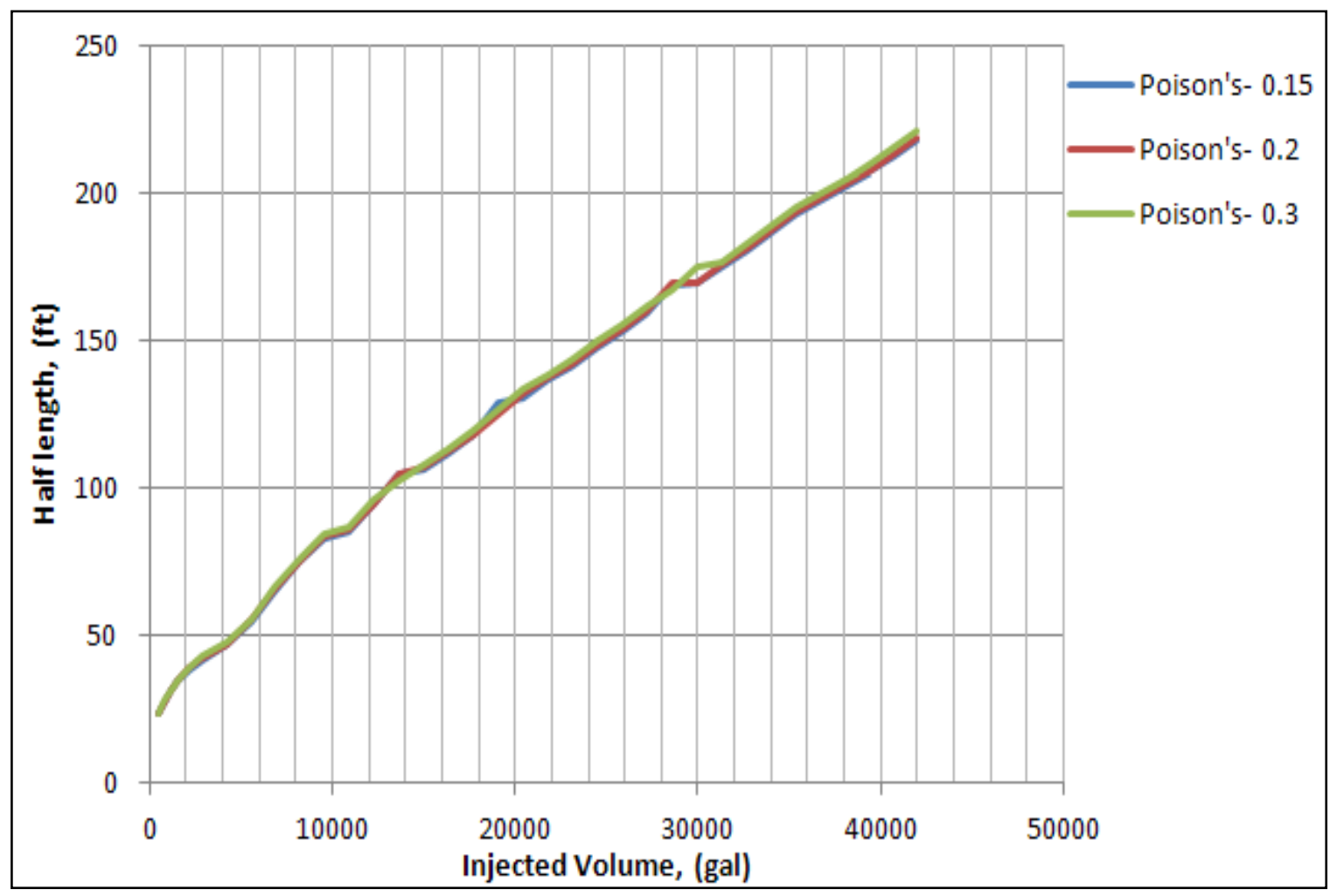

Figure 27: Fracture half length growth for single fracture with three different values of Poison's ratio

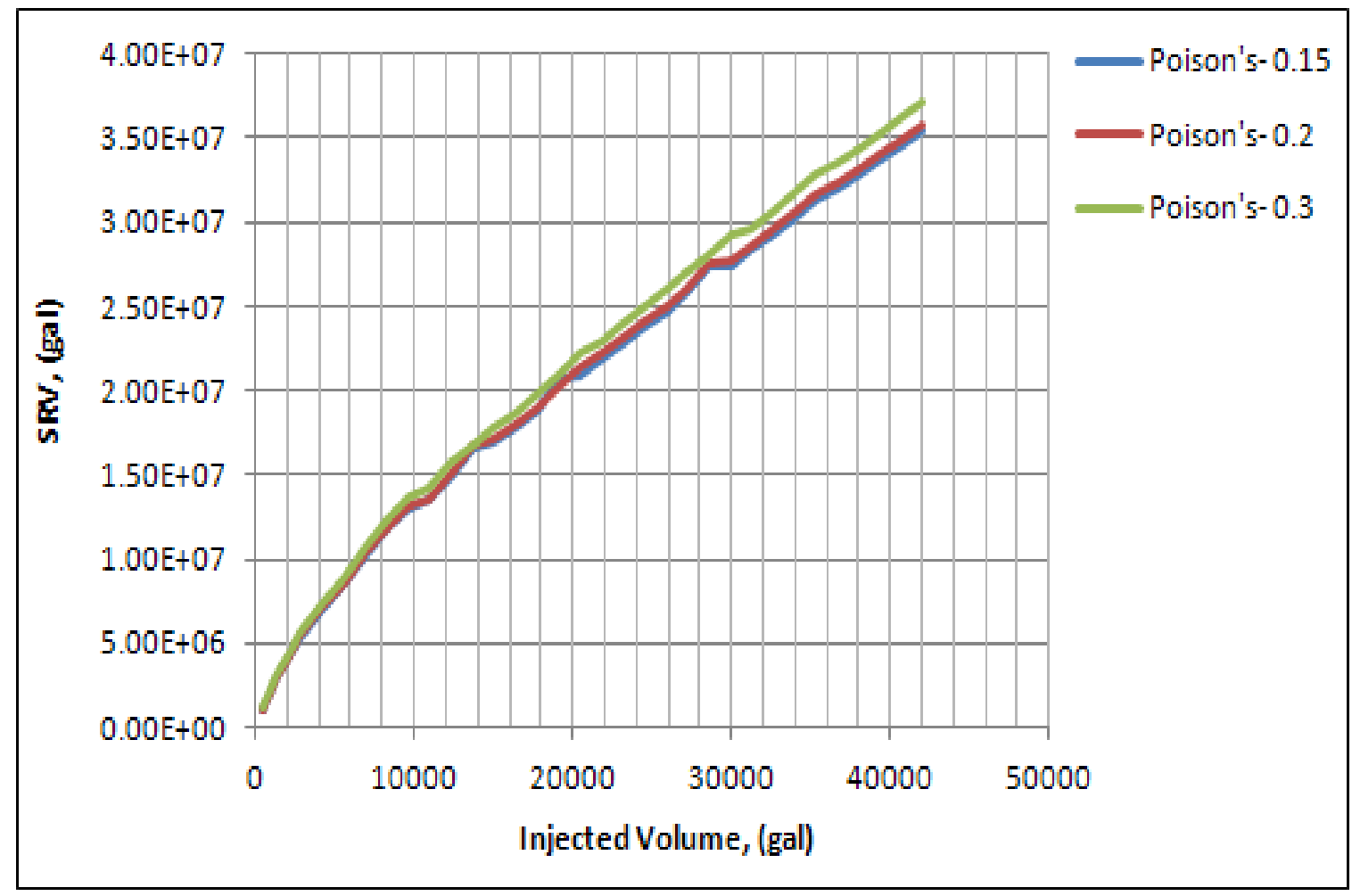

Figure 28: Stimulated reservoir volume for three different values of Poison's ratio 


\subsubsection{Three Clusters Fracturing Treatment}

Table- 8 below tabulates the results for the three-cluster treatment for three different values of Poison's ratio.

Table 8: Three-cluster treatment with three different values of Poison's ratio

\begin{tabular}{|l|c|c|c|}
\hline \multirow{2}{*}{\multicolumn{2}{|c|}{ Parameter, Unit }} & \multicolumn{3}{|c|}{$\begin{array}{l}\text { Poison's Ratio (4000 bbl): } \\
\text { Three-Clusters }\end{array}$} \\
\cline { 2 - 4 } & $\mathbf{0 . 1 5}$ & $\mathbf{0 . 2 0}$ & $\mathbf{0 . 3 0}$ \\
\hline Fracture half length, ft & 253.27 & 254.05 & 255.7 \\
\hline Fracture Avg. width, in & 0.066 & 0.065 & 0.063 \\
\hline Fracture heigth, ft & 96.161 & 96.167 & 96.183 \\
\hline Fracture volume,gal & 2013.5 & 1992.6 & 1909 \\
\hline DFN length,ft & 3745.7 & 3764.7 & 3846 \\
\hline DFN width, in & 0.1469 & 0.145 & 0.139 \\
\hline DFN height, ft & 84.176 & 84.231 & 84.123 \\
\hline Stimulated reservoir volume (SRV), gal & $1.04 \mathrm{E}+08$ & $1.04 \mathrm{E}+08$ & $1.07 \mathrm{E}+08$ \\
\hline
\end{tabular}

Table-4 shows that the Poison's ratio had insignificant impact on both bi-wing fracture and discrete fracture network (DFN) properties. The increase in fracture half length was negligible as the Poison's ratio increased from 0.15 to 0.3 (its maximum in shale formations). The discrete fracture network length increased around $2 \%$ as the Poison's ratio increased from 0.15 to 0.3 . For the DFN width and height, the Poison's ratio had negligible impact. The stimulated reservoir volume increased around 3\% percent as the Poison's ratio increased from 0.15 to 0.3 .

The three-cluster treatment had a shorter bi-wing fracture length and higher stimulated reservoir volume (SRV). Figure-30 below compares the SRV values for single fracture treatment and three-cluster treatment for three different values of Poisson's ratio. 


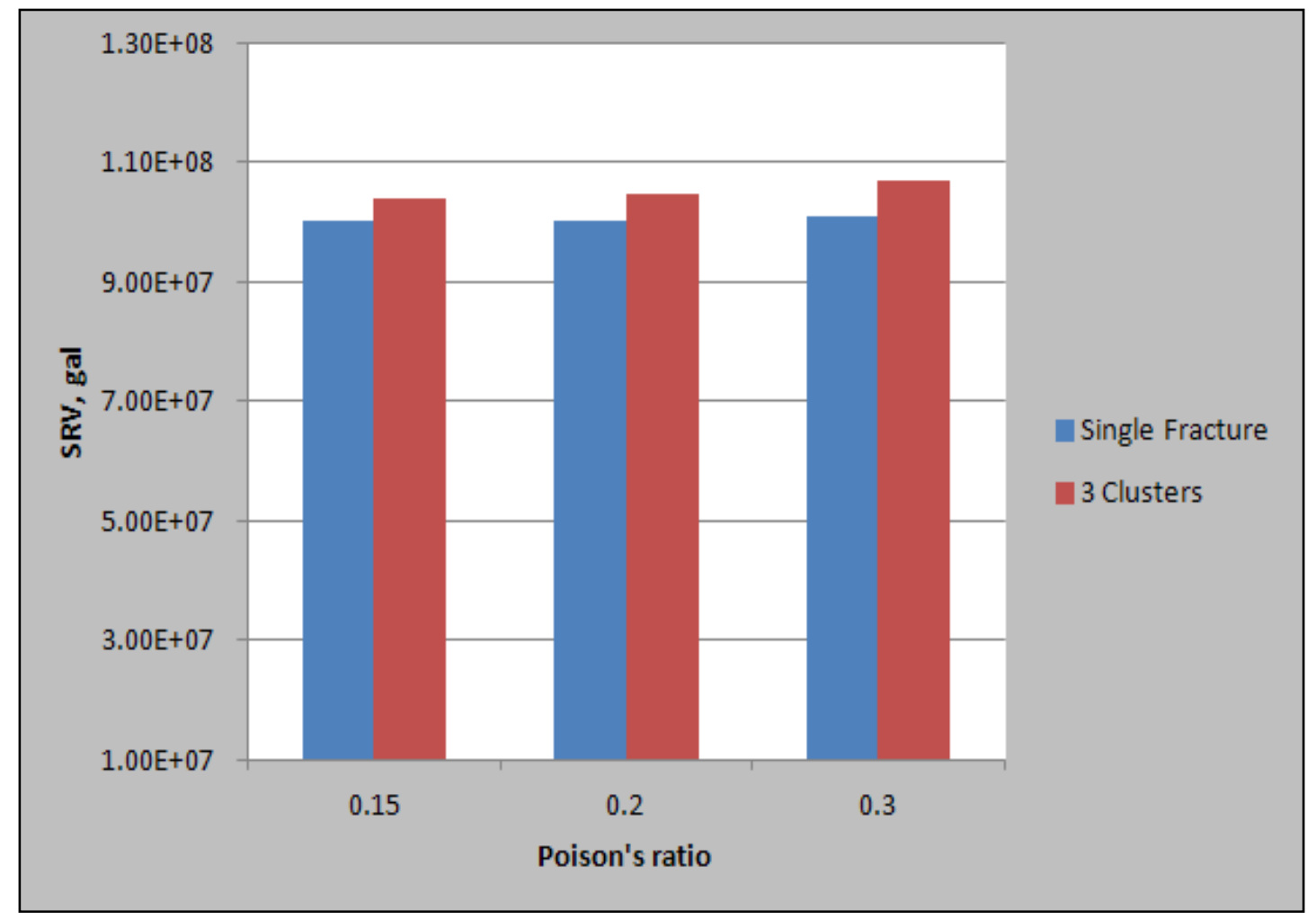

Figure 29: Comparison of Stimulated reservoir volume with three different values of Poison's ratio 


\subsection{Impact of leak-off coefficient}

\subsubsection{Single Fracture Treatment}

The Table-9 below shows the results for single fracture treatment with three different values of Poison's ratio, namely, 0.15, 0.2 and 0.3. This is a typical range for Poison's ratio values of the Appalachian basin shale.

Table 9: Single fracture treatment for three different leak-off coefficients

\begin{tabular}{|l|c|c|c|}
\hline \multirow{2}{*}{ Parameter, Unit } & \multicolumn{3}{c|}{ Poison's ratio, (1000 bbl) } \\
\cline { 2 - 4 } & $\mathbf{0 . 1 5}$ & $\mathbf{0 . 2 0}$ & $\mathbf{0 . 3 0}$ \\
\hline Fracture half length, ft & 218 & 218.6 & 220.75 \\
\hline Fracture Avg. width, in & 0.069 & 0.068 & 0.065 \\
\hline Fracture heigth, ft & 96.05 & 96.06 & 96.08 \\
\hline Fracture volume,gal & 1801.6 & 1783 & 1720.2 \\
\hline DFN length,ft & 3606.7 & 3630 & 3717 \\
\hline DFN width, in & 0.15772 & 0.15596 & 0.14978 \\
\hline DFN height, ft & 84.74 & 84.81 & 85.04 \\
\hline Stimulated reservoir volume (SRV), gal & $3.55 \mathrm{E}+07$ & $3.58 \mathrm{E}+07$ & $3.72 \mathrm{E}+07$ \\
\hline
\end{tabular}

Table-9 shows that the Poison's ration had insignificant impact on the fracturing treatment outcome. The bi-wing fracture length, width and volume increased by less than $1 \%$ as the Poison's ratio increased from 0.15 to 0.2 . Also, the discrete fracture network properties such as the DFN length and stimulated reservoir volume (SRV) increased negligibly as the Poison's ratio increased. The Poison's ratio in shale formations in general ranges from 0.2 to 0.3 and for Utica shale the range used was from 0.15 to 0.25 . Figure-31 and Figure-32 below shows the variation of bi-wing fracture length and the stimulated reservoir volume (SRV), respectively, as a function of injected treatment volume with three different leak-off coefficients values. 


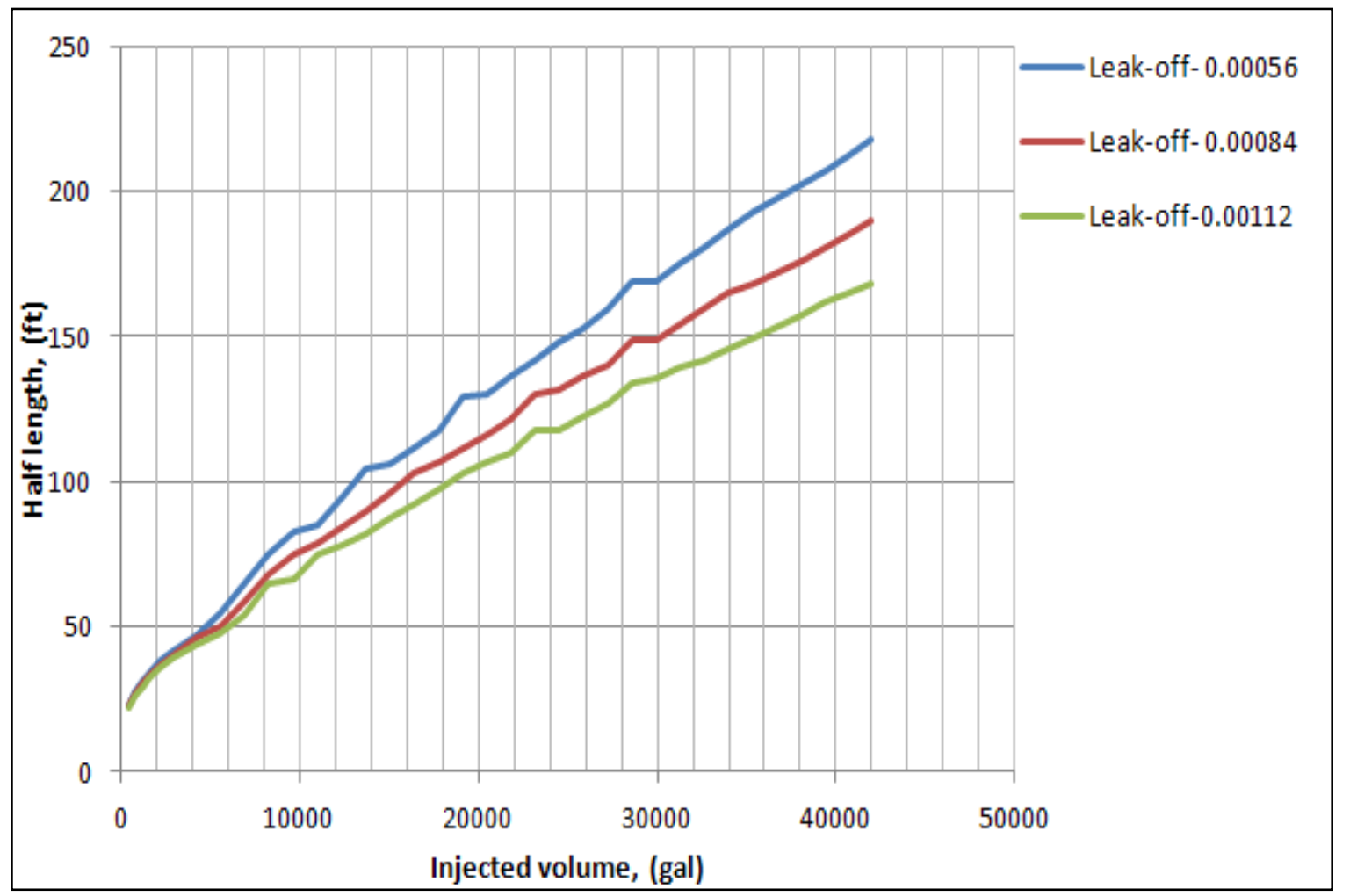

Figure 30: Fracture half-length growth for single fracture with three different values of leak-off coefficient

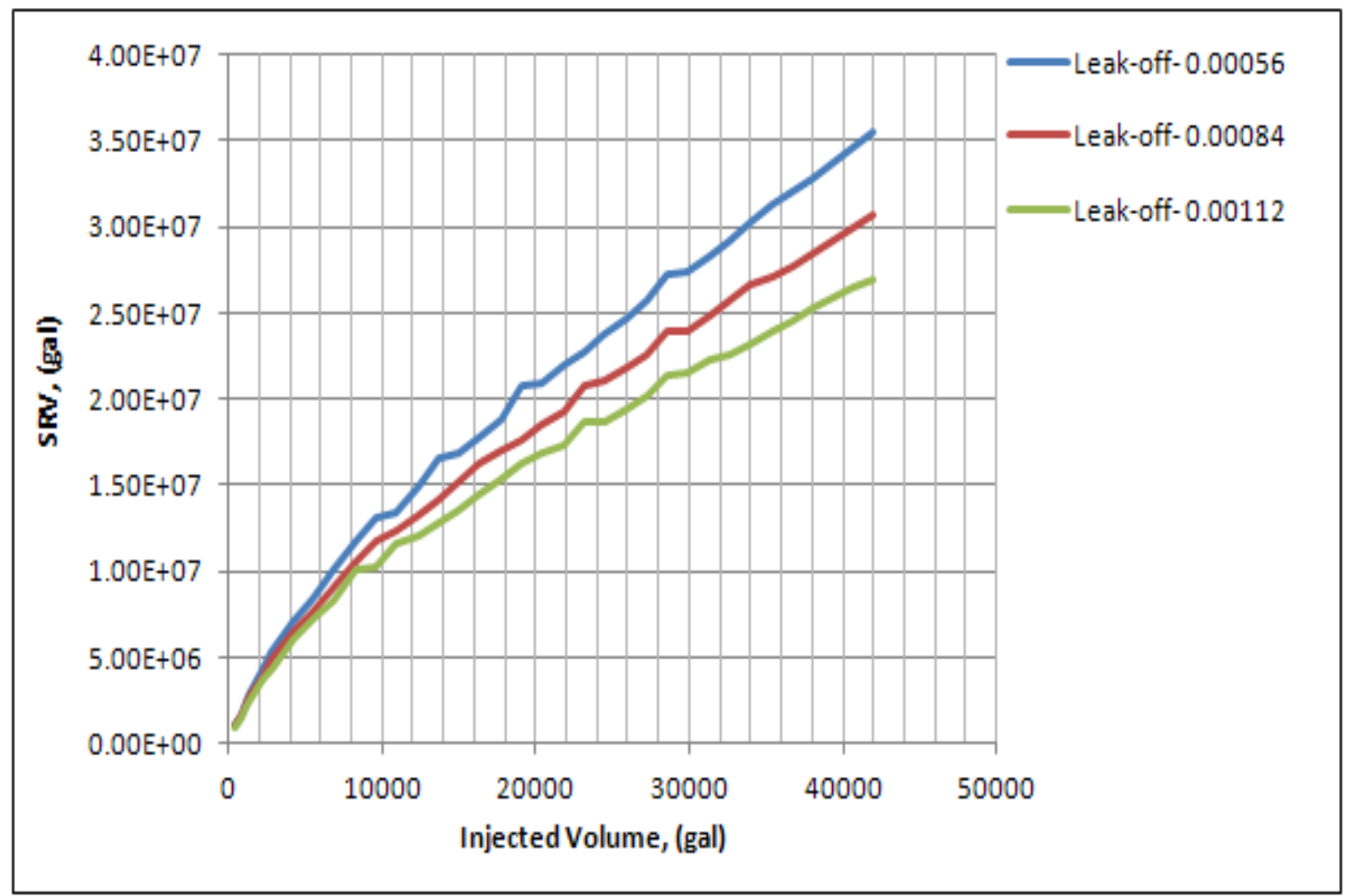

Figure 31: Stimulated reservoir volume with three different values of leak-off coefficient 


\subsubsection{Three-Cluster Fracturing Treatment}

Table-10 below presents results for the three-cluster fracturing treatment using 4000 bbl of fluids for three different values of leak-off coefficient, $0.00056,0.00084$ and 0.00112 $\mathrm{ft} / \min ^{\wedge}{ }^{1 / 2}$

Table 10: Three clusters treatment with three different values of leak-off coefficient

\begin{tabular}{|c|c|c|c|}
\hline \multirow[t]{2}{*}{ Parameter, Unit } & \multicolumn{3}{|c|}{$\begin{array}{l}\text { leak-off coefficient, } \mathrm{ft} / \mathrm{min}^{\wedge} 1 / 2(4000 \\
\text { bbl): } \\
\text { Three-Clusters }\end{array}$} \\
\hline & 0.00056 & 0.00084 & 0.00112 \\
\hline Fracture half length, $\mathrm{ft}$ & 253.27 & 203.38 & 169.7 \\
\hline Fracture Avg. width, in & 0.066 & 0.064 & 0.061 \\
\hline Fracture heigth, $\mathrm{ft}$ & 96.161 & 95.847 & 95.475 \\
\hline Fracture volume,gal & 2013.5 & 1544.3 & 1235.7 \\
\hline DFN length,ft & 3745.7 & 3040.2 & 2539.5 \\
\hline DFN width, in & 0.1469 & 0.1413 & 0.136 \\
\hline DFN height, $\mathrm{ft}$ & 84.176 & 83.072 & 82.402 \\
\hline Stimulated reservoir volume (SRV), gal & $1.04 \mathrm{E}+08$ & $8.32 \mathrm{E}+07$ & $6.93 \mathrm{E}+07$ \\
\hline
\end{tabular}

All fracture and discrete fracture network properties decreased as the leak-off coefficient increased. The fracture length decreased from $253.27 \mathrm{ft}$ to $203.38 \mathrm{ft}$ as the leak-off coefficient increased by $50 \%$ from 0.00056 to $0.00084 \mathrm{ft} / \mathrm{min}^{\wedge}{ }^{1 / 2}$ then decreased to $169.7 \mathrm{ft}$ as the leak-off coefficient reached $0.00112 \mathrm{ft} / \mathrm{min}^{\wedge}{ }^{1 / 2}$. The leak-off coefficient had less impact on the fracture width and height. The SRV also decreased as the leak-off increased and the three-cluster treatment generated higher SRV than the single fracture treatment. The Figure33 below compares the SRV for the single and three-cluster fracture treatments for three different leak-off coefficients. 


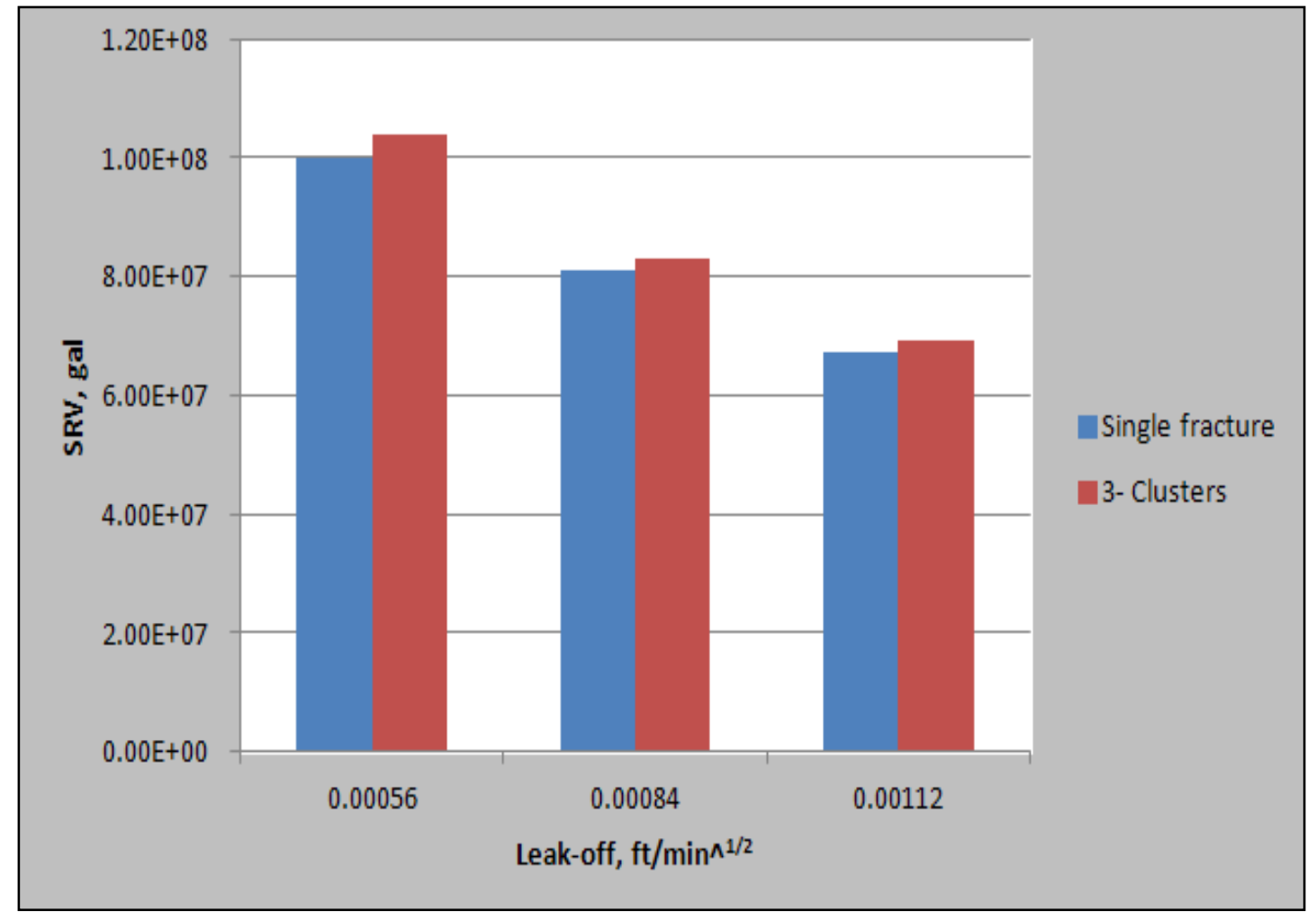

Figure 32: Comparison of Stimulated reservoir volume using different values for leak-off coefficient 


\section{Conclusion and recommendations}

The main goal of this research was to study the impact of formation geo-mechanical properties on the outcome of hydraulic fracturing treatment in horizontal wells in Utica shale. Especially, to study the impact of horizontal stress level, Young's modulus, Poison's ratio and the leak-off coefficient on the fracture geometry and the discrete fracture network (DFN) distribution. A model was created using Utica shale properties to simulate the hydraulic fracturing treatment. Several runs were conducted for single fracture treatment and threecluster treatment and the fracture and discrete fracture network (DFN) properties were obtained. Based on the results the following conclusions are presented:

The horizontal stress level, Young's modulus and the leak-off coefficient have great impact on the fracture and the discrete fracture network properties while the Poison's ratio has insignificant impact.

The bi-wing fracture half length, width and volume were increased as the horizontal stress difference increased while the discrete fracture network (DFN) properties and the stimulated reservoir volume (SRV) were increased. So, the low horizontal stress differential is desirable in order to create high complexity fractures and increase the stimulated reservoir volume.

The high value for Young's modulus generated shorter and smaller bi-wing fracture and higher DFN length and stimulated reservoir volume. Thus, the hydraulic fracturing treatments in areas with high Young's modulus values will yield high SRV and better well performance.

$>$ The Poison's ratio has insignificant impact on the fracturing treatment outcome because of the narrow range for Poison's ratio values in shale formations (0.2 to 0.3$)$. 
The leak-off coefficient represents the amount of fluid escaping into the formation impacting the fracturing treatment. So, the increase of the leak-off coefficient will reduce the fracture and discrete fracture network volume.

The results presented in this study are based on a constant leak-off model and it does not apply to dynamic leak-off conditions.

It is recommended to extend this research to match the fracturing simulation results with the field micro-seismic data, and then use the matched results in production history matching for better evaluation of horizontal well performances in shale gas formations. 


\section{Nomenclature}

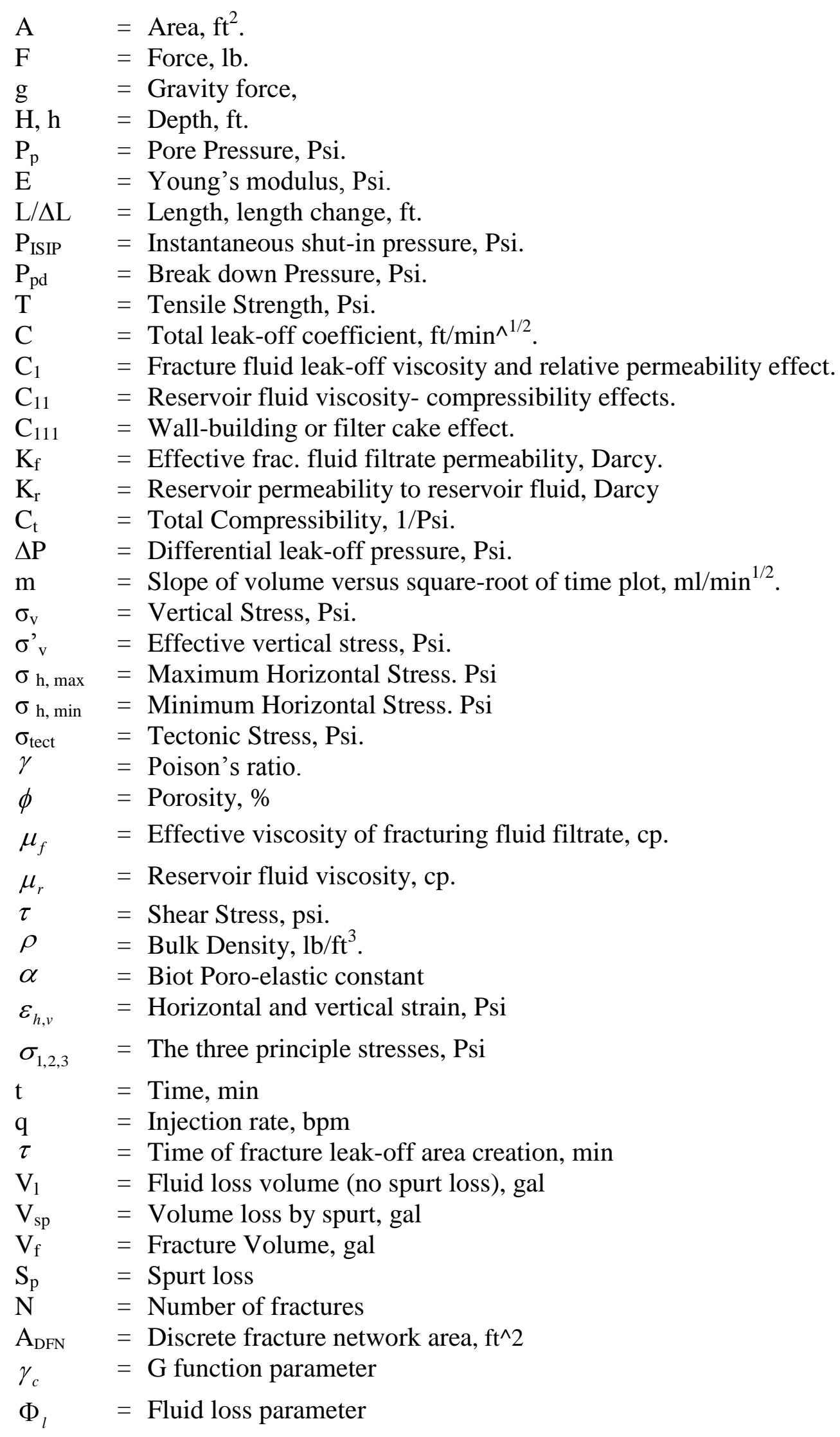




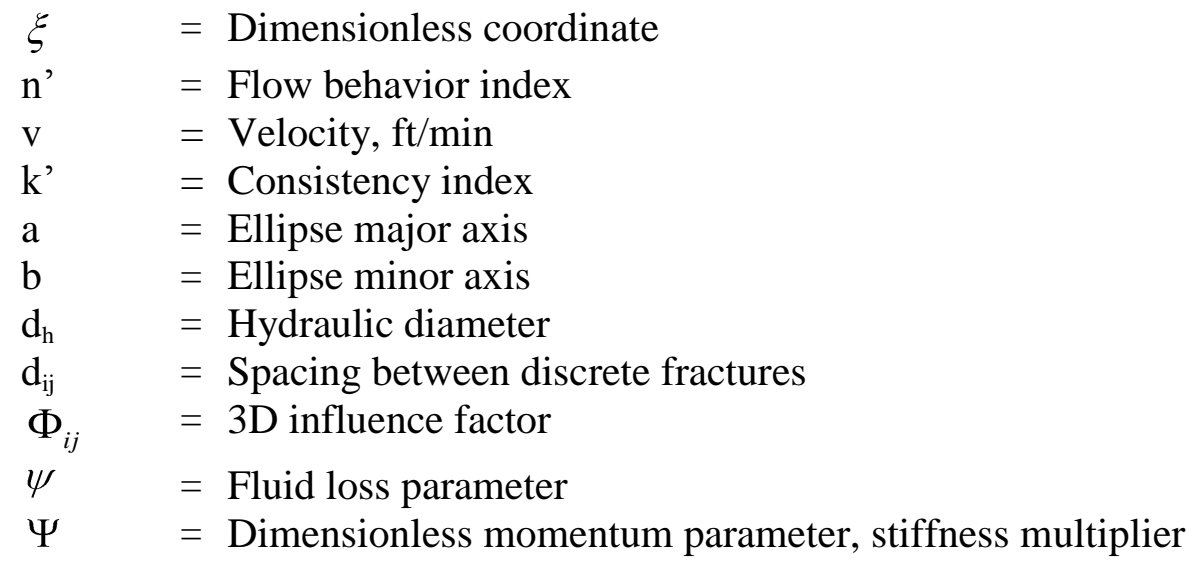




\section{References}

1. EIA. (2012),"What is shale gas and why it is important", Retrieved June 2013, from Energy in Brief: http://www.eia.gov/energy_in_brief/article/about_shale_gas.cfm.

2. Aboaba, LA., (2010) "Estimation of Fracture Properties for a Horizontal Well with Multiple Hydraulic Fractures in Gas Shale”, M.S. Thesis, West Virginia University.

3. EIA, (2013), “"'Technically Recoverable Shale Oil and Shale Gas Resources: An Assessment of 137 Shale Formations in 41 Countries outside the United States", Retrieved June 2103, from Analysis and Projections:

http://www.eia.gov/analysis/studies/worldshalegas/.

4. Schepers, K.C., R.J. Gonzales, G.J. Koperna, and A.Y. Oudinot (2009) "Reservoir Modeling in Support of Shale Gas Exploration", Paper SPE 123057 presented at the SPE Latin American and Caribbean petroleum engineering conference, Cartagena, Colombia, 31 May - 3 June.

5. New York State, (2011), "Supplemental Generic Environmental Impact Statement, Chapter 4, Geology" Retrieved June 2013, from New York State Department of EnvironmentalConservation:

http://www.dec.ny.gov/docs/materials_minerals_pdf/rdsgeisch40911.pdf.

6. Geology, (2013). Retrieved June 2013, from "Utica Shale- the Natural Gas Giant below the Marcellus": http://geology.com/articles/utica-shale/.

7. Paktinat, J., J.A. Pinkhouse, J. Fontaine, G.G. Lash, and G.S. Penny (2007) "Investigation of the methods to improve Utica shale Hydraulic fracturing in the Appalachian Basin", paper SPE 111063 presented at the SPE Eastern Regional Meeting, Lexington, KY, 17-19 October.

8. Wickstrom, Larry, Chris Perry, Ron Riely and Mathew Erenpreiss, (2012) "The Utica-Point Pleasant Shale play of Ohio", Ohio Department of Natural resources.

9. Chesapeake, (2011) EnerVest deal a new high-water mark for the Utica. FuelFix.com, November 3, 2011.

10. Alenezi, F.N., (2011) "Development of Type Curves for Gas Production from Hydraulically Fractured Horizontal Wells in Unconventional Reservoirs", M.S. Thesis, West Virginia University.

11. Joshi, S.D., (1987) "A Review of Horizontal Well and drain hole Technology," paper SPE 16868 presented at the 1987 Annual Technical Conference and Exhibition, Dallas, Sep. 27-30. 
12. Thakur, G.G., (October 1999): "Horizontal Well Technology-A Key to Improving Reserves", Chevron Petroleum Technology Company. Journal of Canadian Petroleum Technology, Vol.38, No. 10.

13. Joshi, S.D., (1991) Horizontal Well Technology, OK: Penn Well Books.

14. Joshi, S.D., (June 1988) "Augmentation of well productivity using slant and horizontal wells", Journal of Petroleum Technology, Vol. 40, pp. 729-739.

15. Joshi, S.D., (2003) “Cost/Benefits of Horizontal Wells” Paper SPE 83621 presented at SPE western regional meeting held in Long Beach, California 19-24 May.

16. Charlez, Philippe A. (1997). "Rock Mechanics: Petroleum Applications”. Paris: Editions Technip. Volume 2, p.239.

17. Ali, S. Tarig, (2010) "Production Data Analysis In Tight Gas Well in Multilayer Reservoir”, M.S. Thesis, West Virginia University.

18. King, George E., (2012) “ Hydraulic Fracturing 101: What every representative, environmentalist, regulator, reporter, investor, university researcher, neighbor and engineer should know about estimating Frac risk and improving Frac performance in unconventional gas and oil wells" Paper SPE 152596 presented at SPE hydraulic fracturing technology conference, Woodlands, Texas, USA, 6-8 February 2012.

19. Montgomery, Carl T. and M.B. Smith, (2010) "Hydraulic fracturing, History of enduring technology" JPT, December 2010.

20. World oil (2013). Retrieved June 2013, from world oil.com: http://www.worldoil.com/Marcellus-groundwater-claims-A-case-for-scientificallyinformed-decisions.html

21. Chen, C. and R. Raghavan, (1997). "A Multiply-Fractured Horizontal Well in a Rectangular Drainage Region”. Soc. Eng. Jour. Vol. 2,(Dec.) 455-465.

22. Mayerhofer, M.J., E.P. Lolon, N.R. Warpiniski, C.L. Cipolla, D. Walser and C.M. Rightmire, (2004) "What is Stimulated reservoir volume?", Paper SPE 119890 presented at the SPE shale gas production conference, Fort Worth, Texas, USA 16-18 November 2004.

23. Cipolla, C.L., N.R. Warpinski, M.J Mayerhofer and E.P Lolon, (2004) "The relationship between fracture complexity, reservoir properties, and fracture treatment design", Paper SPE 115769 presented at the SPE annual Technical conference and exhibition, Denver, Colorado, USA, 21-24 September.

24. Meyer, B.R. and L.W. Bazan, (2011) "A Discrete Fracture Network Model for Hydraulically Induced Fracture: Theory, Parametric and Case Studies", Paper SPE 140514 presented at the SPE hydraulic fracturing Technology and Exhibition, Woodlands, TX, 24-26 January. 
25. Valko, Peter, and Michael J. Economides, (1995), "Hydraulic Fracture Mechanics" NJ, USA, Wiley and sons Inc.

26. Schlumberger. (2013). Retrieved March 2013, from Schlumberger Oilfield Glossary: http://www.glossary.oilfield.slb.com/en/Terms.aspx?LookIn=term\%20name\&filter=a nisotropic\%20formation.

27. Cook, J., R.A. Frederiksen, K. Hasbo, S. Green, A. Judzis, J.W. Martin, R. SuarezRivera, J. Herwanger, P. Hooyman, Don Lee, S. Noeth, C. Sayers, N. Koutsabeloulis, R. Marsden, M.G. Stage and C.P. Tan, (2007), "Rocks Matter; Ground Truth in Geomechanics", Oilfield Review, autumn 2007, p. 36-55.

28. Hubbert, M.K. and D.G. Willis, (1957) "Mechanics of Hydraulic Fracturing" Trans.AIME, 210-153-166.

29. Economides, M.J. and K.G. Nolte, (2010), "Reservoir Stimulation” Page 105 - 120, Wiley and sons Inc.

30. Schlumberger. (2013). Retrieved March 2013, from Schlumberger Oilfield Glossary: http://www.glossary.oilfield.slb.com/Display.cfm?Term=Young\%27s\%20modulus.

31. Schlumberger. (2013). Retrieved March 2013, from Schlumberger Oilfield Glossary: http://www.glossary.oilfield.slb.com/Display.cfm?Term=Poisson's\%20ratio.

32. Hooke, R., and J. B. Hansen, (2005), Stress analysis Strain Analysis and shearing of Soils book title, The Engineering Foundations, McGraw-Hill, New York, NY.

33. Howard, G.C. and C.R. Fast, (1970) "Hydraulic Fracturing”, SPE Monograph 2, SPE, Richardson, TX.

34. Mao, Bai, S. Green, and R.S. Rivera, (2005): "Effect of Leak off Variation on Fracturing Efficiency for Tight Shale Gas Reservoirs" Paper ARMA/USRMS 05-697, presented at the 40th U.S. Symposium on Rock Mechanics (USRMS): Rock Mechanics for Energy, Mineral and Infrastructure development in the Northern Regions, held in Anchorage, Alaska, 25 - 29 June 2005.

35. Meyers (2012), www.mfrac.com , Retrieved April 2013, from Mfrac manual. https://downloads.mfrac.com/Meyer-2012/manual/en/AppendiceD.17.3.html.

36. Lavoie, J. Y., J.S. Marcill, P.K Dorrins, J. Lavoie and R. Aguilera (2011) "Natural potential in the St. Lawrence lowlands of Québec: A case study" Paper SPE 137593 presented at the Canadian Unconventional Resources and International Petroleum Conference, Calgary, Canada. 
37. Ayan C., Achourov V Alpatov A., Sibneft-Khantos and Diyashev I., (2006) "Direct Measurement of minimum horizontal stress, Permeability and permeability Anisotropy in Siberian oil field Using wire-line formation Tester" presented at the SPE Russian Oil \& Gas conference and exhibition, Moscow, Russia 3 -6 October 2006.

38. Mayerhofer, M.J., E.P. Lolon, J.E. Youngblood and J.R. Heinz (2006) "Integration of micro-seismic fracture mapping results with numerical fracture network production modeling in the Barnett shale".

39. Bilgesu, H.I. and A. Yusuf, (2011) "The Impact of stress and formation properties on the outcome of fracture operations in horizontal shale wells", Paper SPE 149512 presented at the SPE Eastern Regional Meeting, Columbus, OH, 17-19 August, 2011. 


\section{Appendix}

\section{Appendix A}

As discussed in part 2.5, the discrete fracture network (DFN) design uses a set of equations that satisfy continuity, mass conservation, constitutive relationship and momentum equations. This appendix shows the main equations used in DFN growth modeling.

All the equations below where documented in the research paper conducted by Bruce R.Meyer and Lucas W. Bazan, "SPE 140514”. (24)

\section{Mass Conservation}

The mass conservation equations state that the injected fluid volume minus the leak-off loss and spurt loss must equal the fracture volume as shown in the equation below.

$$
\int_{0}^{t} q(\tau) d \tau-V_{l}(t)-V_{s p}(t)=V_{f}(t)
$$

The leak-off loss and spurt loss for $\mathrm{N}$ discrete fractures can be calculated using the following relation.

$$
V_{l}(t)=\sum_{i=1}^{N} 2 \int_{0}^{t} \int_{0}^{A} v \gamma_{c} d a d \tau+\sum_{i=1}^{N} 2 \int_{0}^{A} s_{p} \gamma_{c} d a
$$

Where the fluid loss $\gamma_{\mathrm{L}}$ multiplier and the total discrete fracture area can be calculated with the following

$$
\gamma_{l}=\left(A / A_{D F N}-1\right) \Phi_{l}+1
$$




$$
A_{D F N}=\sum_{i=1}^{N} A_{i} .
$$

So, the DFN geometric properties such as length, width, volume and area can be estimated based on the following equations.

$$
\begin{aligned}
& L_{D F N}=\sum_{\zeta=x, y, z}\left\lfloor\sum_{j=1}^{N_{\zeta}} L_{\zeta}(j)\right\rfloor \\
& A_{D F N}=\sum_{\zeta=x, y, z}\left[\sum_{j=1}^{N_{\zeta}} A_{\zeta}(j)\right] \\
& V_{D F N}=\sum_{\zeta=x, y, z}\left[\sum_{j=1}^{N_{\zeta}} V_{\zeta}(j)\right] \\
& \bar{w}_{D F N}=V_{D F N} / A_{D F N}
\end{aligned}
$$

\section{Continuity equation with flow rate Interaction}

The fracture flow rate for $\mathrm{i}^{\text {th }}$ discrete fracture is given by the equation below.

$$
q_{i}=\frac{\partial V_{f i}}{\partial t}+\frac{\partial V_{l i}}{\partial t}+\sum_{j=1}^{N} \frac{\partial V_{j i}}{\partial t}
$$

\section{DFN Momentum equations}

The fluid loss in terms of Darcy friction factor based on the cross-sectional average velocity can be calculated as following.

$$
\frac{d p}{d \zeta}=-\frac{f}{2} \frac{\rho\langle\bar{v}\rangle^{2}}{d_{h}}
$$




\section{Laminar flow}

The DFN momentum equation for incompressible laminar flow steady state with major and minor radius $\mathrm{a}$ and $\mathrm{b}$ and power law fluid:

$$
\frac{d p}{d x}=-\left(\frac{2 n^{\prime}+1}{4 n^{\prime}}\right)^{n^{\prime}} \frac{k^{\prime}(q / a)^{n^{\prime}}}{\Phi\left(n^{\prime}\right)^{n^{\prime}} b^{2 n^{\prime}+1}}
$$

The governing fluid front relationship in terms of the slot width $(2 \mathrm{~b})$ and pressure loss, $\Delta \mathrm{P}$, is given as:

$$
\Delta L \cdot L^{1 / n^{\prime}}=\left(\frac{4 n^{\prime}}{2 n^{\prime}+1} \cdot \frac{\Phi\left(n^{\prime}\right)}{\pi}\right) \frac{\Delta t}{k^{\prime 1 / n^{\prime}}} b^{1+1 / n^{\prime}} \Delta p^{1 / n^{\prime}}
$$

\section{Turbulent Flow}

The pressure loss in terms of Darcy friction factor for turbulent flow in an elliptical slot is given by the equation below.

$$
\frac{d p}{d x}=-\frac{f}{2} \frac{\rho q^{2}}{\pi^{3} a^{2} b^{3}}
$$

The cross-sectional average velocity can be calculated using the following equation

$$
\langle\bar{v}\rangle=q /(\pi a b)
$$

And the hydraulic diameter for narrow elliptical slot:

$$
d_{h}=\pi b .
$$


The fluid front propagation for each discrete fracture is given by the following equation

$$
\Delta L \cdot L^{1 / 2}=\left(\frac{2 \pi^{3}}{f \rho} b \Delta p\right)^{1 / 2} \Delta t
$$

\section{Width-opening pressure constitutive relationship with mechanical interaction}

The aperture relationship that includes mechanical interaction at the mid length (height) of the fracture can be determined using the following equation:

$$
w_{\zeta}=\Gamma_{w} \frac{2 H_{\zeta}\left(p_{\zeta}-\sigma_{\zeta}-\Delta \sigma_{\zeta \zeta}\right)}{E^{\prime}}
$$

The aperture ratio for uniformly pressurized fracture is given by the equation below:

$$
\omega(\zeta)=\frac{w_{\zeta}}{w_{\zeta}(0)}=1-\Delta \sigma_{\zeta \zeta} / \Delta p_{\zeta}=1-\Phi_{\zeta}
$$

And the 3D influence function is given as following:

$$
\Phi_{\zeta}=1-\left(1+\left(\frac{h}{2 d_{i}}\right)^{2}\right)^{-3 / 2}
$$




\section{Interior and Exterior aperture ratios}

For a finite number of interacting equally spaced fractures, the interior and exterior aperture ratios can be estimated using the following relations.

For Interior:

$$
\omega_{i}=\frac{\left.w_{\zeta}\right|_{i}}{w_{\zeta}(0)}=1-\Delta \sigma_{\zeta \zeta} / \Delta p_{\zeta}=1-\Phi_{\zeta}
$$

For Exterior:

$$
\omega_{e}=\frac{\left.w_{\zeta}\right|_{e}}{w_{\zeta}(0)}=1 / 2\left(1+1-\Delta \sigma_{\zeta \zeta} / \Delta p_{\zeta}\right)=1 / 2+1 / 2\left(1-\Phi_{\zeta}\right)
$$

The stiffness multiplier can be calculated using the equation below.

$$
\Psi_{\zeta}=\frac{E_{\zeta}}{E}
$$

And the stiffness multipliers for the interior and exterior fractures are given by the following equations:

For Interior:

$$
\Psi_{i}=\frac{1}{\omega_{i}}=\frac{1}{1-\Phi_{\zeta}}
$$


For Exterior:

$$
\Psi_{e}=\frac{1}{\omega_{e}}=\frac{1}{1 / 2+1 / 2\left(1-\Phi_{\zeta}\right)}
$$

The average dimensionless ratio and the stiffness multiplier for $N(n>1)$ fracture are given by the equations below.

$$
\begin{gathered}
\bar{\omega}=\frac{2 \omega_{e}+(N-2) \omega_{i}}{N} \\
\bar{\Psi}=\frac{N \Psi_{e} \Psi_{i}^{\prime}}{2 \Psi_{i}+(N-2) \Psi_{e}}
\end{gathered}
$$

